$$
\begin{gathered}
D R-0529-0 \\
\pm-17146
\end{gathered}
$$

\title{
Radioactive Waste Isolation in Salt: Peer Review of the Office of Nuclear Waste Isolation's Reports on-Multifactor Life Testing of Waste Package Materials
}

C. C. McPheeters, W. Harrison, J. C. Ditmars, A. Lerman, D. M. Rote, D. E. Eugar, and D. F. Hambley 


\section{ARGONNE NATIONAL LABORATORY \\ 9700 South Cass Avenue \\ Argonne, Illinois 60439}

ANL/EES-TMY--263

ANL/EES-TM-263

DE85 000692

RADIOACTIVE WASTE ISOLATION IN SALT:

PEER REVIEW OF THE OFFICE OF NUCLEAR WASTE ISOLATION'S

REPORTS ON MULTIFACTOR LIFE TESTING OF

WASTE PACKAGE MATERIALS

by

C.C. McPheeters, * W. Harrison, J.D. Ditmars, A. Lerman, **

D.M. Rote, D.E. Edgar, and D.F. Hambley

Energy and Environmental Systems Division

Geoscience and Engineering Group

September 1984

work sponsored by

U.S. DEPARTMENT OF ENERGY

Salt Repository Project Office

Office of Civilian Radioactive Waste Management

*Chemical Technology Division, ANL

**Northwestern University

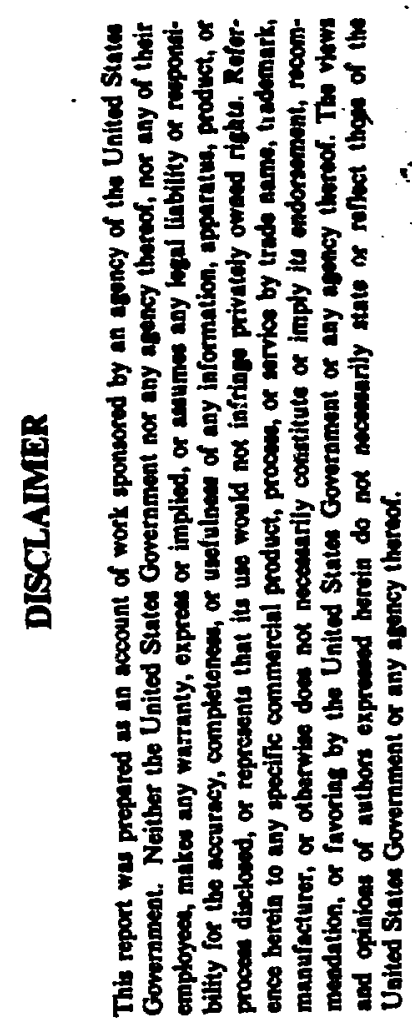




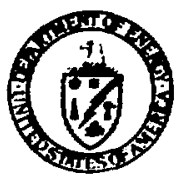

\section{Department of Energy}

Chicago Operations Office

Salt Repository Project Office 505 King Avenue

Columbus, Ohio 43201-2693

August 8,1984

\section{NOTICE TO READERS}

At the request of the Sa7t Repository Project Office (SRPO), Argonne Mationa] Laboratory carried out a review of two closely related repcrts entitled, "Design of a Multifactor Life Test to Investigate Uniform Corrosion of Low-Carbon Cast Steel as a Nuclear Waste Package Overpack Material in a Salt Repository Environment," ONWI 0/TM-48,* and "Methodology for Predicting the Life of Waste Package Materials and Components Using Mut tifactor Accelerated Life Tests," ONII-501. The two documents provide the approaches in designing a test progran to investigate uniform corrosion of low-carbon cast steel in a salt repository emironment. The results of the test will provide the characteristics of the reference overpack material and the data base necessary to support design, modeing, and licensing activities associated with the salt repository project.

Specific instructions me provided to the review panel to define the scope of the review. The panel aiso reviewed the documents from the overall point of view. Valuable comnents were provided that should contribute to the quality of the documents and the improvenent of the design of our test program.

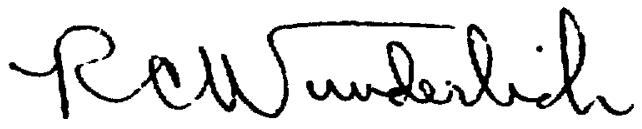

R. C. Wunderlich

Deputy Project Manager

Salt Repository Project Office

ST: 746-84

*A wicrofiche copy of this report is attached to the inside back cover of this report. 


\section{FOREWORD}

Documents are being submitted to the Salt Repository Project Office (SRPO) of the U.S. Department of Energy (DOE) by Battelle Memorial Institute's Office of Nuclear Waste Isolution (ONWI) to satisfy milestones of the Salt Repository Project of the Civilian Radioactive Waste Management Program. Some of these documents are being reviewed by multidisciplinary groups of peers to ensure DOE of their adequacy and credibility. Adequacy of documents refers to their ability to meet the standards of the U.S. Nuclear Regulatory Commission, as enunciated in 10 CFR Part 60, and the requirements of the National Environmental Policy Act and the Nuclear Waste Policy Aet of 1982. Credibility of documents refers to the validity of the assumptions, methods, and conclusions, as well as to the rompleteness of coverage.

Since late 1982, Argonne National Laboratory has been under contract to DOE to conduct multidisciplinary peer reviews of program plans and reports covering research and development activities related to siting and constructing a mined repository in salt for high-level radioactive waste. This report summarizes Argonne's review of two ONWI documents. The first report is an internal technical memorandum that treats the design of a multifactor life test to investigate uniform corrosion of low-carbon cast steel. This steel is being considered for use as an overpack material for nuclear waste packages to be emplaced in a mined repository in salt. The second document is a published report that covers the methodology used by ONWI to predict the life of waste package materials, a methodology used, in part, by the authors of the internal technical memorandum.

Argonne was requested by DOE to review these reports on May 14, 1984 (see App. A). The review procedure involved obtaining written comments on the reports from four members of Argonne's core peer review staff and from two Argonne experts and one extramural expert in related research areas. The peer review panel met at Argonne on June 11, 1984, and reviewer comments were integrated into this report by the review session chairman, with the assistance of Argonne's core peer review staff. All of the peer review panelists concurred in the way in which their comments were represented in this report (see App. B). A draft of this report was sent to SRPO on June 21, 1984. 
PREVOUSL Y PUBLASED REPORTS IN THE 8ERS

"RADIOACTIVE WASTE ISOLATON IN SALT"

ANL/EES-TM-242 Peer Review of the Office of Nuclear Waste Isolation's Geochemical Program Plan (Feb. 1984)

ANL/EES-TM-243 Peer Review of the Office of Nuclear Waste Isolation's Socioeconomic Program Plan (Feb. 1984) (revised July 1984)

ANL/EES-TM-246 Peer Review of the Office of Nuclear Waste lsolation's Plans for Repository Performance Assessment (May 1984)

ANL/EES-TM-254 Peer Review of the Office of Nuclear Waste Isolation's Reports on Preferred Repository Sites within the Palo Duro Basin, Texas (June 1984)

ANL/EES-TM-256 Special Advisory Report on the Status of the Office of Nuclear Waste Isolation's Plans for Repository Performance Assessment (Oct. 1983)

ANL/EES-TM-258 Peer Review of the Office of Nuclear Waste Isolation's Plan to Decommission and Reclaim Exploratory Shafts and Related Facilities (July 1984)

ANL/EES-TM-259 Peer Review of the Office of Nuclear Waste Isolation's Final Report on the Organic Geochemistry of Deep Groundwaters from the Palo Duro Basin, Texas (Aug. 1984)

ANL/EES-TM-260 Peer Review of the Texas Bureau of Economic Geology's Report on the Petrographic, Stratigraphic, and Structural Evidence for Dissolution of Upper Permian Bedded Salt, Texas Panhandle (Aug. 1984)

ANL/EES-TM-261 Peer Review of the Office of Nuclear Waste Isolation's Report on Functional Design Criteria for a Repository for High-Level Radioactive Waste (Aug. 1984)

ANL/EES-TM-262 Peer Review of the D'Appolonia Report on Schematic Designs for Penetration Seals for a Repository in the Permian Basin, Texas (Sept. 1984) 


\section{CONTENTS}

PEER REVIEW PANEL MEMBERS $\ldots \ldots \ldots \ldots \ldots \ldots \ldots \ldots \ldots \ldots \ldots \ldots \ldots \ldots \ldots \ldots \ldots$ ix

SUMMARY OF RECOMMENDATIONS $\ldots \ldots \ldots \ldots \ldots \ldots \ldots \ldots \ldots \ldots \ldots \ldots \ldots \ldots \ldots$

1 INTRODUCTION $\ldots \ldots \ldots \ldots \ldots \ldots \ldots \ldots \ldots \ldots \ldots \ldots \ldots \ldots \ldots \ldots \ldots \ldots \ldots \ldots \ldots \ldots \ldots .4$

2 REGULATORY ISSUES AND O/TM-48 $\ldots \ldots \ldots \ldots \ldots \ldots \ldots \ldots \ldots \ldots \ldots \ldots \ldots$

3 SUGGESTIONS TO IMPROVE PRESENTATION IN O/TM-48 $\ldots \ldots \ldots \ldots \ldots \ldots \ldots \ldots$

3.1 Introductory Material ................................. 8

3.1.1 Need for a Section on Background, Objective, and Scope ......... 8

3.1.2 Definition of Overpack and Explanation of Its Importance ......... 9

3.1.3 Areas of Expertise, Roles, and Affiliations of Key

Participants .................................. 9

3.2 Test Design Methodology $\ldots \ldots \ldots \ldots \ldots \ldots \ldots \ldots \ldots \ldots \ldots \ldots \ldots \ldots \ldots \ldots \ldots \ldots \ldots$

3.3 Results $\ldots \ldots \ldots \ldots \ldots \ldots \ldots \ldots \ldots \ldots \ldots \ldots \ldots \ldots \ldots \ldots \ldots \ldots \ldots \ldots \ldots \ldots \ldots \ldots \ldots$

3.4 Summary $\ldots \ldots \ldots \ldots \ldots \ldots \ldots \ldots \ldots \ldots \ldots \ldots \ldots \ldots \ldots \ldots \ldots \ldots \ldots \ldots \ldots \ldots \ldots \ldots \ldots$

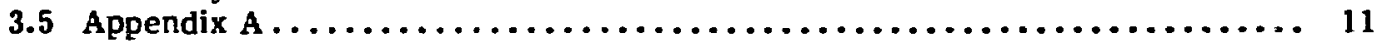

3.6 Appendix B .................................... 11

4 TECHNICAL CONSIDERATIONS $\ldots \ldots \ldots \ldots \ldots \ldots \ldots \ldots \ldots \ldots \ldots \ldots \ldots \ldots \ldots \ldots \ldots \ldots . \ldots 12$

4.1 O/TM-48: Design of a Multifactor Material-Life Test . . . . . . . . . . . . 12

4.1.1 Specification, Description, and Application of Key Stresses ....... 12

4.1.2 Applicability of Eyring Model to Data ...................... 13

4.2 ONW1-501: Methodology for Predicting Material Life .............. 15

4.2.1 Test Objectives ................................ 16

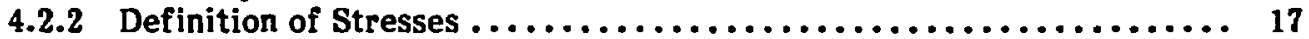

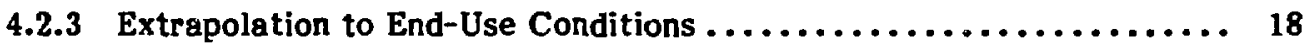

4.2 .4 Use of the Eyring Model ................................ 18

4.2.5 Use of Hierarchical Trees ............................ 19

4.2.6 Mechanics of Computations ......................... 19

4.2 .7 Other Technical Issues $\ldots \ldots \ldots \ldots \ldots \ldots \ldots \ldots \ldots \ldots \ldots \ldots \ldots \ldots \ldots \ldots \ldots \ldots$

5 ANSWERS TO DOE/SRPO QUESTIONS AND REQUESTS FOR COMMENTS ...... 22

$5.1 \mathrm{O} / \mathrm{TM}-48$ : Design of a Multifactor Material-Life Test .............. 22

5.2 ONWI-501: Methodology for Predicting Material Life ............... 23

6 PAGE-BY-PAGE COMMENTARY $\ldots \ldots \ldots \ldots \ldots \ldots \ldots \ldots \ldots \ldots \ldots \ldots \ldots \ldots \ldots$

$6.1 \mathrm{O} / \mathrm{TM}-48$ : Design of a Multifactor Material-Life Test . . . . . . . . . . . .. 25

6.2 ONW1-501: Methodology for Predicting Material Life .............. 26

REFERENCES $\ldots \ldots \ldots \ldots \ldots \ldots \ldots \ldots \ldots \ldots \ldots \ldots \ldots \ldots \ldots \ldots \ldots \ldots \ldots \ldots \ldots \ldots \ldots \ldots \ldots . \ldots 28$ 


\section{CONTENTS (Cont'd)}

APPENDIX A: U.S. Department of Energy Letter Requesting Peer Review ........ 29

APPENDIX B: Concurrence Sheet $\ldots \ldots \ldots \ldots \ldots \ldots \ldots \ldots \ldots \ldots \ldots \ldots \ldots \ldots \ldots \ldots \ldots \ldots \ldots \ldots$

APPENDIX C: Credentials of Peer Review Panel Members . . . . . . . . . . . . . . .... 37

\section{FIGURE}

1 Natural Log of Corrosion Rate versus Inverse of Temperature for

Data of Tables 4 and 5

A microfiche copy of the following unpublished document is attached to the inside back cover of this report: R. Cote and R. Thomas, Design of a Multifactor Life Test to Investigate Uniform Corrosion of Low-Carbon Cast Steel as a Nuclear Waste Package Overpack Material in a Salt Repository Environment, Office of Nuclear Waste Isolation internal technical memorandum O/TM-48, Battelle Memorial Institute, Columbus, Ohio (April 1984).

The second report reviewed herein -- R.E. Thomas and R.W. Cote, Methodology for Predicting the Life of Waste-Package Materials and Components using Multifactor Accelerated Life Tests, Office of Nuclear Waste Isolation report ONWI-501 (Sept. 1983) -- has been formally published and may be ordered from Battelle Memorial Institute, Columbus, Ohio. 


\section{RADIOACTIVE WASTE ISOLATION IN SALT: \\ PEER REVIEW OP THE OPFICE OF NUCLEAR WASTE ISOLATIONS \\ REPORTS ON MULTTFACTOR LIPE TESTMNG OF \\ WASTE PACKAGE MATERIXIS}

by

C.C. McPheeters, w. Harrison, J.D. Ditmars, A. Lerman,

D.M. Rote, D.E. Edgar, and D.F. Hambley

\section{SUMMARY OF PRCOMMENDATIONS}

This Argonne report reviews two related documents prepared by Battelle Memorial Institute's Office of Nuclear Waste Isolation (ONWI): Design of a Multifactor Life Test to Investigate Uniform Corrosion of Low-Carbon Cast Steel as a Nuclear Waste Package Overpack Material in a Salt Repository Environment, O/TM-48, an ONWI internal technical memorandum that is relatively preliminary in nature, and Methodology for Predicting the Life of Waste-Package Materials and Components Using Multifactor Accelerated Life Tests, ONWI-501, a freviously reviewed and published report. The following recommendations for improving the two documents have been abstracted from the body of this review report. In genersl, the peer review panelists found serious deficiencies in $\mathrm{O} / \mathrm{TM}-48$, while $\mathrm{ONWI-501}$ was judged to be generally understandable and useful, although certain amplifications of the methodology were deemed desirable.

\section{O/TM-48: DESIGN OF A MULTIFACTOR MATERLAL-LIFE TEST}

This report should be revised and augmented to:

1. Explain the relationship between the methodology for accelerated material-life testing, as described in ONWI-501, and the long-term test design being considered in $\mathrm{O} / \mathrm{TM}-48$.

2. Show how the proposed testing relates to other corrosion testing in ONWI's national waste package program, with particular attention to completed and ongoing testing.

3. Document the reasons for selecting uniform corrosion as the casis of the test program and low-carbon steel as the test material.

4. Provide an adequate connection between the body of the report and the recommended, but unsupported, test plan in Table 6.

5. Describe more completely the method of "pruning" used to reduce the complete factorial design shown in Table 2 to the experimental matrix given in Table 6 . 
6. Follow the guidelines of ONWI-501 more closely, perticularly those related to documentation of the essential aspects of test-plan formulation.

7. Describe the types of data to be collected and discuss how these data will be used in demonstrating compliance with U.S. Nuclear Regulatory Commission criteria and guidance.

The manner of presentation in $0 / T M-48$ should be improved by:

1. Providing at the beginning of the report a section on background, objective (or purpose), and scope.

2. Defining upon first use the terms "overpsek" and "reference overpack material."

3. Including information on the theoretical or experimental areas covered by the panelists and their duties and responsibilities as participants in the test design group.

4. Giving examples of how the design team attempted to carry out each step of the method given in ONW1-501.

5. Providing complete definitions for each variable or parameter in Table 1, together with the rationale for their selection.

6. Specifying the two types of trine studied by using a notation other than "e" and "1/e."

7. Explaining what is involved in modifying the test matrix "as more data become available from experiments currently underway."

8. Informing the reader of the relationship of App. A to the rest of the document and clarifying many of the bulleted items in that appendix.

9. Releting information on brine composition to published references, wherever possible.

\section{ONWI-501: METHODOLOGY FOR PREDICTING MATERIAL LIFE}

The authors of this report should have:

1. Provided stronger and more specific links between two generic concepts, performance degradation and time to failure, and the objectives of uniform corrosion testing, the primary type of life testing being addressed. 
2. Expancled the discussions of the test stresses to include consideration of the stress characteristics that may frustrate the appropriate and successful application of the methodology.

3. Provided specific guidanse on the method of predicting failure or lorig-term performance once hypothetical or real test results are available (or deleted the words "methodology for predicting" from the title).

The understandability of ONWI-501 would be improved if it:

1. Explained how the equation on page 42 is related to the original reaction rate model of Eyring. The mathematical form alone is not sufficient to call the equation "the Eyring model."

2. Provided improved descriptions of the procedures given for computing the values used in the factorial tables and hierarchical trees.

3. Addressed the issue of variable uncertainty in the corrosion rate estimates and its potential effect on the analysis. 


\section{INTRODUCTION}

Corrosion-resistant waste package materials are important components of the engineered barriers of a nuclear waste isolation system. A durable container (overpack) for the waste canister should prevent hydrothermal interactions between the canister and the waste form it contains. Battelle Memorial Institute's Office of Nuclear Waste Isolation (ONWI) is under contract to the U.S. Department of Energy's (DOE's) Salt Repository Project Office (SRPO) to design an overpack to isolate commercial high-level radioactive waste in a repository constructed in salt.

Argonne National Laboratory conducted a peer review of ONWI's design of a test to investigate uniform corrosion of low-carbon cast steel overpack materials, as reported in an ONWI internal technical memorandum, O/TM-48: R. Cote and R. Thomas, Design of a Multifactor Life Test to Investigate Uniform Corrosion of Low-Carbon Cast Steel as a Nuclear Waste Package Overpack Material in a Salt Repository Environment (1984). The Argonne review also considerea an ONWI meîhodology for predieting the life of waste package materials through use of multifactor accelerated corrosion tests, a methodology detailed in a published ONWI report, ONWI-501: R. Thomas and R. Cote, Methodology for Predicting the Life of Waste-Package Materials and Components Using Multifactor Accelerated Life Tests (1983).

Argonne's peer review involved obtaining written eritiques of both ONWI documents from four members of Argonne's core peer review staff and from two Argonne experts and one extramural expert in related research areas. The Argonne panelists then reviewed all of the comments, and the review session chairman drafted the present report, with the assistance of Argonne's core peer review staff. Panelists did not contact ONWl personnel, and none of the panelists have been involved in any programs sponsored by DOE or directed by ONWI such that their participation in the review could be construed as a conflict of interest.

Although no specific guidance was provided to Argonne by DOE/SRPO on how the review of the two reports was to be conducted, a set of questions and requests for comments were prepared by DOE/SRPO to assist in the review process (see App. A). These questions and requests for comments form the basis of Sec. 5 of this report. In addition, Secs. 2 and 3 relate the test design report, O/TM-48, to regulatory requirements and recommend improvements in the presentation of material in O/TM-48, respectively. Section 4 considers a variety of technical issues related to both ONWI reports, and Sec. 6 presents a page-by-page commentary. 


\section{REGJLATORY ISSUES AND O/TM-48}

Both the U.S. Environmental Protection Agency (EPA) and the U.S. Nuclear Regulatory Commission (NRC) have developed regulations pertinent to the performance of repositories for high-level radioactive waste. Because the EPA standards are not yet in final form, only NRC regulations are considered in the following discussion.

Waste package performance is addressed by NRC in several sections of 10 CFR Part 60 (U.S. Nuclear Regulatory Commission, 1981). Package integrity is of concern relative to Sec. $60.111(\mathrm{~b})$, which requires that the ability to retrieve waste be maintained for up to $\mathbf{5 0}$ years after waste emplacement operations begin. More specifically, Sec. 60.113(a)(1)(ii)(A) states that "containment of HLW [high-level waste] within the waste packages will be substantially complete for a period to be determined by the Commission ... provided that such period shall be not less than 300 years nor more than 1000 years af ter permanent closure of the geologic repository," and Sec. 60.113(a)(1)(ii)(B) stipulates that "the release rate of any radionuclide from the engineered barrier system following the containment period shall not exceed one part in 100,000 per year of the inventory of that radionuclide calculated to be present at 1000 years following permanent closure ..." Section 60.135(a)(1) further requires that "packages for HLW shall be designed so that the in situ chemical, physical, and nuclear properties of the waste packgge and its interactions with the emplacement environment do not compromise the function of the waste packages or the performance of the underground facility or the geologic setting." Finally, Sec. 60.143 presents information on the monitoring and testing program required to evaluate waste package performance before repository closure.

The Nuclear Regulatory Commission has published a draft technical position on waste package perfurmance after repository closure (Davis and Schweitzer, 1983), which presents the major issues and problems associated with evaluating the ability of a waste package to comply with the performance objectives and the criteria and design requirements stipulated in 10 CFR Part 60 in general, and those in Sec. 60.113 in particular. This document notes that several alternatives are available to address the performance criteria. In general, the objectives may be achieved by the whole waste package or by the individual compcnents (waste form[s], container system, and packing). As stated in Davis and Schweitzer (1983, p. 6-7), NRC's preferred approaches for ensuring compliance of a waste package with NRC criteria are, in decreasing order of acceptability:

1. Combinations of independent high-integrity components which, by their individual behavior, can satisfy the NRC criteria (i.e., redundant compliance).

2. A single component which, by itself, can satisfy the NRC criteria, in combination with other barriers that may not individually mee $\hat{\imath}$ these criteria (single compliance).

3. Combinations of components that cooperatively comply but individually do not completely satisfy the proposed NRC eriteria. These components acting together can be assigned, with some level 


\begin{abstract}
of assurance, credit for complying with the performance objectives (composite compliance). The package constructed from these components should satisfy the 300 - to 1000 -year containment requirement.
\end{abstract}

Frch of these options involves different considerations in terms of demonstrating "reasonable assurance" of the necessary compliance with the performance criteria.

Davis and Schweitzer (1983) identified a number of major, generic issues related to reducing the uncertainties in waste package performance after repository closure (i.e., issues that are independent of material and design choices and specific repository site conditions). These generic issues are (1) characterization of repository water and groundwater attributes, including chemistry and flow rates; (2) anticipated repository temperatures; (3) predietability of accelerated testing of waste package materials (i.e., mechanisms responsible for aging and estimated rates of degradation identified under accelerated conditions may not be applicable to normal stress conditions); (4) radiation effects; (5) total package testing, as opposed to testing of only individual components; (6) use of statistics to demonstrate compliance; and (7) use of modeling. Davis and Schweitzer's publication should be consulted for thic details of each of these issues and the corresponding NRC positions.

It is difficult to evaluate tie test design presented in O/TM-48 in terms of NRC requirements because the testing effort described there is presumably only one portion of DOE's waste package program and because NRC apparently will require that compliance be demonstrated for the entire package and engineered barrier systems. It was assumed during this review that compliance would not be based solely on the performance of this low-carbon cast steel overpack component of the package.

The existing report would benefit from the addition of a section that describes the relationship of this particular testing activity to the larger waste package program and presents the current thinking on how the program i. 1 address NRC licensing requirements. This discussion should present the rationale for selecting low-carbon steel as the test material and for evaluating uniform corrosion rather than other modes of chemical failure (such as pitting corrosion, erevice corrosion, galvanic corrosion, stress corrosion, selective leaching, and hydrogen embrittlement) and should provide information on the other materials and degradation niechanisms that are being considered and tested for other package components. The discussion should also recognize that the testing program is to provide the information necessary for licensing and address the issues identified by NRC. Although some information on completed tests is presented in App. A of $\mathrm{O} / \mathrm{TM}-48$, it is difficult to determine how these test results are related to proposed tests, to each other, or to the entire waste package program.

One of the regulatory concerns presented by Davis and Schweitzer (1983) is that the anticipated repository environment of the package be accurately characterized and that the testing program be representative of these conditions. The two brines to be used in the proposed tests are identified as Permian Basin Brines 1 and 2, and their ionic concentrations are presented in App. B of O/TM-48. The basis for selecting these compositions and the evidence that such compositions are representative of anticipated repository conditions should be deseribed. 
Additional details should be provided on the specifics of the experimental methodolopy and the types of data to be collected. Although an experimental matrix is presented, details on these two topies are lacking. Two fundamental issues raised by Davis and Schweitzer (1983) are the detailed physical and chemical processes operative at the metal-fluid interface (e.g., do corrosion products remain on the metal or are they removed to expose new material?) and the effect of the package and degradation products on fluid chemistry. The existing discussion provides no information on whether these topies will be evaluated during the course of the experiments.

Some difficulties exist in evaluating the specific information needs for license application. The existing NRC criteria contain terms such as "reasonable assurance" and "substantially complete containment." Because these terms are unclear, additional guidarice and clarifieation by NRC will be required to ensure that information provided by DOE is appropriate. Davis and Schweitzer (1983) correctly note that evaluating whether a waste package complies with regulatory criteria requires judgment. They aiso note that "reasonable assurance" is the concept to be used to determine whether the data, models, and rationale submitted justify the performance claimed. Here, too, reasonable assurance requires judgment.

In general terms, it appears that the experimental program described in O/TM-48 is intended to collect some of the data required to support the application for a repository license. However, because of the qualitative nature of the criteria and the absence of specific guidelines for obtaining requisite information for their evaluation, the ability of the proposed experimental program to meet anticipated licensing requirements cannot be objectively evaluated with any reasonable degree of certainty. 


\section{SUGGESTIONS TO IMPROVE PRESENTATION IN O/TM-48}

As presently written, $\mathrm{O} / \mathrm{TM}-48$ is sometimes difficult to understand and lacking in needed detail. The following suggestions should assist the authors in their nex revision.

\subsection{INTRODUCTORY MATERIAL}

\subsubsection{Need for a Section on Background, Objective, and Scope}

Strong statements of background, objective, and scope are needed at the beginning of $\mathrm{O} / \mathrm{TM}-48$. Although the first paragraph in the introduction (p. 1)* is a statement of objective and scope, it is so brief as to be frustrating. At a minimum, it raises the following important questions:

- Is this the only corrosion test matrix under test by ONWI?

- Has ONW1 prepared a document describing a design-basis scenario that specifies expected repository conditions as a function of time (e.g., oxygen potential, temperature, stress, radiation level, and brine quality)?

- Are the data from this test program expected to provide the entire corrosion "data base necessary to support design, modeling, and licensing activities ..."?

Another statement of objective is found on page 3: "... obtain a statistically sound data base on the performance of low-carbon cast steel in a salt repository environment ..." This statement is too broad. Only one corrosion mechanism is addressed in this document - uniform corrosion. The term "performance" implies an entire spectrum, not just one performance measure.

Between the title, the introduction, the section on results, and App. A, one can almost form a picture of the overall corrosion program, where this test program fits in, and the scope of the testing activity. However, a separe te section that clearly describes these things would be much more helpful, as would a description of the relationship between ongoing and completed tests and the test design.

\footnotetext{
*AIl page, table, and figure numbers, as well as section headings, are from O/TM-48 unless otherwise specified.
} 


\subsubsection{Definition of Overpack and Explanation of Its Importance}

Inasmuch as the term overpack is used in the title, it should be defined clearly upon its first use. The following definition would appear adequate: secondary external containment for the waste canister, or the metallic container into which the canister is placed.

The authors should also explain why overpack materials, rather than canister materials, are being addressed. If different lifetimes (corrosion properties) are being contemplated, the authors should explain why. The Introduction mentions "the reference overpack material," but does not explain what is involved. Since the authors state that "the results of this work will be used to characterize the reference overpack material ...," it is extremely important that said reference overpack material be defined.

\subsubsection{Areas of Expertise, Roles, and Affiliations of Rey Participants}

The names and affiliations of 10 key partieipants of the test design group are given in the Introduction. The credibility of this group may be beyond question, but readers unfamiliar with the individuals cannot make that judgment. At the very least, the theoretical or experimental areas of expertise of these individuals should be indicated. (An appendix containing one-page resumés for each participant would also be desirable.) The roles of the panelists -- such as committee duties and responsibilities -should alsc be spelled out.

The composition of the group is likely to raise questions. Why are 9 of the 10 participants affiliated with Battelle's Pacific Northwest Laboratory? Were so many of the participants selected from that laboratory because of travel considerations or for ease of interaction? Other national laboratories are studying the corrosion of waste package materials and could have supplied team members who "represent the various scientific disciplines that are associated with the physics of the degradation process" (ONW1-501, p. 5). Sandia National Laboratories, in particular, could have undoubtedly supplied participants with extensive, usefui experience in the corrosion of waste package materials by repository brines.

To summarize, an adequate case must be made for the eredibility of the test design group. At present, critical reader's would be unconvineed that the "responsibility for the accelerated test designs [has been assigned] to a highly competent team of independent scientists selected to represent an appropriate mix of scientific and statistical disciplines" (ONWI-501, p. 1).

\subsection{TEST DESIGN METHODOLOGY}

In the Test Design Methodology section of $\mathrm{O} / \mathrm{TM}-48$, examples should be given of how the design team attempted to carry out each step of the method given in ONWI501. Such an approach would provide a needed logical structure for the subsequent explanation under "Results." For example, under the first bullet on page 2, the nature of the multidisciplinary team and how it functioned could be explained. Under the second 
bullet, an example could be given of how the team's test matrix reflected "both the (statistical) experimental design and the data analysis characteristics that are required to identify magnitudes of different stresses and their interactions." Under the third bullet, details could be presented on how a team member made "quantitative predictions of the experimental outcomes associated with each combination of stresses."

In addition, the authors should explain the relationship between the methodology for accelerated life testing (ONWI-501) and the long-term test design being considered in O/TM-48. Such additional information, presented in a logical step-by-step fashion, would greatly improve the understandability of $\mathrm{O} / \mathrm{TM}-48$.

\subsection{RESULTS}

The first paragraph of the Results section (p. 3) deals with objectives and should be moved to the Introduction or placed under a new heading or subheading, such as "Objectives and Scope."

The second paragraph on the same page indicates that the five bullets that follow cover key results and conclusions from the initial meeting of the test design team. (However, the second bullet on page 4 may be irrelevant to the present program.) it is not clear whether the text that follows the fifth bullet covers additional results of the first meeting. If not, appropriate subheadings are necessary, beginning at the top of page 5.

Also, in the second paragraph on page 3 , "the dominant failure mechanism" is identified as uniform corrosion, but no explanation is given for its selection. Bacause the choice of a dominant failure mechanism is a critical issue, the basis for the choise should be described in detail.

The title of Table 1 (p. 5) is confusing. Are the words "associated with" equivalent to "chosen by the test design team for"? How were values for temperature, radiation, brine composition, and SA/V selected? Is the parameter $\mathrm{SA} / \mathrm{V}$ a flow rate, as indicated in Table 1, or a surface-area-to-volume ratio (and related flow rate), as defined on page 15? What is implied by "Flowing, Static" opposite SA/V in Table 1? For the document to be understandable, complete definitions are needed for each variable or parameter, as is a statement of the rationale for selecting the values for each.

Specification of the two types of study brines by means of the notation "l/e" and " $\mathrm{e} "$ (p. 7) is completely meaningless as far as the chemical characteristics of the brines are concerned. It may be a matter of algebraic expedience, but no one can tell anything about a brine that has been identified as "l/e."

\subsection{SUMMARY}

The conclusion of the Summary (pp. 15-16) is unclear. A better explanation is needed of how the test matrix will be modified "as more data become available from experiments currently underway." The kinds of data that will be forthcoming should be 
described, as should the experiments that are under:ay. The oyerall relationship between $\mathrm{O} / \mathrm{TM}-48$ and the actual testing program should also be explained.

\subsection{APPENDIX A}

The title to App. A in O/TM-48 does not make sense. What is meant by "matrix of structural barriers tests"? Also, what is the context for this matrix? What relationship does it have to the rest of the document? Which individuals or what grcups conducted each test? It is desirable that the tests be related to published references, if any are available.

Many of the bullets describing test conditions need clarification or amplification to make them understandable to readers unfamiliar with the jargon used in the field of corrosion testing. For example, how does one interpret the following?

- Orientations $=$ TL, LT [Test. 3]

- Samples $=$ corrosion coupons [Test $2 \mathrm{c}]$

- Orientations = through-thickness, parallel to surface [Test 6]

Finally, although the title of this appendix includes the words "tests completed," the status of Test $2 b$ and parts of Tests 3 and 4 is given as "in progress" and that of Test 6 as "initiated November 1983." This basic confusion should be resolved.

\subsection{APPENDIX B}

It is generally desirable to relate brine compositions to published references wherever possible. For example, the stratigraphic positions from whence the brines came may prove to be important to performance assessment considerations at some later date. Also, one could question the composition of Brine No. 3, whose listed chemical composition is not weli balanced. The concentrations of the cations exceed those of the anions by about 18\% (cations: 6.388 equivalents/liter; anions: 5.957 equivalents/liter). There is either too much of something on the positive side or too little on the negative side, or both. 


\section{TECHNICAL CONSIDERATIONS}

\subsection{O/TM-48: DESTGN OF A MULTIFACTOR MATERML-LIFE TEST}

\subsubsection{Specification, Description, and Application of Key Stresses}

Specifiction of Key Stresses. The O/TM-48 report deals with the corrosion effects of four stresses: temperature $\left(70^{\circ}, 150^{\circ}\right.$, and $\left.250^{\circ} \mathrm{C}\right)$, radiation $\left(10^{3}\right.$ and $10^{5}$ $\mathrm{rad} /$ hour), brine composition (intrusion and inclusion brines), and brine flows (static and flowing).

If the eifects of pressure at the in situ conditions of waste-package burial are insignificant (i.e., if lithostatic or hydrostatic pressures do not affect the anticipated corrosion rates), this should be stated clearly in the report. Also, it seems surprising that SA/V (flow) is considered more important than air/no-air conditions. Flow of brine will only occur under accident conditions (repository flooding), while air will certainly be present af ter emplacement and for a significant fraction of the life of the containers. Is this an experimental convenience or a belief on the part of the team that brine flow is more realistic or a higher stress than the presence of air? Consider that Basham (1984, p. 281) found that for cast steel, oxic conditions resulted in higher corrosion rates than anoxic conditions.

Description and Application of a Key Stress. Brine composition, one of the four key stresses, is not adequately described in terms of the main parameters that can be monitored and those that can affect the corrosion reactions. 'Appendix $B$ gives the compositions of three brines. Brines 1 and 2 are very similar to each other and are referred to in the text as intrusion brines, while Brine 3 is the inclusion brine. The intrusion brines are close to saturation with respect to $\mathrm{NaCl}$. It is likely that $\mathrm{NaCl}$ would either precipitate from the solution or dissolve from the host rock, but whether it did would depend on local changes in temperature and brine composition.

Brines 1 and 2 contain calcium and sulfate, about 4.5 grams $\mathrm{CaSO}_{4}$ per liter in Brine 1 and 2.7 grams $\mathrm{CaSO}_{4}$ per liter in Brine 2. Solubilities of $\mathrm{CaSO}_{4}$ (solid-phase $^{\text {(s) }}$ Eypsum, $\mathrm{CaSO}_{4} \cdot 2 \mathrm{H}_{2} \mathrm{O}$ ) in pure water and in $\mathrm{NaCl}$ aqueous solutions bracket the $\mathrm{CaSO}_{4}$ concentrations in the subject Permian brines:

$$
\left.\begin{array}{l}
\mathrm{H}_{2} \mathrm{O}, 65^{\circ}-100^{\circ} \mathrm{C}: \\
\text { solubility } 1.9 \text { to } 1.6 \text { grams } \mathrm{CaSO}_{4} \text { per liter } \\
260-320 \text { grams } \mathrm{NaCl} \text { per liter, } 25^{\circ} \mathrm{C}: \\
\text { solubility } 6.5 \text { to } 5.7 \text { grams } \mathrm{CaSO}_{4} \text { per liter }
\end{array}\right\} \begin{aligned}
& \text { Seidell's solubilities } \\
& \text { of inorganic compounds }
\end{aligned}
$$

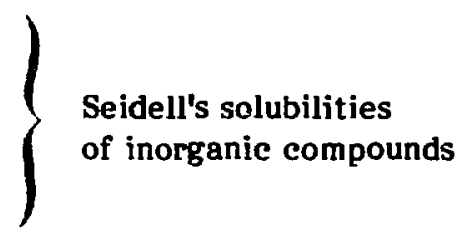

From the above solubility vaiues, it is conceivable that gypsum could precipitate locally. 
ldentification of a key stress, such as brine composition, can be very misleading. The initial brine composition can change greatly during the process of corrosion and irradiation of the brine and the host rock. Evidence for the occurrence of such dissolved species as $\mathrm{OCl}^{-}, \mathrm{HOCl}$, and $\mathrm{H}_{2}$ in brines of irradiated salt has been given by Jenks et al. (1975). Levy (1983) reported that when rock salt is irradiated for variable periods at $150^{\circ} \mathrm{C}$, significant quantities of Na-gel are formed, accompanied by evolution of chlorine gas. Such a rock salt, if it were in contact with water, would be likely to react and produce $\mathrm{NaOH}$ and $\mathrm{H}_{2}$, making the brine highly alkaline. The stress intensity of the brine would be determined by the extent to which this hypothetically high concentration of $\mathrm{OH}^{-}$ions could be neutralized by acidic species.

Such brir: composition parameters as $\mathrm{Cl}^{-}, \mathrm{HS}^{-}, \mathrm{H}_{2} \mathrm{~S}, \mathrm{HCO}_{3}^{-}$, and $\mathrm{CO}_{2}$ are listed in Table 1 (p. 5) in the category of "brine dictated." Although this designation takes into account the possibility that their concentrations will vary during the time of corrosion, it tells nothing about which of these chemical species may be more stressful than the others. The distinction between the two kinds of brines -- Brines 2 and 3 - is based on the magnesium concentration. However, other important chemical parameters must be considered to be among the "stressful characteristics" of a brine, such as:

- Oxidation and reduction of sulfur-containing species.

- Precipitstion or dissolution of minerals in the host rock (primarily $\mathrm{NaCl}$ and $\mathrm{CaSO}_{4}$ ).

- Formation of exotic chemical species caused by prolonged irradiation of the host rock, including the ionic species and dissolved gases.

- Possible roles of the electrical potentials at the steel-brine and brine-salt interfaces.

- Development of variably acidic or alkaline conditions in the course of active corrosion.

\subsubsection{Applicability of Eyring Model to Data}

The mathematical formulation of the rate of corrosion is given on page 7 in the following form:

$$
C R=A e^{B / T}(R)^{C+D / T}(B R)^{E+F / T}
$$

where:

$$
\begin{aligned}
\mathbf{C R} & =\text { corrosion rate (length } / \text { time }), \\
\mathbf{R} & =\text { radiation, }
\end{aligned}
$$




$$
\begin{aligned}
\mathrm{T} & =\text { temperature, and } \\
\mathrm{BR} & =\text { brine. }
\end{aligned}
$$

Parameters A through F can be obtained statistically from the "consensus data" on the corrosion rate $\mathrm{CR}$. Equation 1 can be simplified to:

$$
C R=K e^{a / T}
$$

by making the following substitutions:

$$
\begin{aligned}
& K=A(R){ }_{(B R)}{ }^{E}, \\
& \ln (R)=r, \\
& \ln (B R)=b, \text { and } \\
& a=B+r D+b F .
\end{aligned}
$$

Although Eg. 2 does not distinguish between the effects of individual stress factors, it gives an identical dependence of the corrosion rate on temperature and other parameters. Thus, if the corrosion rate $C R$ were determined at different temperatures, keeping all the other parameters at their constant vaiues (i.e., presumably independent of temperature), then the graphs of $\ln (\mathrm{CR})$ plotted against $1 / T$ would be identical. The data in Tables 4 and 5 give consensus $e$ timates of the corrosion rates at three temperatures for two brines and two levels of radiation, for a total of $3 \cdot 2^{2}=12$ corrosion rate values. These data are shown plotted in Fig. 1 and consist of two curves for a low-magnesium brine (brine "1/e") and two curves for a high-magnesium brine (brine "e"), for low and high radiation levels, respectively.

If the Eyring model held for the results, the three data points (three temperatures) for each consensus experiment would fall on a straight line. As Fig. 1 shows, however, considerable departures from linearity are clearly visible to the eye, with no need for statistical analysis of the data. Thus, a conclusion that the Eyring model does not apply to the data should be drawn for the entire set of the consensus estimates, not only for the high-temperature portion of the set.

To determine whether the Eyring model is appropriate to corrosion of iron in a radiation field in saline brines at elevated temperatures, the behavior of the individual stress factors and their interactions must be examined. Obtaining a statistically good fit of the consensus estimates to the Eyring model cannot be meaningful if the individual estimates are based on different corrosion-mechanism models.

For the three temperature data $k$ ints (see Fig. 1), either the Eyring (or Arrhenius) model does not fit or the power exponents (B, D, F, and a) in Eqs. 1 and 2 are temperature dependent. Such a conclusion is obviously unsatisfactory.

One of the problems seems to lie in the definition of the stress factors. Brine composition is not a sufficiently precise stress factor, as explained earlier, and the 


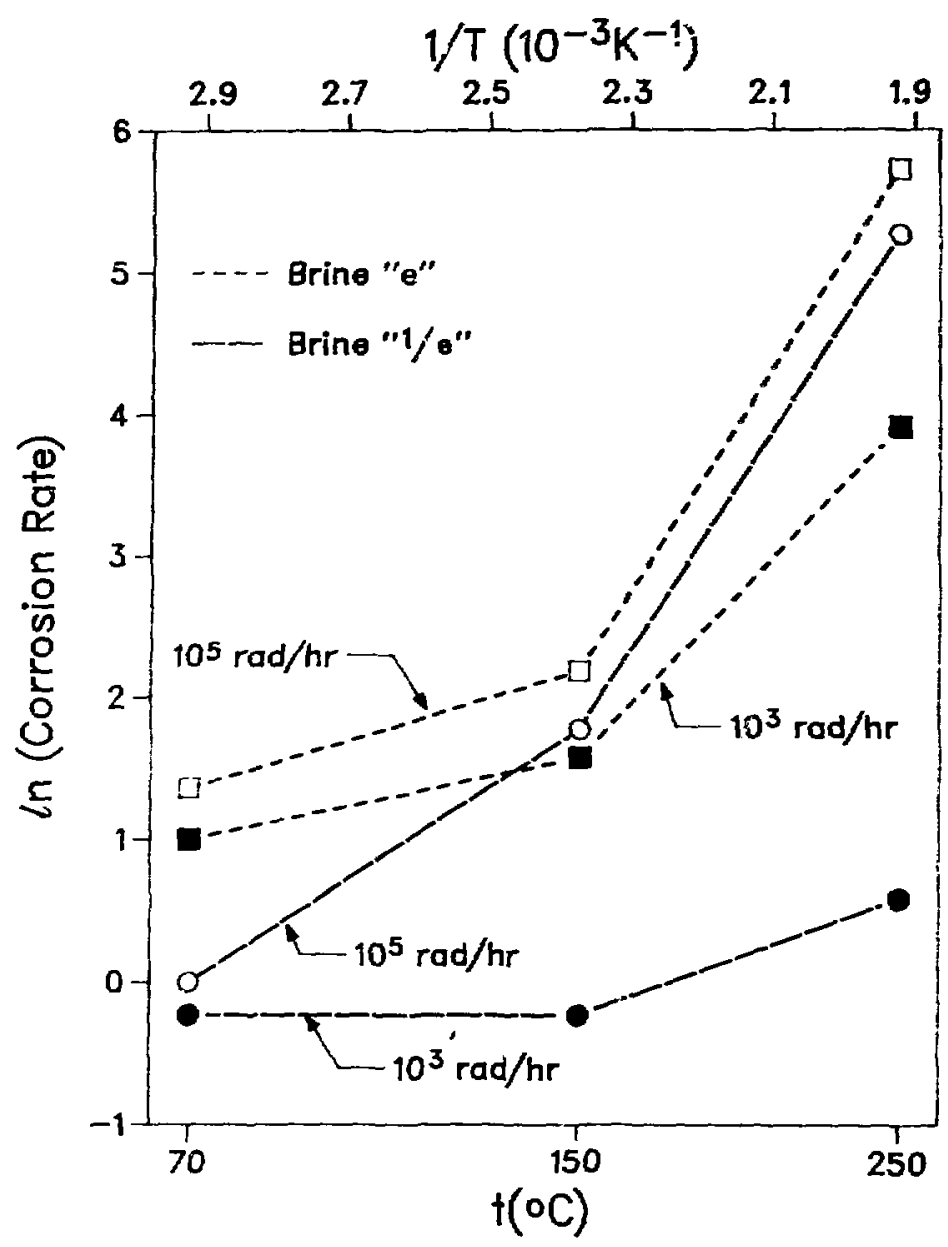

FIGURE 1 Natural Log of Corrosion Rate versus Inverse of Temperature for Data of Tables 4 and 5

additional stresses originating from the irradiated host rock have not been explicitly included in the model. To test the applicability of the Eyring model, one must know more about the corrosion mechanism, which requires a better understanding of the chemical changes taking place in a system comprised of an iron alloy, salt brine, and a host rock. A departure from the simple Arrhenius, or Eyring, plot -- such as that shown in Fig. 1 - may also indicate that the mechanism of the chemical reaction changes with temperature. If this is the case, understanding the relevant mechanisms is indispensable to successful modeling.

\subsection{ONWI-501: METHODOLOGY FOR PREDICTING MATERIAL LIFE}

The technical purpose of the ONWI document is clear. However, the scope and objective of the technical discussion and the depth to which some topies are covered are 
not always well defined. The report title, Methodology for Predicting the Life of WastePackage Materials and Components Using Multifactor Acceierated Life Tests, is probably the best statement of objective in the document.

With a few specific exceptions, the technical 2spects of the administrative approach (Sec. 2) and the mechanical aspects of the technical approach (Sec. 3 and Apps. $A, B$, and C) are relatively clear and understandable. While the discussion of the mechanics of factorial tables and hierarchical trees is quite complete, the discussion of the two aspects of multifactor accelerated life tests that logically follow that topie are incomplete, or at least confusing. These important aspects are (1) technical definition of the objectives of the tests and related definitions of the stresses and (2) extr apolation of test results to predict behavior, or time to failure, at end-use conditions. Both items receive somewhat scant attention, as in Secs. 4.2.1-4.2.3, yet appear to be essential to successful application of the subject methodology to evaluation of waste package materials and components.

\subsubsection{Test Objectives}

The introductory sections of Sec. 3 (Technical Approach) should provide the rationale for the technical approach. However, the generic description of performance is not well linked to the specific problem of uniform corrosion testing. The use of the term "degradation curve" leads to some confusion. For example, Sec. 3.1 is entitled "Degradation Curves" and Secs. 3.1.1 and 3.1.2 are entitled "Hypothetical Degrodation Curves" and "Desired Graphical Output." The latter two topics are quite distinet and probably should not appear under the same heading unless the relationship between them is spelled out more clearly. As the heading implies, Sec. 3.1.1 addresses the dependence of some measure of performance $P$ on the time $t$ during which a sample is exposed to a constant level of stress. The form

$$
\frac{P\left(t / t_{F}\right)}{P(o)}=\left[1-\left(t / t_{F}\right)\right]^{1 / n}
$$

is suggested as a way to express the degree of nonlinearity of this relationship, where ${ }^{F}$ is the time required for the sample to fail.

Section 3.1.2, on the other hand, addresses a type of graphical display that can serve as a guide to the analysts of accelerated material-life test programs. In this display (Fig. 3-2), the corrosion rate relative to a reference corrosion rate (center point value) is plotted against the time to failure divided by the reference time to failure (center point value). This graph is constructed so that all of the points fall on a single straight line with a slope of -1 . This construction assumes that the time to failure $(t)$ is inversely proportional to the corrosion rate $(C R)$. In other words $\left(C R / C R_{0}\right)=\left(t_{0} / t\right)$.

What is the relationship between Secs. 3.1.1 and 3.1.2? In particular, what is the relationship between performance measure $P$ and corrosion rate $C R$ ? $O r$, is the linearity or lack thereof between $P$ and $t$ relevant? What are the implications of the relationship between $P$ and $t$ with respect to the applicability of a corrosion rate model such as the 
Eyring model, which does not have any explicit time dependence? The authors note that failure of performance need not be defined initially. However, if there are eritical urderlying relationships between some measures of performance of the waste package and the corrosion rate, then perhaps the question deserves more attention. Furthermore, if the relationsitip between $P$ and $t$ is to be determined experimentally, additional requirements may be placed on the design of the accelerated life test, especially if destructive testing is required.

\subsubsection{Definition of Stresses}

The introductory portions of Sec. 3 include little discussion of the characteristics of the stresses that may frustrate the successful application of the methodology. Section 3.1.1 begins with these statements: "It is assumed that the system (waste package material or component) has a long life under the stress conditions associated with enduse exposure ... Reduced lifetimes can sometimes be achieved by operating the component under higher-than-normal stress." However, no specific example is given to illustrate how one takes the time-varying stress conditions expected in the repository environment and arrives at a set of constant end-use stress conditions for use with this methodology. Likewise, determination of "higher-than-normal stress" values from transient stress conditions of an actual repository needs fuller explanation.

It would seem that the nature of the stresses deemed important for testing may impose limitations on the methodology. A discussion of such "theoretical" limitations would be helpful. For example, simple quantification to represent brine composition for use in the proposed methodology can be a daunting problem, as demonstrated in the specific application of the methodology given in O/TM-48. Yet, the limitations that such stresses place on the methodology are not covered in ONWI-501.

Another fundamental problem associated with definition of the stress is that the choice of a low and a high value of a stress factor in each model test explicitly assumes that the effects due to such a stress vary monotonically with the value of the stress factor. However, in the case of the stress factor $\mathrm{pH}$, it may be that the effects on iron alloys (and possibly other materials as well) show a different type of behavior. For example, the solubility of iron and aluminum oxides and oxy-hydroxides in aqueous solutions goes through a minimum as the $\mathrm{pH}$ is allowed to vary from low to high. Such behavior may be missed if too wide a range of $\mathrm{pH}$ values is chosen for the model. The use of $\mathrm{pH}$ as a stress factor leads to strange results. Given the definition of $\mathrm{pH}(\mathrm{pH}=$ $-\log \mathrm{a}_{\mathrm{H}^{+}}$), the outcome of a reaction is determined in part by the activity of the hydrogen or hydronium ion in solution. If the negative logarithm of the activity is used, it becomes difficult to understand the complicated chemical mechanisms of the reactions that are involved in corrosion processes and to predict the long-term ef fects of corrosion processes. Thus, the use of $\mathrm{pH}$ raised to a power in Eq. 1 on page 27 looks like a computational convenience divorced from any chemically meaningful reaction mechanisms.

While the purpose of ONWI-501 is to describe a test methodology, conerete examples of the relationships between the stresses imposed in the test situation and those expected in the repository situation would bolster arguments supporting the utility of this approach. 


\subsubsection{Bxtrapolation to End-Use Conditions}

The concept of extrapolation is introduced in Sec. 3.1 (pp. 16-17), rhich states that the plot shown in Fig. 3.2, which includes the straight-line extrapolation, may be helpful for assessing final experimental design but is not to be construed as a method of data analysis. The authors also note that "more appropriate methods for analysis of accelerated aging aata are considered later" (p. 17). Although references to specific sections are not given, App. $C$ and portions of Sec. 4 are probably the most relevant. However, these later parts of the text still leave some questions unresolved.

First, how are the times to failure and their mean values and, hence, the corresponding rates of corrosion or performance degradation, to be experimentally determined? Second, given this information, how should the extrapolation to meaningful real-world stress levels be carried out? Section 4.2 conveys how the test specimens should be allocated to maximize the extrapolation precision and concludes with a numerical example that indicates that acselerated life testing may be undesirable. Section 4.3.1 addresses the problem of experimentally determining the times to failure, but concludes that there are a number of serious problems, not to mention possible nonlinearities, in the time dependence. The authors do say that a method is proposed in App. $C$ that avoids some of these problems. Finally, Sec. 4.3.2 briefly summarizes several corrosion models, all of the same general exponential form, that may be suitable for extrapolation to the end-use stress levels.

Considering all of the above, no justification is given, other than previous applications to electronic components, for the use of any of these models in corrosion testing. In particular, no reason is given for not using a general multiple regression analysis. Granted, the specific models do provide suggestions for particular functions of the stresses to be used in a regression analysis.

As a result of trying to assimilate these related portions of the text, the reader is given the distinct feeling that the methodology is not yet complete and that more specific guidance would be very helpful in answering the questions raised above.

\subsubsection{Use of the Eyring Model}

Use of the Eyring model for corrosion studies is discussed explicitly in Sec. 4.3.2 o: ONWI-501 but is implicit in much of the earlier discussion. It is far from clear how the equation cited on page 42 is related to the original reaction rate model of Henry Eyring and his associates. In general, the Eyring theory of rate processes allows one to compute the forward and backward reaction-rate parameters'as functions of the state of an activated complex. In a nutshell, the reaction rate as applied in O/TM-48 depends on an exponential factor of the form $\exp [(X+Y+\ldots) / R T]$, where $X, Y, \ldots$ are thermodynamic functions, $R$ is the gas constant, and $T$ is the absolute temperature. The mathematical form alone is not sufficient to call the model "the Eyring model." From the text of the two reports, it is not clear whether the parameters $X$ and $Y$ can be identified with the thermodynamic functions. It seems that the authors of the two reports treat parameters like $X$ and $Y$ as if they were freely adjustable, without any clear connection to Eyring's reacticn rate model. While the particular name associated 
with a clearly defined model may not be significant in practice, the association of Eyring's name with the model without noting modifications or limitations leads to confusion of the type indicated above.

\subsubsection{Use of Hierarchical Trees}

Developing hierarchical trees for presenting corrosion data is a valuable technique for evaluating interactions between parameters important to the corrosion process. Furthermore, the exercise would be very helpful for a team responsible for desig.jing a test matrix. However, the document does not clearly express how one goes from the hierarchical tree to the life prediction. Several alternatives are suggested in Sec. 4.3 of ONWI-501, but the connection between the hierarchical tree process and the life-prediction process is weak or poorly explained.

\subsubsection{Mechanies of Computations}

The explanations of the computations made in developing a hierarchical tree (e.g., App. A, pp. 49-51) are rather mechanical, and they lack much explicit generality to ther factorial layouts. Although the specific numerical example is very helpful, a more general description of the procedure, or a more fundamental formulation of the computations, should be added.

An example follows of the type of confusion that a "mechanical" explanation of a computation can lead to. Computation of values used in the factorial tables and hierarchical trees (Apps. A and B) is straightforward and makes use of simple arithmetic or geometric means. However, in a numerical example in App. B, the authors compute the corrosion rate at the "center point" stress conditions using the geometric mean of the corrosion rates obtained from each of the eight possible combinations of the three stresses, rather than by simply evaluating the fitted Eyring modal at the center point stress condition. The text does not mention the fact that the two methods of computing $C R_{0}$ are equivalent under the assumed form of the Eyring model and the corresponding special definitions of the mean temperature and stress. It might prove misleading if some alternative model were used.

In modeling the relationship between stress levels and corrosion rates to permit extrapolation to the corrosion rate under the normal stress condition, the authors point out that the Eyring model, or various special cases of it, can be considered a default model when the dependence of corrosion rate on the various stresses is not known. This model and its use is satisfactorily described by the authors. However, in one numerical example, a total of five parameters in an Eyring model are fitted to eight points using a regression analysis. No estimates of the standard errors of these five parameters are given. When one has almost as many points as parameters, the quality of the fit is generally very poor.

Another issue related to the methodology, which may become important in a computational sense, is the matter of handling the variability of the uncertainties associated with hypothetical corrosion rates. As the computational procedures for 
hierarchical trees stand in App. A, all estimated corrosion rates would appear to have identical levels of uncertainty. However, one can imagine in practice that even consensus estimates for corrosion rates might have varying degrees of uncertainty associated with them because of the variability in the knowledge and predictive capabilities available for the ranges of stress conditions encountered. Should the levels of uncertainty vary widely among the estimates, the hierarchical tree methodology could lesd to biased, and thus misleading, results. The issue of variable uncertainty in the estimates and its potential effects on the analysis should be addressed.

\subsubsection{Other Technical Issues}

Assessment of the confounding effects of "pruning" the hierarchical tree (Sec. 4.1) involves the straightforward use of algebra to solve a system of simultaneous linear equations and is quite satisfactory. The objective is to retain the ability to distinguish the effect of each individual stress. However, the physics of the situation and experience may indicate that it is not worthwhile to separate out individual stress effects. Allowance is made in the administrative structure for such a contingeney, but it might be reemphasized in the technical portion of both reports.

Determination of the average lifetime $\tau$ under constant stress conditions (Sec. 4.3.1) is one of the more interesting and challenging aspects of the accelerated materiallife test problem. It is clearly pointed out that one has to make compromises when the process of determining an average time to failure requires that one conduct tests leading to a number of failures. (Some confusion exists between the topic of failure of some performance measure and the topic of corrosion rate. The two are never clearly connected.) In particular, the report points out that if a one-parameter exponential distribution function is used to describe the distribution of the time-to-failure random variable, the standard deviation and therefore the expected error of the mean lifetime $\bar{\tau}$ is inversely proportional to the square root of the number of failures. In other words, for no or few failures, the expected error in $\bar{\tau}$ is unacceptably large.

The authors suggest an interesting and potentially very useful (but untested) alternative approach that can be used with few or no failures (App. C). It involves assuming that the times to failure are distributed according to a two-parameter Weibull distribution. Using the assumption that the Weibull parameters are invariant under changes in stress level, they develop a relationship bミtween the number of samples required under normal conditions and the number required under overstress conditions to make the same statistical inferences regarding sample survival. This alternative procedure should be investigated further and validated with test data.

Allocation of test samples (Sec. 4.2.1) involves the following problem. Given a total of $\mathrm{N}$ tests, at which stress levels should the tests be conducted and what fraction of the tests should be conducted at each stress condition to maximize the precision at the extrapolated corrosion rate under normal stress conditions? This problem was solved, as noted by the authors of ONWI-501, by Hoel and Levine (1964) for only one independent variable (i.e., one stress). The authors of ONWI-501 assumed without formal proof that Hoel and Levine's soiution could be generalized to the case of several stresses. Although the generalization was straightforward, it is not clear under what conditions Hoel and 
Levine's results remain valid. Of particular concern is the case where some of the stresses may not be entirely independent of one snother. This problem needs to be investigated more fully, beceuse specifying the number of replications of tests at given stress conditions and the spacing hetween stress levels is critical to the design of a corrosion test program. 


\section{ANSWERS TO DOE/SRPO QUESTIONS AND REQUESTS FOR COMMENTS}

\subsection{O/TM-48: DESIGN OP A MULTIFACTOR MATERIAL-LIPE TEST}

Will the resulting test matrix generate a statistically sound data base on the performance of low-carbon cast steel in a salt repository environment to support design, modeling, and licensing activities?

The test matrix reported in O/TM-48 is not final. Although the final test matrix developed using this approach may prove to be acceptable, the present test result (Table 6) is not supported by the document. The statistical soundness of the present form of the data base cannot be judged.

The offered test matrix does not provide a complete data base. Other corrosion mechanisms must be, and apparently are being, addressed. The authors need to explain how they selected uniform corrosion as the dominant degradation mechanism. The method of selection is not described or referenced.

Are there other key stresses, besides those mentioned in the report, that should be considered in the design of the test matrix to meet the stated objectives?

The preclosure environment of the repository includes an air environment, which is not addressed in O/TM-48. Lithostatic and induced pressure stresses are not addressed, nor are sulfide and carbonate concentrations and chemical reactive stresses individually identified in the report. The reasons for excluding these stresses are not given. Also, the chosen stresses are neither well referenced nor well justified.

Are there better approaches for the nominal variables?

One could argue that a better approach to the nominal variables would be to analyze them mechanistically and not necessarily statistically. Guidance must be given as to which variables will be used to accelerate the life tests. This guidance would allow clearer identification of the physically and chemically meaningful variables within the artificially lumped eategory of a nominal variable.

Comment on the dominant type of degradation for the overpack material.

Selection of the dominant degradation mechanism underlies the document, yet it is neither described nor referenced. Therefore, we cannot evaluate the selection process. Actually, the assumption that uniform corrosion dominates the degradation process is not adequately justified in either O/TM-48 or ONWI-501.

Are the interpretation[s] of the results presented correct?

One cannot tell, because Table 6 has not been interpreted. 
Comment on the Eyring model used in the curve fitting. Are there other better models?

The Eyring model may be appropriate, but sefer to the answer to the next question. However, the report seems to conclude that the model is not adequate and states that a model presently under development to address the problem will be relied upon.

What happens when radiation approaches zero?

Since zero radiation levels will not be achieved within the lifetime of the package, this issue should not be of concern. The zero-radiation case may be an important experimental link to existing data on low-carbon cast steel.

If this question refers to the fact that in O/TM-48 the radiation level (R) enters the Eyring model in such a way that when $R$ approaches zero so does the corrosion rate (CR), then the following answer applies: Since one does not expect $C R$ to go to zero when $R$ does, it follows that the form of the Eyring model being used is inadequate. A better choice of corrosion rate riodel would allow the corrosion rate to remain finite even when the radiation level is zero. In general, if the corrosion rate remains finite when a particular stress is turned off, that stress should be represented by an additive term rather than a multiplicative factor.

\subsection{ONWI-501: METHODOLOGY FOR PREDICTING MATERIAL LIFE}

Comment on the technical approaches for the designing of the test matrix.

The basic approach seems good. It highlights the important parameters and allows the design team to visualize the interactions of the parameters. However, the method has two weaknesses. First, the importance of selecting the dominant degradation mechanism is underemphasized. If the wrong mechanism is selected, the whole process is wcrthless. Second, the method for extrapolating supporting data to end-use conditions is not well defined. Each user must devise a mechanistic model to make a meaningful extrapolation.

Comment on the $2^{n}$ factor approaches.

The $2^{\mathrm{n}}$ factor approaches seem appropriate and justifiable, although individual stresses may be difficult to quantify and interactions between nonthermal stresses are not accommodated. Some distinetion should be made between the variables that are suitable for accelerating corrosion rates and those that are not. In addition, using only a high and a low value of a variable may be helpful in the preliminary design phase, but such a limited choice of values is not consistent with the need to allocate test specimens to maximize the precision of the extrapolation at normal stress conditions. 
Comment on the mathematical approaches to the accelerated life testing.

See Sec. 4.2 of this review report, especially Secs. 4.2.3-4.2.6. 


\section{PAGE-BY-PAGE COMMENTARY}

\subsection{O/TM-48: DESIGN OF A MULTIFACTOR MATERIAL-LIFE TEST}

\begin{tabular}{|c|c|c|}
\hline Page(s) & Line(s) & Comment \\
\hline 6 & 5 & $\begin{array}{l}\text { What were the bases for the "predicted" corrosion rates? Were } \\
\text { they quantitative predictions? If so, how were these predictions } \\
\text { made, given the "undefined" nature of the steel, specimen } \\
\text { orientation, salt solid phase, and oxide film thickness? }\end{array}$ \\
\hline 9 & & $\begin{array}{l}\text { The right-hand column in Table } 3 \text { should be labeled "LOG(EST } \\
\text { CR)," not "LOG(CR)." }\end{array}$ \\
\hline 10 & 19 & $\begin{array}{l}\text { The Eyring model does not account for nonthermal stress } \\
\text { interactions. What the model is proposed to quantitatively } \\
\text { describe is interactions between, say, brine composition and } \\
\text { radiation level. Is there any guarantee that the mechanistic } \\
\text { models under development can account for these interactions? } \\
\text { Will this same type of analysis be used to refine the test design } \\
\text { once those models are available? These conclusions should be } \\
\text { stated somewhere, as should plans for revising the test matrix. }\end{array}$ \\
\hline 13 & 4 & "Rows 1 and 4" should be changed to "rows 1 and $5 . "$ \\
\hline 13,14 & & $\begin{array}{l}\text { The right-hand columns in Tables } 4 \text { and } 5 \text { should be labeied } \\
\text { "LOG(EST C R)," not "LOG(CR)." }\end{array}$ \\
\hline 14 & $14-16$ & $\begin{array}{l}\text { A bit of confusion has gradually crept into the discussion. In the } \\
\text { second paragraph on page } 7 \text {, it is clear that the corrosion rates are } \\
\text { "hypothetical predicted corrosion rates that represent the } \\
\text { consensus of the members of the team." On page 8, these } \\
\text { hypothetical data are fitted to the Eyring model. Then, on page } \\
13 \text {, the hypothetical consensus values are called "data," and the } \\
\text { fitted values are called "estimated corrosion rates." Now, on page } \\
14 \text {, we have "estimated CR" and "actual CR." The terminology } \\
\text { needs to be consistent throughout to make it elear that actual } \\
\text { experimental data are not being introduced on pages } 13 \text { and } 14 \text {. }\end{array}$ \\
\hline 15 & 7 & $\begin{array}{l}\text { In this discussion, "actual data" presumably means actual experi- } \\
\text { mental data, and "hypothetical data" means the "hypothetical } \\
\text { consensus values" referred to earlier. This distinetion should be } \\
\text { clarified through the use of appropriate, consistent language } \\
\text { throughout. }\end{array}$ \\
\hline
\end{tabular}




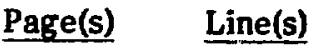

Comment

16

$16 \quad 21-23$

In Table 6, only one test condition involves righ radiation. Radiation is estimated (hypotheticel consensus values) to be an important splitting parameter, so at least two or three high-stress cases should be tested. Why is only one case being tested?

This concluding sentence should be in the Introduction. One has to read the entire document before finding out that it does not describe the entire ONWI corrosion testing program.
\end{abstract}

\title{
6.2 ONWI-501: METHODOLOGY FOR PREDICTING MATERIAL, LIPE
}

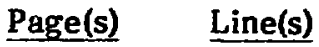

3

25-30

6-7 13-31; $1-9$

\section{Comment}

The ideas expressed here should be presented near the beginning of Sec. 1, and the references especially should be cited there. Also, a clearer statement of the scope and objectives of the document would be helpful.

While identification of failure mechanisms and selection of the dominant failure mechanism are discussed here, the importance of these steps is not placed in proper perspective. At least half the effort should be placed on this item, or it will be necessary to take all reasonable failure mechanisms through the same design procedure.

The first paragraph of Sec. 2.2.2 implies that more than one failure mechanism will be examined. The second bullet refers to the "first iteration of the design procedure." However, the point should be highlighted. Selection of the dominant failure mechanism is critical. Corrosion testing programs have been known to spend millions of dollars studying a particular mechanism only to have the material fail in service as a result of some other cause.

The importance of identifying all reasonable failure mechanisms and selecting the dominant mechanism cannot be overemphasized. ONWl-501 treats the issue entirely too lightly. The reader is then lulled into a false sense of security by the mathematies and statistics in the rest of the report. The idea of iterating through several possible failure mechanisms seems to get lost in the mathematical details. 


\begin{abstract}
$\underline{\text { Page(s) }} \quad \underline{\text { Line(s) }}$

\section{Comment}

11 8-25 Further iterations on other failure mechanisms are not mentioned. Only one failure mechanism is analyzed. For the case of metal corrosion, at least three mechanisms should be examined by this process: uniform corrosion, stress corrosion cracking or environmentally enhanced crack growth mechanisms, and localized corrosion (pitting and crevice corrosion). In addition, at least two environments should be evaluated: the preclosure environment, ineluding air-saturated (perhaps steam) úiy or moist salt, and the postclosure environment, including anoxic inclusion brine. The preclosure environment obtains over a significant fraction of the total life requirement, that is, over more than $\mathbf{5 0}$ years out of a total of $\mathbf{3 0 0}$ years.
\end{abstract}

15 The phrase "... first iteration ..." oceurs agæin. What does this refer to? It implies more than one iteration. Do the iterations include the mechanism determination st $€$ ??

" $L_{6}=0.5682$ " should be " $L_{6}=0.0568$."

" $L_{7}=0.5682$ " should be " $L_{\eta}=0.0568 . "$

" $P_{8}=0.001$ " should be $" \mathrm{P}_{8}=0.003 . "$

The citation for "Davies, 1977" is not given in the references.

In the caption to Table A-1, "rotation" should be changed to "radiation." Also, the mechanical description of the analysis (e.g., add successive pairs) is not very general or appealing. Finally, the description of column (5) is very weak. 


\section{REPERENCES}

Basham, S.J., Jr., Waste Package for a Repository Located in Salt, Proc. 1983 Civilian Radioactive Waste Management Information Meeting, U.S. Department of Energy, Washington, D.C., CONF 831217, pp. 280-283 (1984).

Davis, M.S., and D.G. Schweitzer, Draft Technical Position Subtask 1.1: Waste Package Performance after Repository Closure, U.S. Nuclear Regulatory Commission Report NUREG/CR-3219, Vol. 1 (Aug. 1983).

Hoel, P.G., and A. Levine, Optimal Spacing and Weighting in Polynomial Prediction, Annals of Mathematical Statistics, 35:1553 (1964).

Jenks, G.H., et al., Reaction Products and Stored Energy Released from Irradiated Sodium Chloride by Dissolution and by Heating, J. Physical Chemistry, 78:87 1 (1975).

Levy, P.W., Radiation Damage Studies on Natural Rock Salt from Various Localities of Interest to the Radioactive Waste Disposal Program, Nuclear Technology, 60:231-243 (1983).

U.S. Nuclear Regulatory Commission, Disposal of High-Level Radioactive Wastes in Geologic Repositories; Licensing Procedures, Code of Federal Regulations, 10 CFR Part 60 (June 30, 1983). 


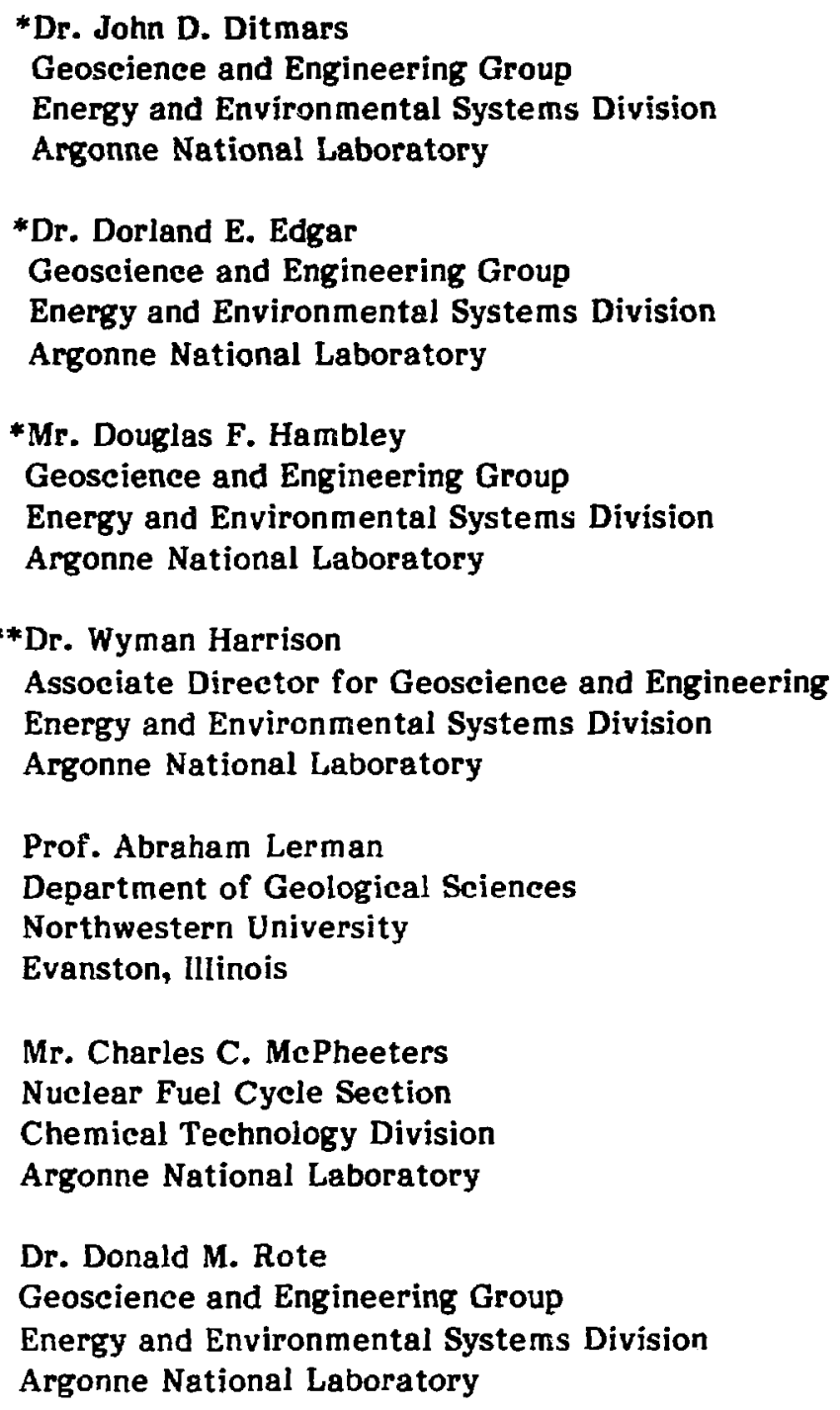

The credentials of the panel members are summarized in App. C.

* Member of core peer review staff.

**Review panel and review session chairman, and member of core peer review staff. 
$29 / 30$

APPENDIX A

U.S. DEPARTMENT OF ENERGY LETTER

REQUESTING PEER REVIEW 


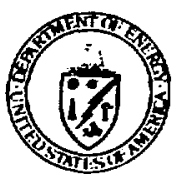

Department of Energy

Chicago Operations Office

Salt Repository Project Office

505 King Avenue

Columbus, Ohio 43201-2693

May 14, 1984

Wyman Harrison

EES-362

Argonne National Laboratory

9700 South Cass Avenue

Argonne, I11inois 60439

Dear Dr. Harrison:

SUBJECT: REVIEW OF REPORTS ENTITLED, "DESIGN OF A MULTIFACTOR LIFE TEST TO INVESTIGATE UNIFORM CORROSION OF LOW-CARBON CAST STEEL AS A NUCLEAR WASTE PACKAGE OVERPACK MATERIAL IN A SALT REPOSITORY ENVIRONMENT," ONHT 0/TM-48, AND "METHODOLOGY FOR PREDICTING THE LIFE OF WASTEPACKAGE MATERIALS AND COMPONENTS USING MULTIFACTOR ACCELERATED LIFE TESTS," ONWI-501

We would appreciate your forming a panel to review the attached subject reports. Since these two reports are closel' related, we feel it is appropriate to review both reports simultaneously. The review should include, but need not be limited to, the following points:

DNWI $0 /$ TM-48

1. Will the resulting test matrix generate a statistically sound data base on the performance of 1 ow-carbon cast steel in a salt repository environment to support design, modeling, and licensing activities?

2. Are there other key stresses, besides those mentioned in the report, that should be considered in the design of the test matrix to meet the stated objectives?

3. Are there better approaches for the nominal variables?

a. Comment on the dominant type of degradation for the overpack materia?

5. Are the interpretation of the results presented correct?

6. Comment on the Eyring model used in the curve fitting. Are there other better models?

7. What happens when radiation approaches zero?

8. Other comments. 
ONWI-501

1. Corment on the technical appproaches for the designing of thie test matrix.

2. Comment on the $2^{n}$ factor approact?es.

3. Comment on the mathematical approaches to the accelerated life testing

4. Other comments.

Please complete the reviek and submit the final report to SRPO by June 18, 1984. If you have any questions, please contact Roger Hu at FTS 976-5916.

Sincerely,

SRPO:KKW:2367B

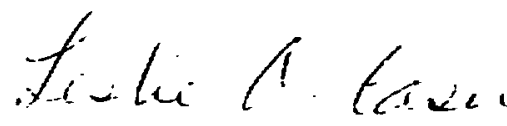

Robert C. Wunderlich

Acting Chief

Engineering and Technology

Salt Repository Project office

ST\# 579-84

Enc?osures:

1. OHWI-501, "Methodology for Predicting the Life of Waste-Package Materials and Components using Mul tifactor Acce? erated Life Tests" (September 1983)

2. ONWI 0-TM/48, "Design of a Mul tifactor Life Test, to Investigate Uniform Corrosion of Loiy-Carbon Cast Steel as a Huclear Has te Package Overpack Material in a Salt Repository Environment." (Apri? 1984)

cr: T. Baillieu?, SRPO

R. WU, SRPO

J. Sherwin, SRP0 
$33 / 34$

APPENDLX B

CONCURRENCE SHEET 
$35 / 36$

CONCURRENCE SHEET

I concur that the Argonne National Laboratory report on ONW!'s internal technical memorandum $\mathrm{O} / \mathrm{TM}-48$ and on ONWI-501 fairly represents my comments, where incorporated, to the peer review panel.
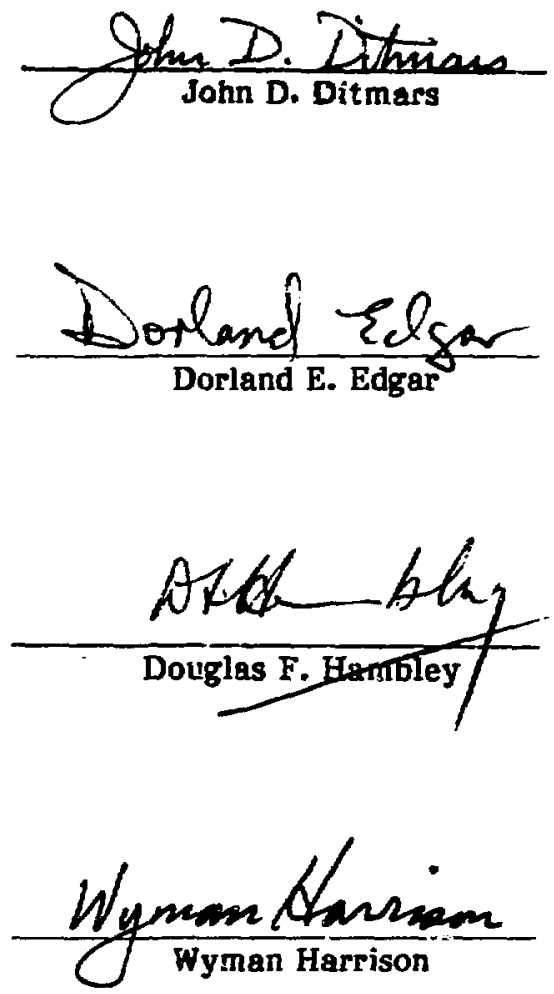
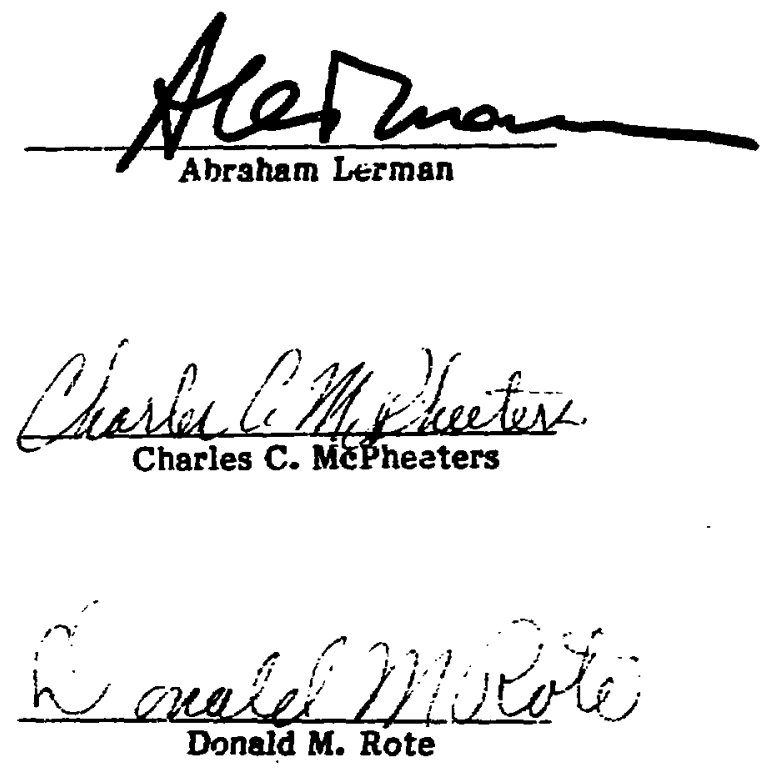


\section{John D. Ditmars}

Princeton University: B.S.E., Civil Engineering (1965)

California Institute of Technology: M.S., Civil Engineering (1966)

California Institute of Technology: Ph.D., Civil Engineering (1971)

Dr. Ditmars is leader of the Geophysics and Engineering Section of the Geoseience and Engineering Group of the Energy and Environmental Systems Division at Argonne National Laboratory. Measuring and modeling portions of the hydrosphere impacted by energy technologies and natural resource development has been the main research area of this section. Particular attention has been given to evaluations of model performance and to experimental designs for the acquisition of data at prototype scales for performance evaluation. Dr. Ditmars has extensive experience in modeling and measurement of transport and mixing processes in the hydrologic environment. He was for several years responsible for the annual literature review in the area of "Mixing and Transport" for the Journal of the Water Pollution Control Federation and is presently the Chairman of the Paper Awards Committee of the Hydraulics Division of the American Society of Civil Engineers. He is also the Chairman of the Task Committee on Verifieation of Models of Hydrologie Transport and Dispersion for the Hydraulies Division of the same society and, as such, has been concerned with the generic aspects of verification and validation as well as with those aspects of particular models.

Before joining Argonne in 1977, Dr. Ditmars was Assistant Professor of Civil Engineering at the University of Delaware. From 1970 to 1972 he was Visiting Assistant Professor in the Water Resources and Hydrodynamies Division of the Civil Engineering Department at MIT. His teaching and research activities at the University of Delaware and MIT focused on hydraulic engineering and fluid mechanical processes in the natural hydrologic environment, and involved analytical and numerical modeling as well as laboratory and field experiments. He is author of more than 45 technical publications in these areas. 


\author{
Dorland B. Edzar \\ Central Missouri State University: B.S., Geology (1968) \\ Colorado State University: M.S., Geology (1973) \\ Purdue University: Ph.D., Geology (1976)
}

Dr. Edgar joined the Geoscience and Engineering Group of the Energy and Environmental Systems Division of Argonne National Laboratory in 1978. Since that time he has worked as a geologist and hydrologist on programs related to waste management and energy and mineral resources development. From 1981 through 1983, he participated in studies of the geologic setting of erystalline rocks of the northeastern and Lake Superior regions of the United States for the purpose of assessing their suitability as sites for a high-level radioactive waste repository. His primary areas of responsibility on this project were surface-water and groundwater hydrology, geomorphology, and surficial geoiogy.

From 1978 to 1981, Dr. Edgar was affiliated with Argonne's Land Reclamation Program and Environmental Control Technology Program, where he studied the relationships between surface mining and reclamation activities, and geomorphic processes, hydrology, water quality, and erosion and sedimentation. Dr. Edgar also served as a U.S. Department of Energy representative to an interagency group that reviewed comments and drafted revised regulatory guidelines for the U.S. Office of Surface Mining.

Before coming to Argonne, Dr. Edgar was employed at Oak Ridge National Laboratory, where he conducted research on surface and subsurface hydrologic and geologic conditions, and their relationship to the shallow land disposal of low-level radioactive waste. One project involved the study of the hydrologic and geomorphic processes involved in transporting radionuclides from burial sites through an instrumented watershed. Dr. Edgar's graduate research was directed primarily toward the relationships between hydrology and the geomorphic processes operating within alluvial stream channels and drainage basins.

Dr. Edgar has authored approximately 25 scientific and technical publications, and is a member of two professional societies. 


\section{Douglas F. Hambley}

Queen's University at Kingston: B.Sc., Mining Engineering (1972)

Lewis University: MBA candidate .

Registered Professional Engineer, No. 18026014, Province of Ontario, and

No. 062-03920i, State of Illinois

Mr. Hambiey has more than 10 years experience in mining, tunneling, and underground construction. He joined the staff of the Geoscience and Engineering Group of the Energy and Environmental Systems Division of Argonne National Laboratory in 1984. Prior to working at Argonne, Mr. Hambley was employed as a Senior Mining Engineer for nearly four years by Engineers International, Inc., a mining/tunneling consulting firm located in Westmont, III. In addition to designing several large tunnels for various purposes, he spent over two years as Project Engineer on U.S. Nuclear Regulatory Commission contracts to assess retrievability from repositories for high-level radioactive waste and to provide technical assistance for repository design reviews.

Between 1972 and 1980, Mr. Hambley held various technical positions with major Canadian mining companies, including Denison Mines Ltd. and Falconbridge Nickel Mines Ltd. During his employment at Denison (1977-1980), he was responsible for several major projects, including (1) a tripartite (Denison/Rio Algom/CANMET) regional stability study; (2) investigation, specification preparation, and tender evaluation for Stanrock Mine dewatering and shaft rehabilitation; (3) design of the backfill system for a pillar recovery scheme; and (4) design of the underground garage and supply station for diesel fuel at No. 1 shaft.

Mr. Hambley has published on retrievability of high-level nuclear waste, design of shafts and tunnels, computer modeling of mine openings, and raise boring cost estimation. He is active in several technical societies. 


\title{
Wyman Harrison
}

\author{
University of Chicago: S.B., Geology (1953), after three years of \\ undergraduate work at Stanford University \\ University of Chicago: S.M., Geology (1954) \\ University of Chicago: Ph.D., Geology (1956) \\ Registered Geologist, No. 2476, State of California \\ Certified Professional Geologist, No. 134, American Institute of \\ Professional Geologists, and No. 487, State of Virginia
}

Dr. Harrison is Associate Director for Geoscience and Engineering for Argonne National Laboratory's Energy and Environmental Systems Division. He directs a 25person group that performs analytical and experimental studies related to management of energy and mineral resources and to development and deployment of related technologies. Major activities of the group include (1) acquisition of geophysical and geotechnical data bases, (2) analysis of the data of geoscience to support design and deployment of energy technologies, and (3) development of physical and mathematical models of geophysical/geotechnical systems.

Dr. Harrison's group recently completed comprehensive surveys of the geoscience data pertaining to crystalline rock complexes in the northeastern and Lake Superior regions of the United States to help assess their potential as possible sites for repositories for high-level radioactive waste. Dr. Harrison has conducted numerous other geological and geotechnical studies at Argonne, ranging from esíimating the petroleum resources of selected basins in the Soviet Union to determining near-shore circulation in Lake Michigan.

From 1971 to 1975, Dr. Harrison was Professor of Geography (Associate Department Chairman) at the University of Toronto, where he specialized in geophysical studies related to slope stability in sedimentary terrains and the siting of supertanker ports. Prior to that, he was Associate Director for Physical, Chemical, and Geological Oceanography at the Virginia Institute of Marine Science and a Professor of Marine Science at the University of Virginia. Dr. Harrison was Director of Environmental/ Science Services Administration's (now National Oceanic and Atmospheric Administration's) Land and Sea Interaction Laboratory from 1964 to 1968 . Before that he was on the faculty of Dartmouth College's Department of Geology and a geologist with the Indiana Geological Survey.

An author of over 100 papers, reports, reviews, and books, Dr. Harrison was made Senior Seientist at Argonne in 1976. 


\section{Abraham Lerman}

The Hebrew University: M.Se., Geology (1960)

Harvard University: Ph.D., Geology (1964)

Dr. Lerman joined the Department of Geological Sciences at Northwestern University in 1971 as Associate Professor and has been Professor since 1975. Dr. Lerman has extensive experience in aqueous geochemistry, geochemistry of brines, isotope geochemistry, and radionuclide migration. He is a resource consultant on waste packaging and geochemistry for the Basalt Waste Isolation Project Overview Committee. During 1980 Dr. Lerman was a member of the Backfill Evaluation Panel for Battelle's Pacific Northwest Laboratory.

While associated with Northwestern University, Dr. Lerman has served, at various times, as a visiting professor at several European universities. Prior to joining the faculty at Northwestern, he was a Research Scientist in Chemical Limnology at the Canada Certre for Inlend Waters (1969-1971), a Visiting Investigator and Senior Seientist in Isotope Research at Weizman Institute of Seience (1966-1969), an Assistant Professor of Geology at the University of llinois at Chicago Circle Campus (1965-1968), a Visiting Investigator (geochemistry) at Lamont-Doherty Geological Observatory of Columbia University (Summer, 1965), and a Lecturer and Assistant Professor of Geology at the Johns Hopkins University (1964-1965).

Dr. Lerman has published extensively in the areas of geochemical processes in water and sediments, halite and brines, chemical limnology, geochemical cycles, and radionuclides in sedimen is. He is a member of five professional societies and a Fellow of the Geological Society of America. 


\section{Charles C. McPheeters \\ University of Missouri: B.S., Metallurgical Engineering (1963) \\ University of New Mexico: M.S., Engineering Science of Materials (1968)}

Mr. McPheeters joined the Chemical Technology Division of Argonne National Laboratory in 1970 and currently provides technical support to the Materials Integration Office of the U.S. Department of Energy's Chicago Operations Office. He has helped coordinate the development and review of test methods and data used to support nuclear waste repository licensing and acceptance of waste for disposal in repositories. In previous work at Argonne, Mr. McPheeters developed a computer model for a sodium impurity precipitation process, various sodium processing systems, and instrumentation for monitoring impurities. Other areas of research have included lithium/sulfur batteries, liquid-metal fast breeder reactor safety experiments in TREAT, and detection and location systems for failures of fuel elements.

Prior to joining Argonne, Mr. McPheeters was employed by Atomies International, Rockwell International, where he designed equipment for sodium purification and removal of dissolved gases from sodium in liquid metal fast breeder reactors. Between 1963 and 1968, at Los Alamos Scientific Laboratory, he developed a solidelectrolyte electrochemical cell for determining oxygen activity in sodium and studied the corrosion of containment materials in liquid Pu-Co-Ce alloys. During this time he supervised and operated a metallography laboratory where the effects of Pu-alloy corrosion of containment materials were studied. patents.

Mr. McPheeters has authored approximately 25 publications and has three 
APPENDIX C

CREDENTIALS OF PEER REVIEW PANEL MEMBERS 


\section{Donald M. Rote}

Cleveland State University: B.E.S., Engineering Seience (1960)

Case Western Reserve: M.A., Theoretical Physics (1963)

Case Western Reserve: Ph.D., Theoretical Nuclear Physics (1967)

Dr. Rote is a geophysicist in the Geoscience and Engineering Group of the Energy and Environmental Systems Division of Argonne National Laboratory. He has served as principal investigator since 1970 on numerous projects sponsored by the U.S. Environmental Protection Agency, U.S. Air Force, and Federal Aviation Administration concerned with development, verification, validation, and documentation of models used for air pollution assessment. He has also directed a number of field programs that required the acquisition, analysis, and interpretation of air-quality, meteorological, and source data.

Dr. Rote has concurrently served as an advisor on model validation, model applications, monitoring, and data analysis techniques to the above institutions. In addition, he has given series of lectures on these subjects at both the Majorana Sehool of Physics of the Planetary Boundary Layer held at Erice, Sicily, and the Korean Institute for Science and Technology at Seoul, Korea.

Dr. Rote has published over 60 reports, book chapters, and journal articles. 


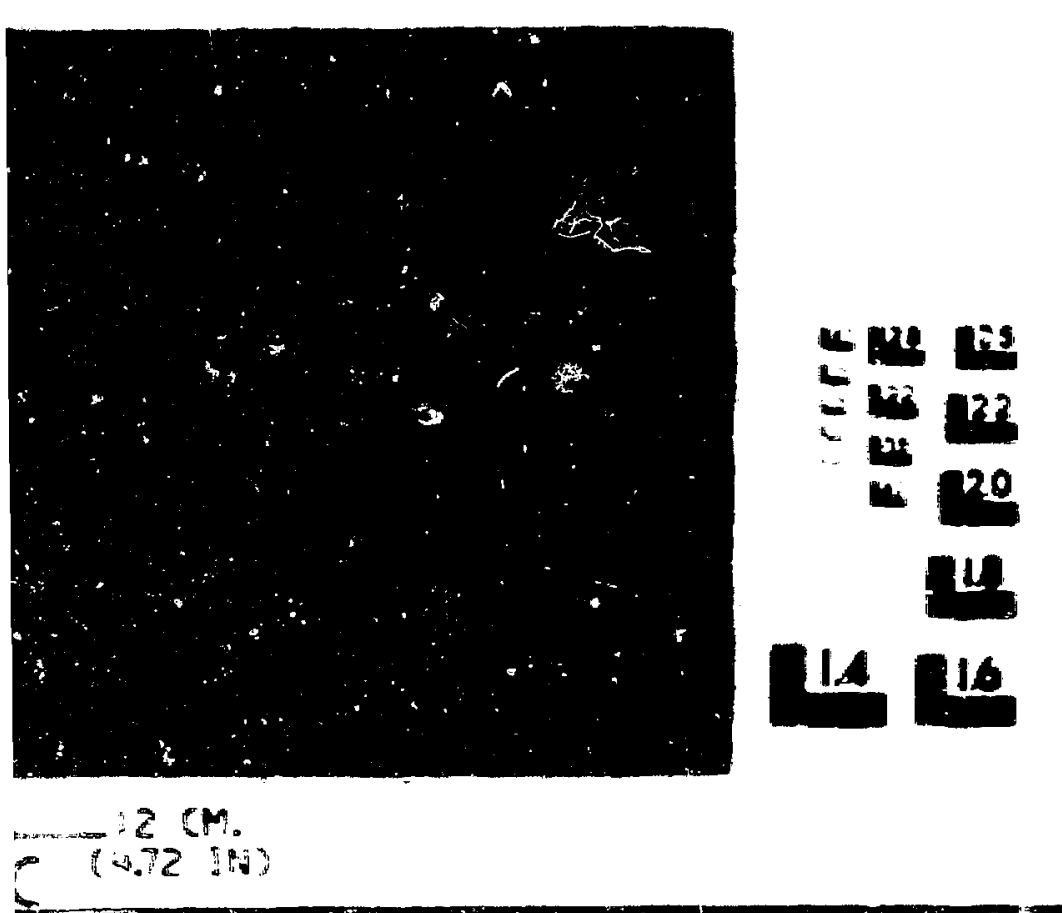

to tine por mon motarechana

TEST CHAT

man m112-196

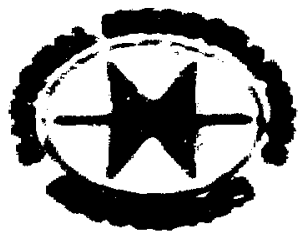

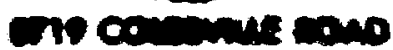

$\lim 20$

mano

(2)i soles

compreatron sinme

का 1

CM. (2.15 IN)

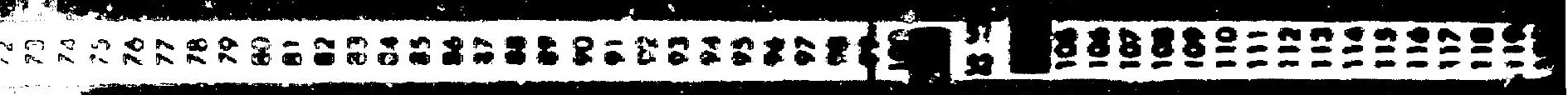
if 1:

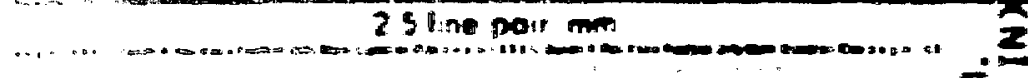
$\Rightarrow 000 \%$ 180

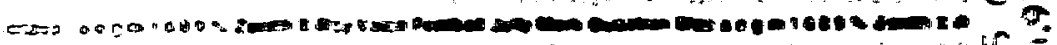

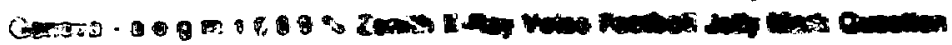
$\therefore$ i. : :

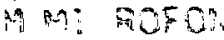

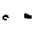
bisth

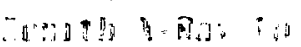
i) it b 59 36 ZF

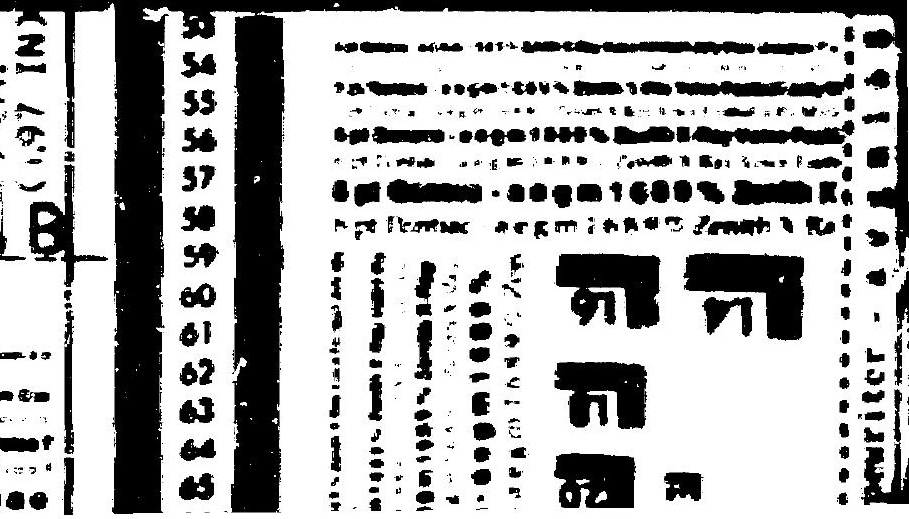




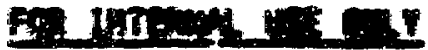

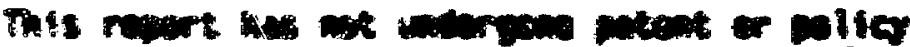

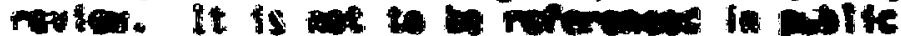

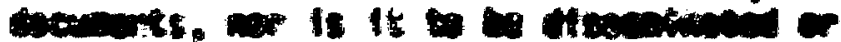

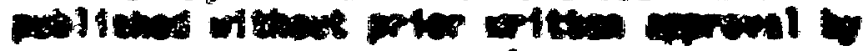 navereat.
}

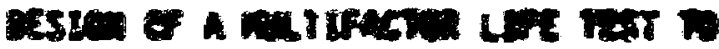

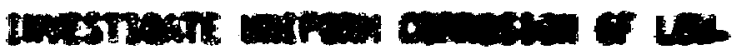

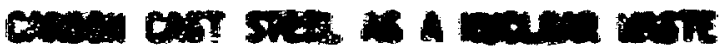

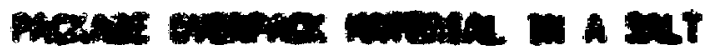
agastiny emsingat
\end{abstract}

Intermal Techiteal

matt ins

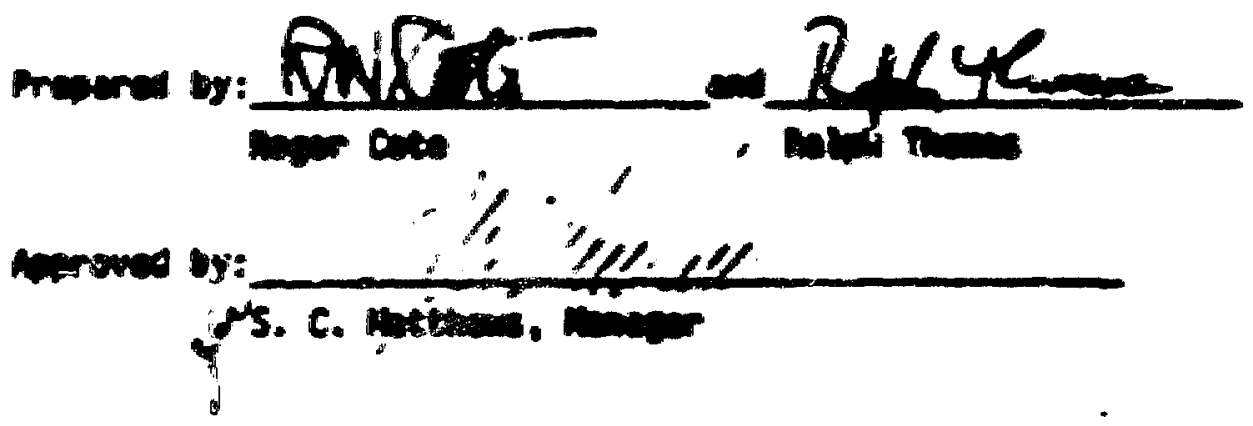

Eaginoring Futtion ofice of tucles mate Isoletion Catedite frasect manont Bivisies

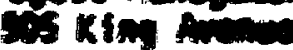
colvens, onio Aren-zing 
Design of a Nultifecter hife Test to

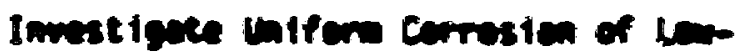

certea cost stasel is a mocher unse

Peckese overnact beterial in a salt

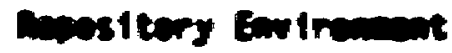

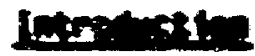

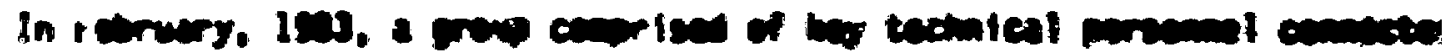

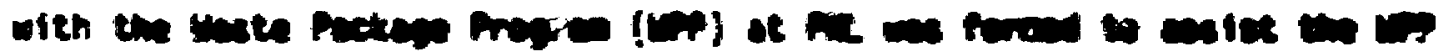

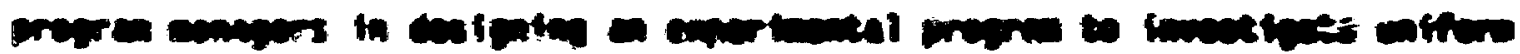

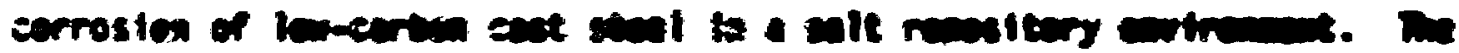

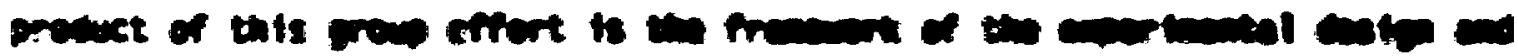

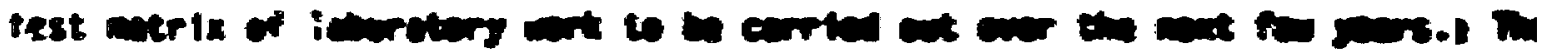

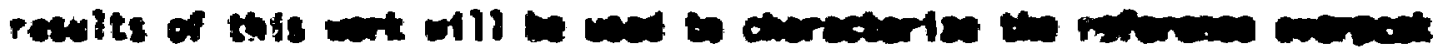

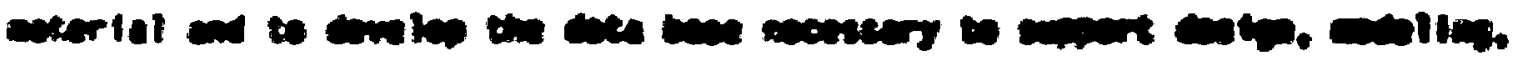

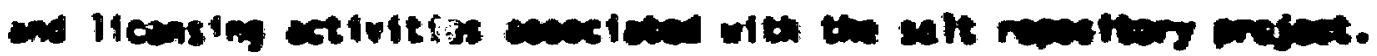

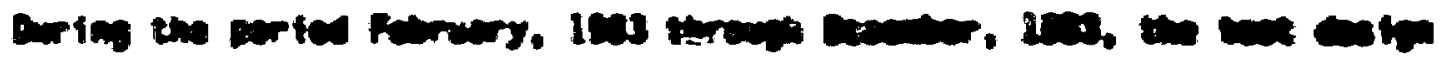

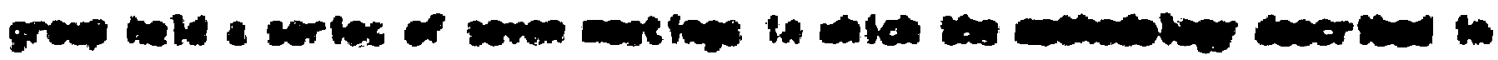

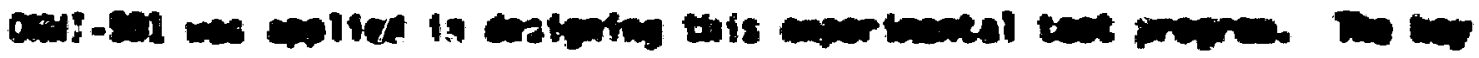

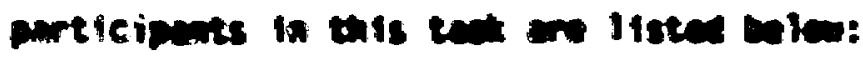
Ce inotionsens
it rim, in
and, manes
sc P1tom, ma
a sisen, in

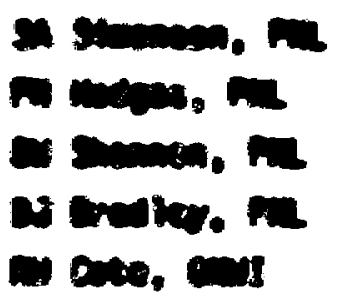

Mis repoet oresonts the rewits of this tom emort. 


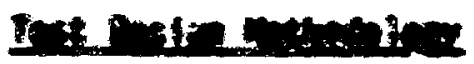

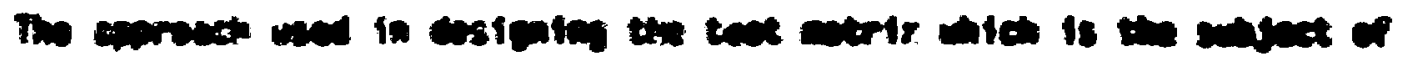

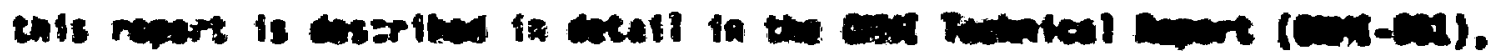

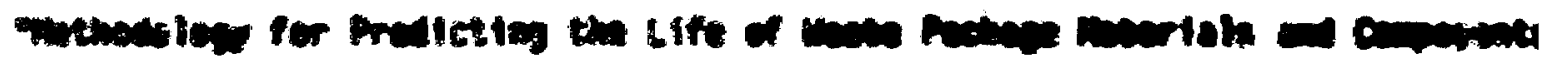

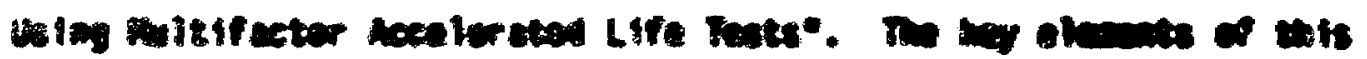

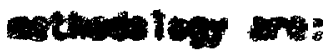

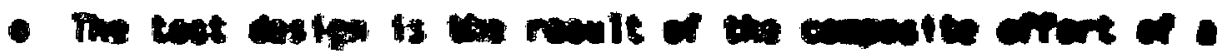

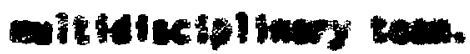

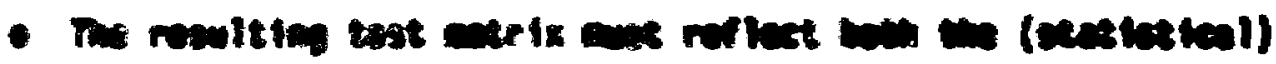

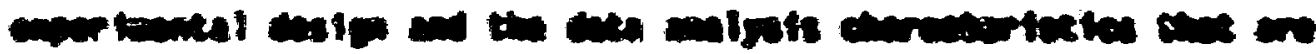

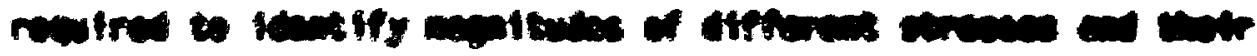

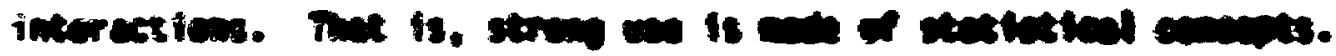

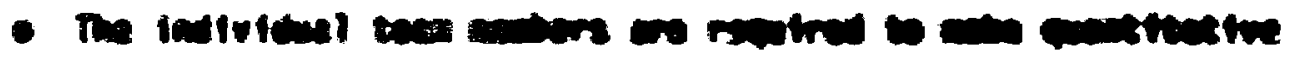

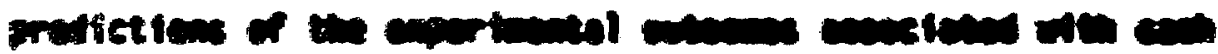

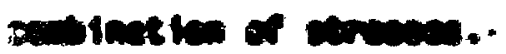

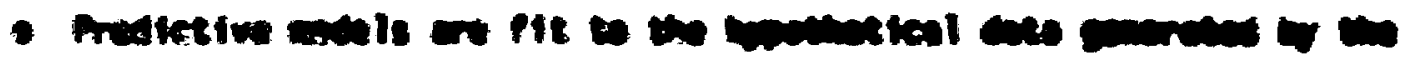

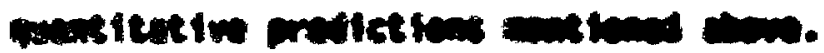

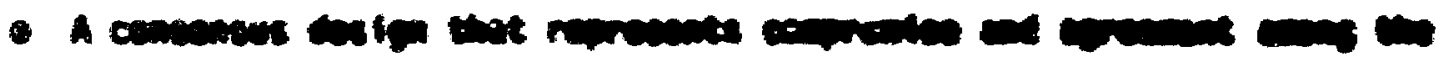

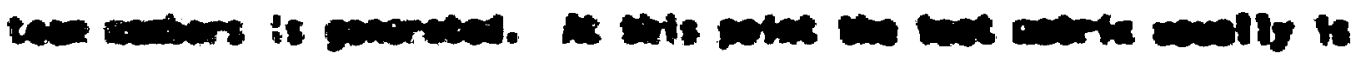

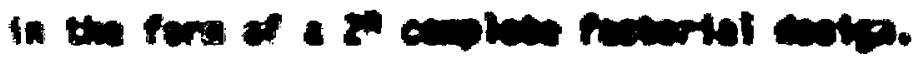

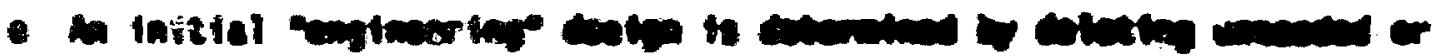

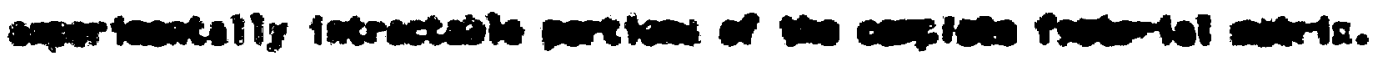

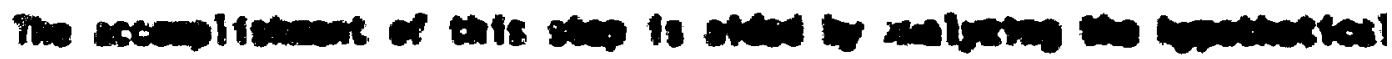

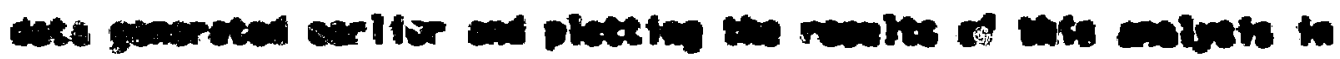
the fow of a hiererditcal trim.

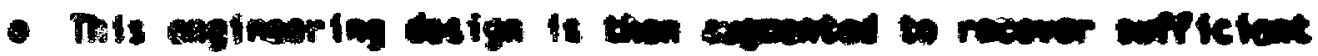

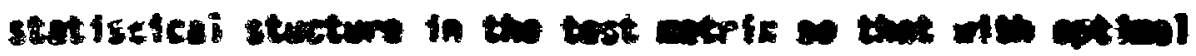

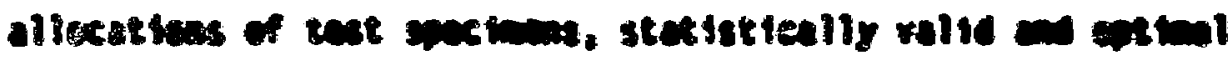

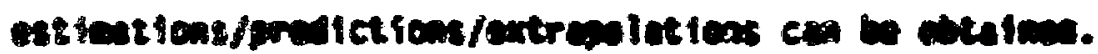

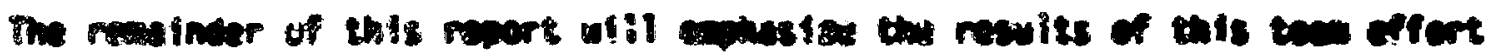

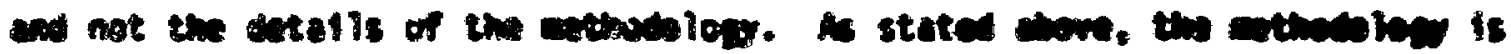
ceecribed in ant-50i. 
Bame.

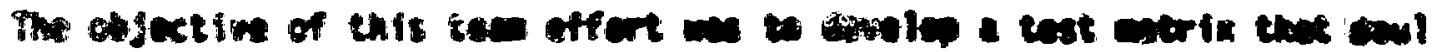

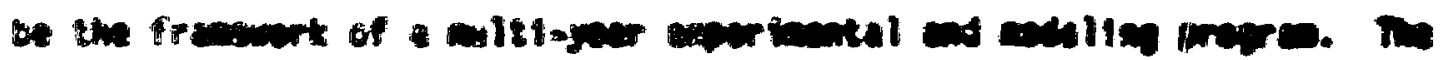

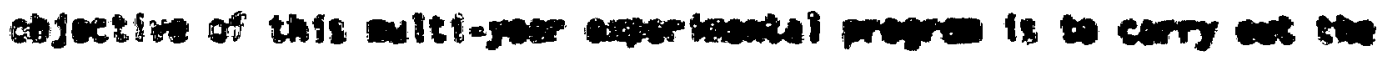

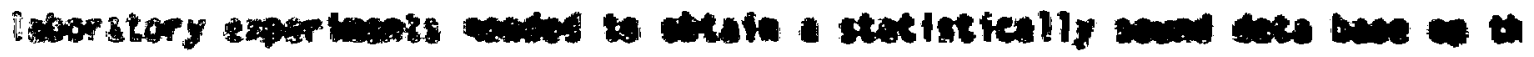

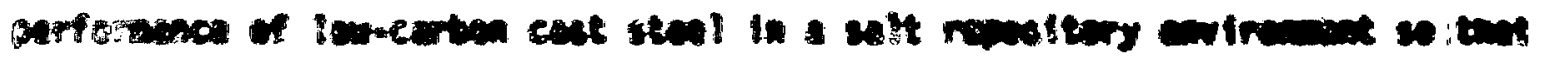

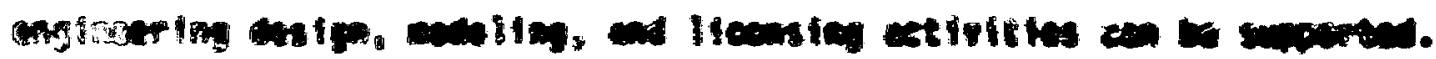

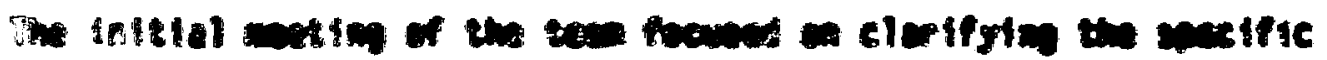

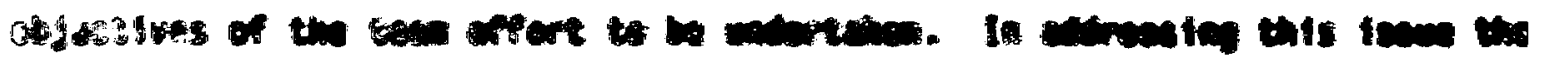

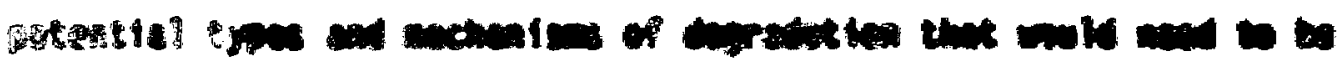

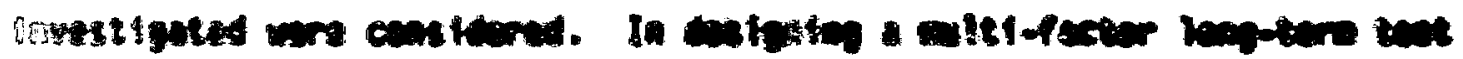

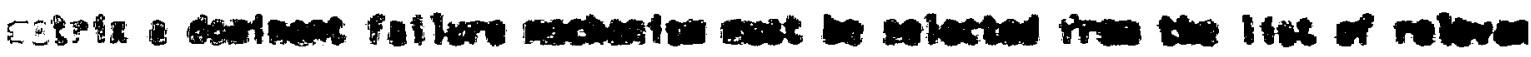

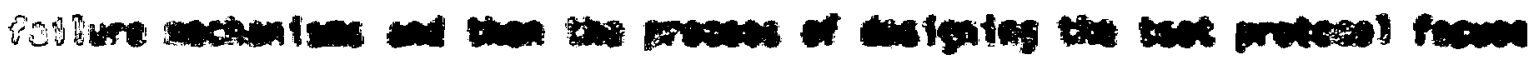

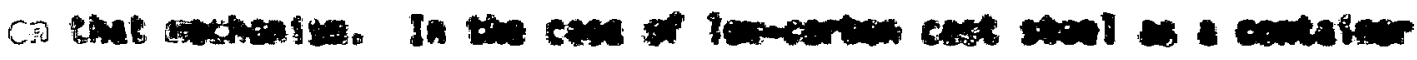

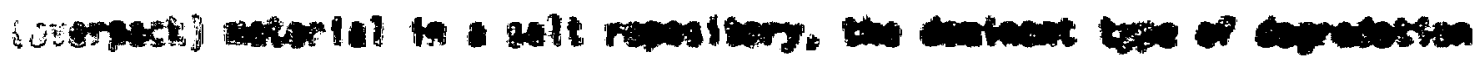

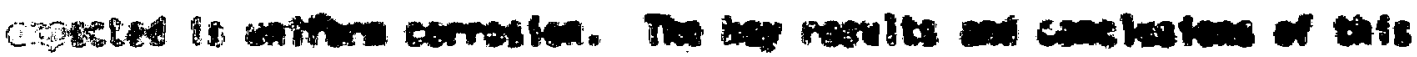

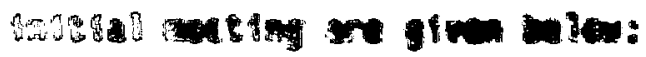

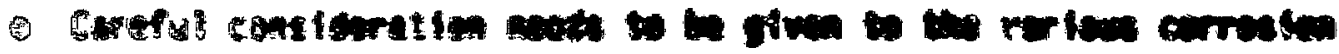

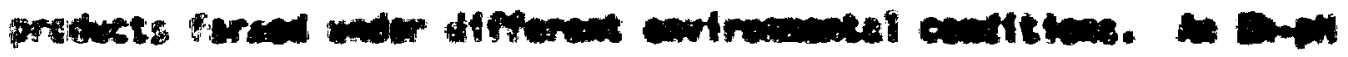

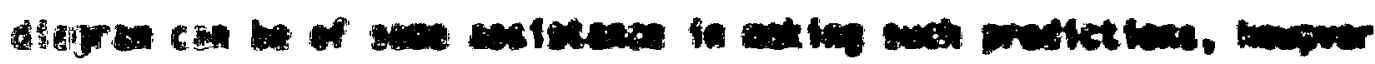

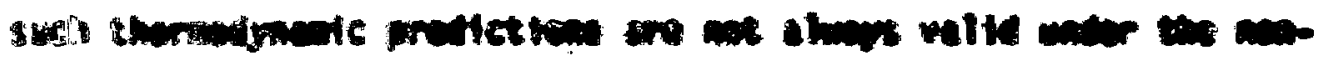

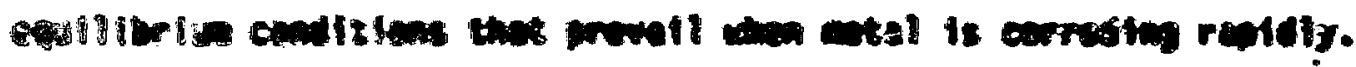

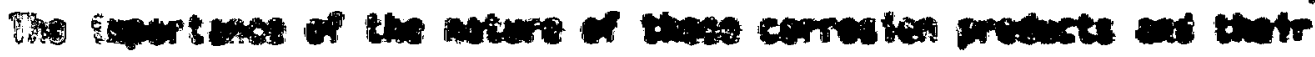

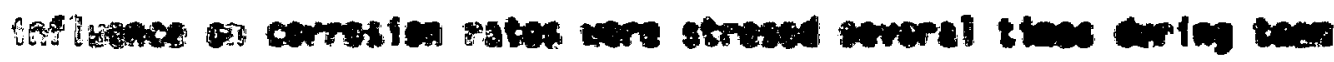

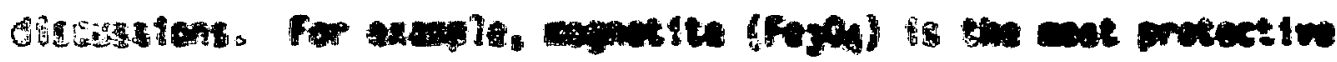

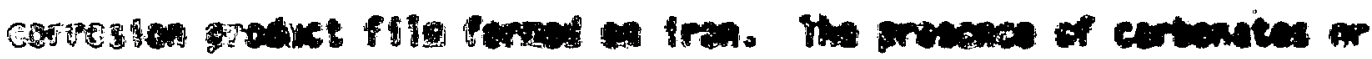

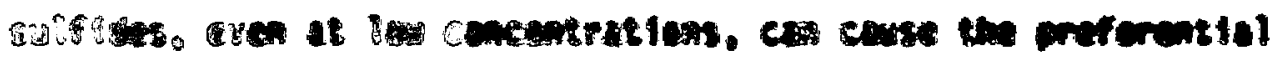

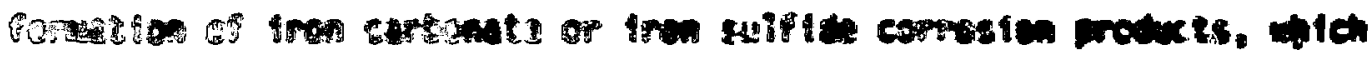

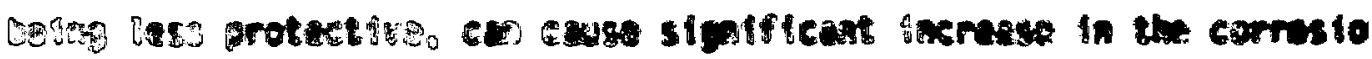

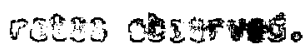




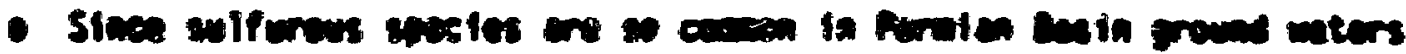

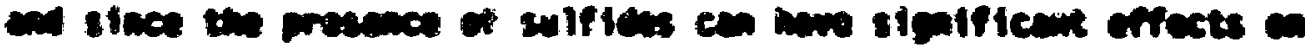

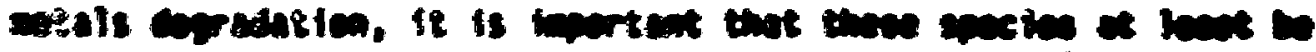

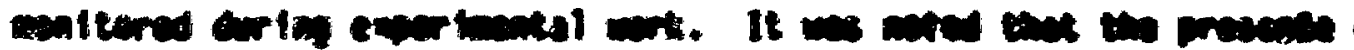

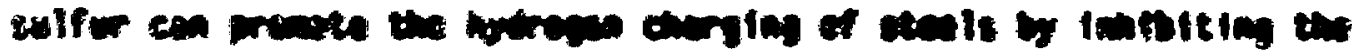

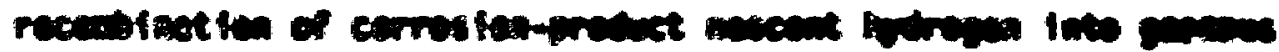

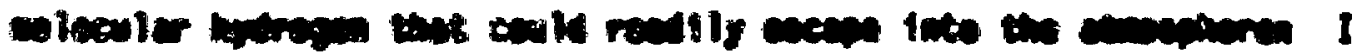

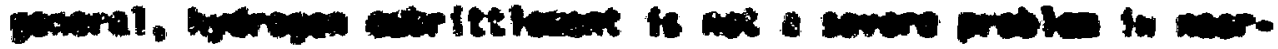

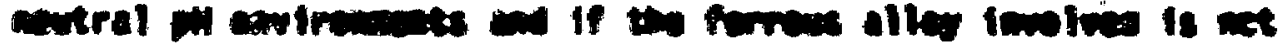
manewes.

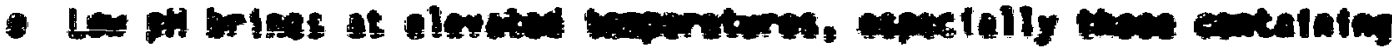

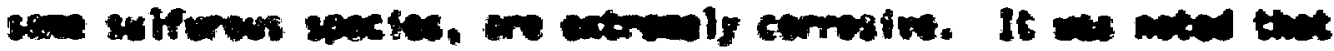

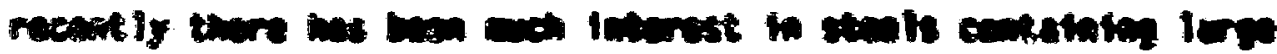

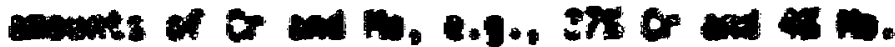

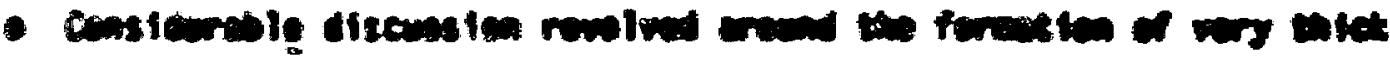

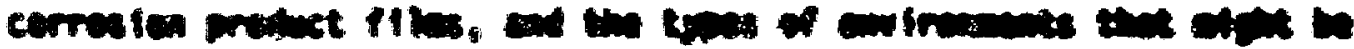

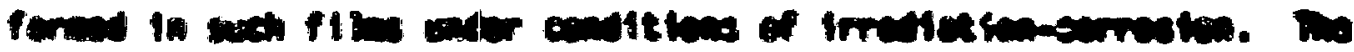

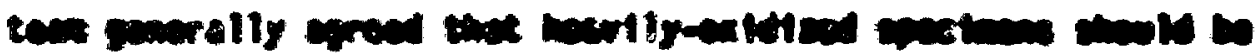

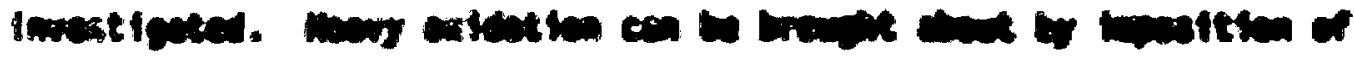

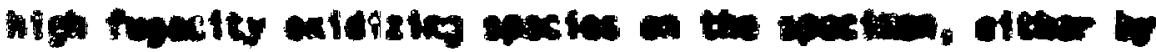

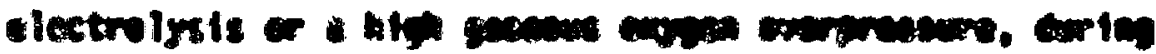
mplostereal apenos.

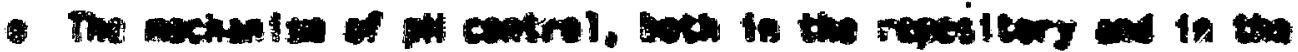

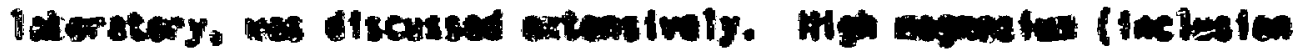

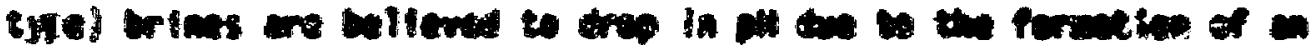

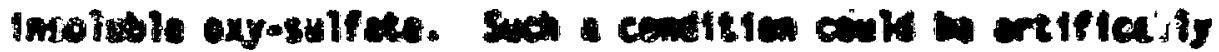

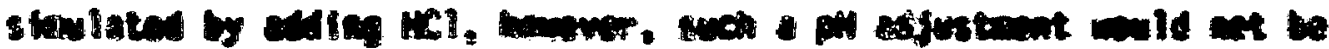

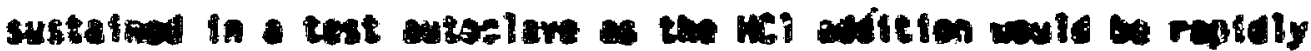

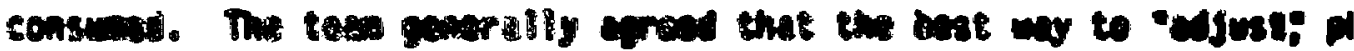

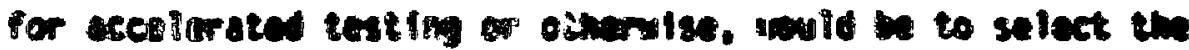

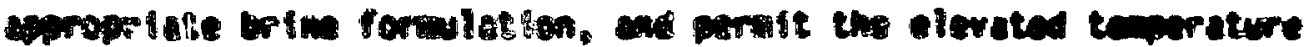




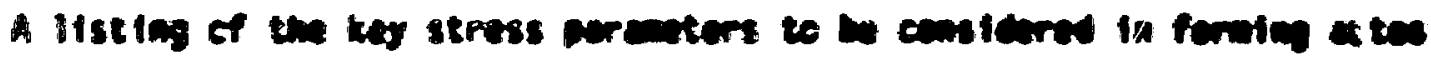
catrix for lon ton testim ts given in Toble 1.

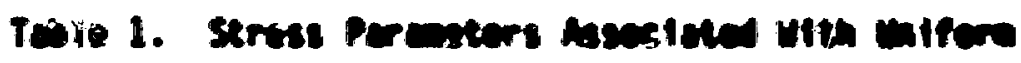

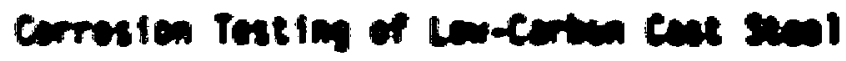

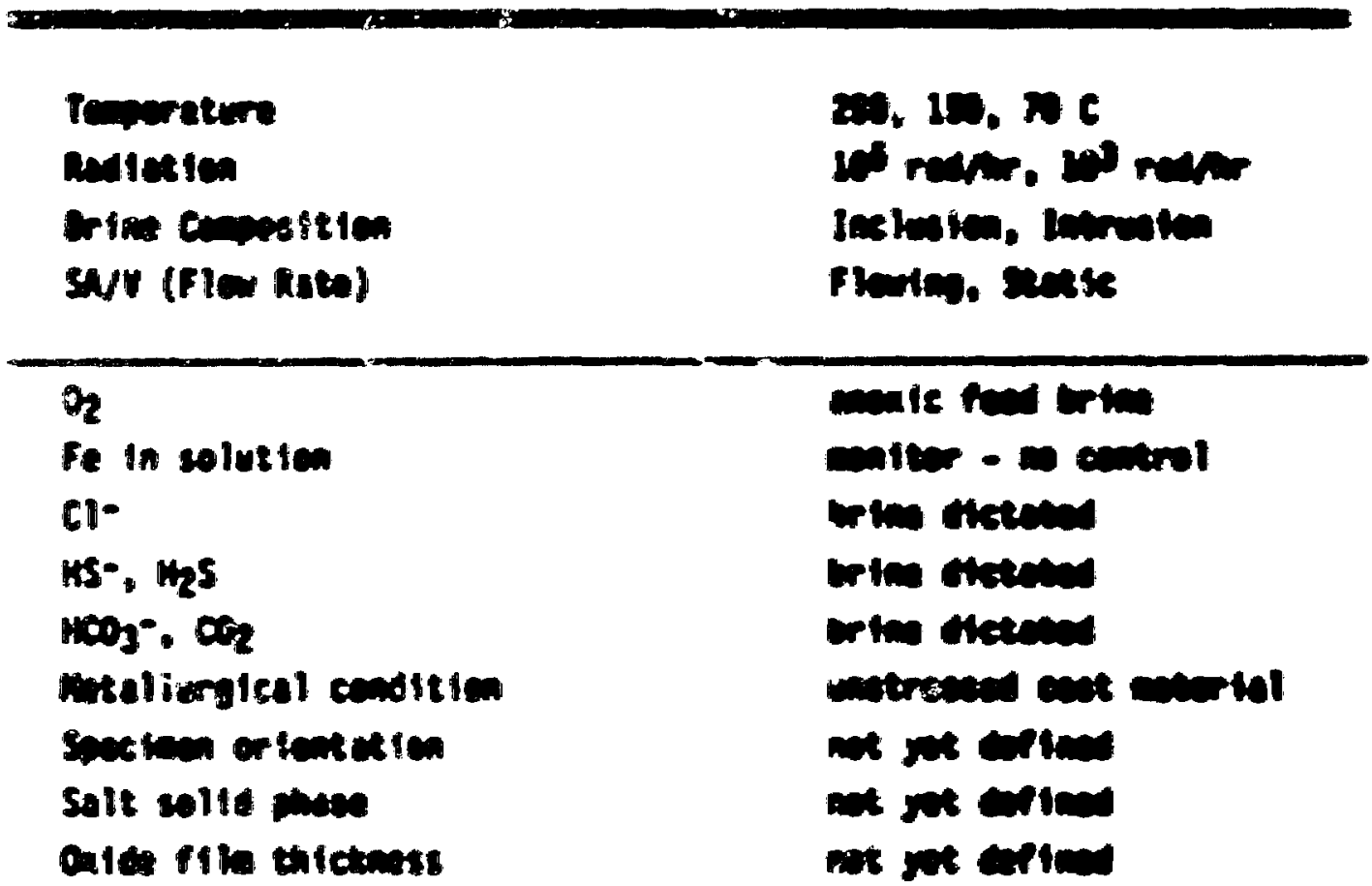




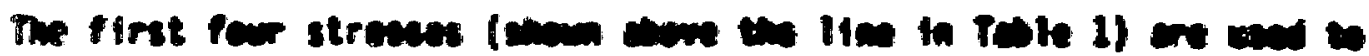

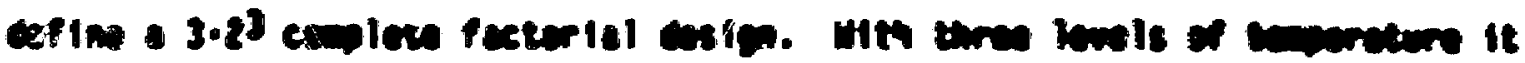

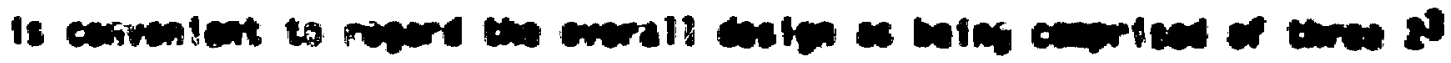

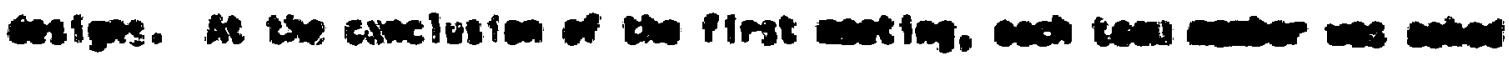

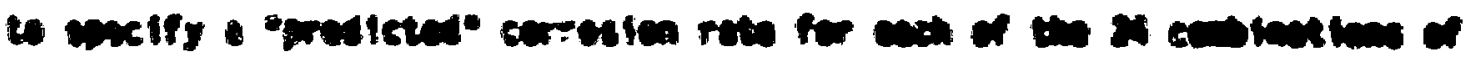

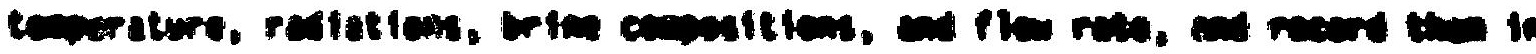
- toble ruch a man in Tale 2.

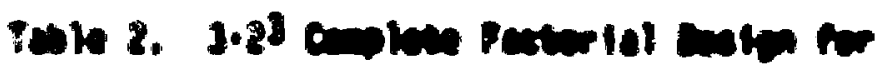 wifere corrovion notien

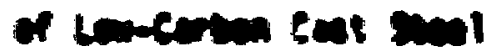

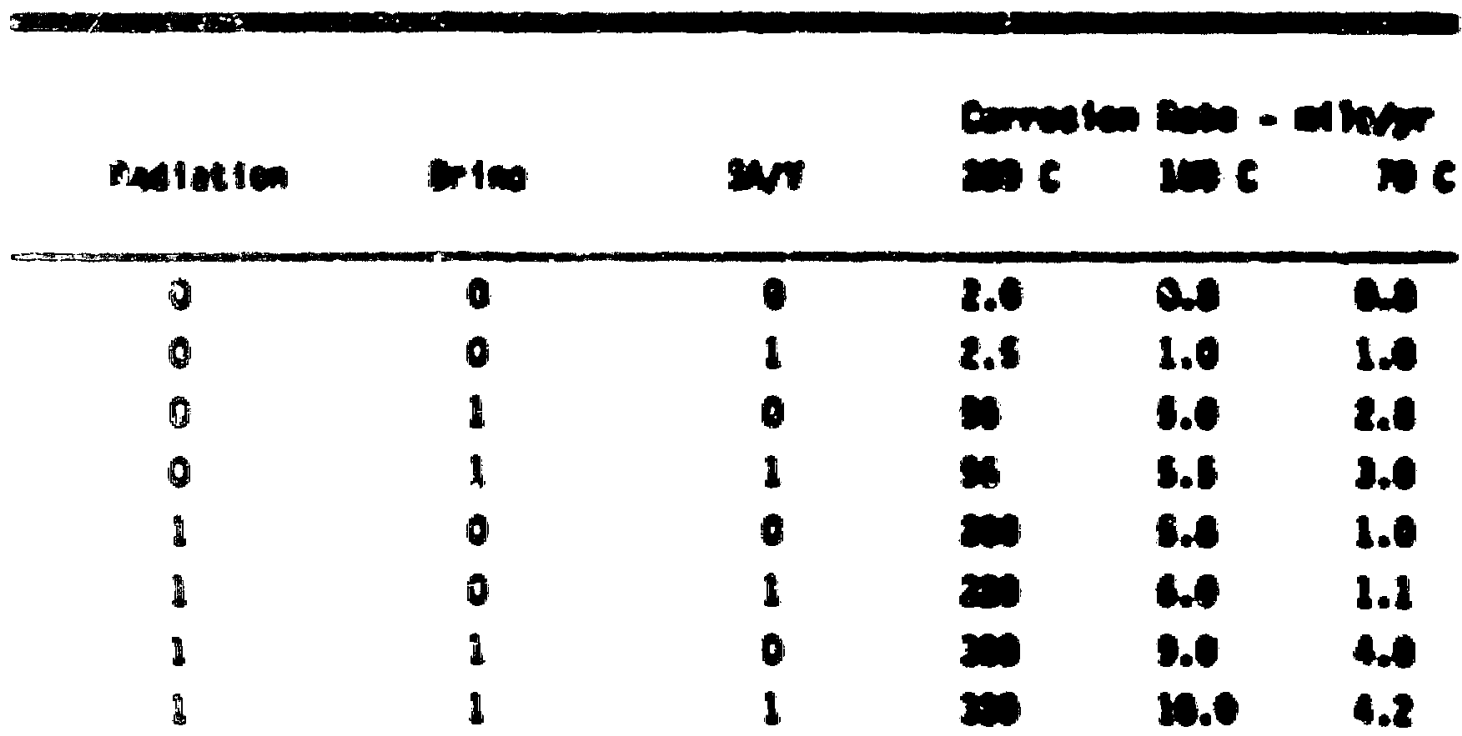




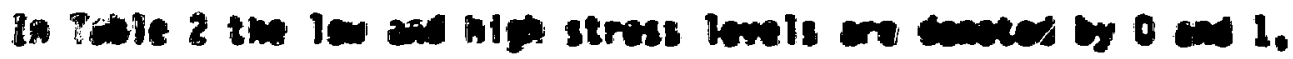

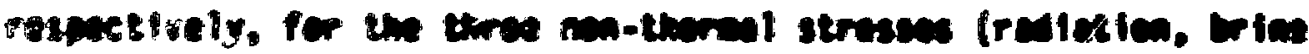

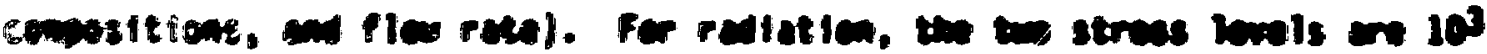

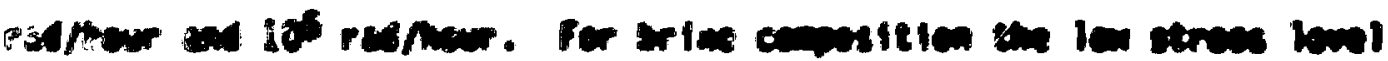

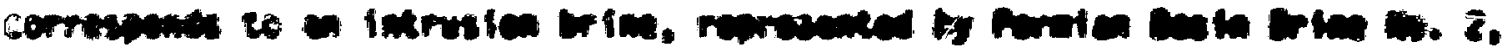

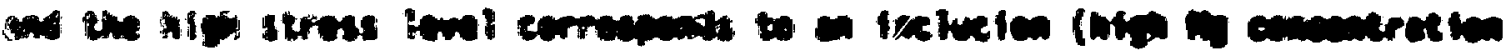

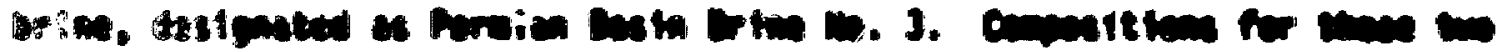

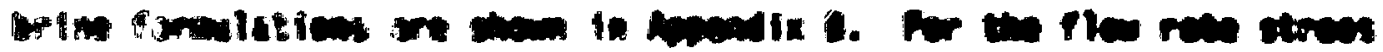

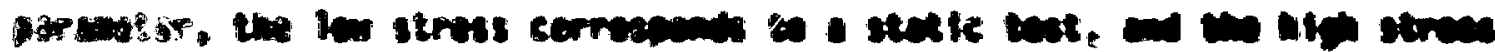

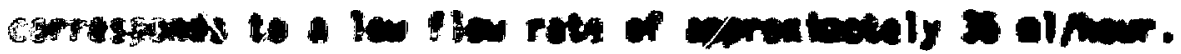

The vilus given in the three rien ent colwo of Tole 2 are the

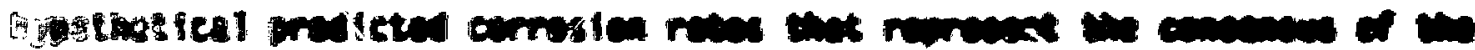
A as?.

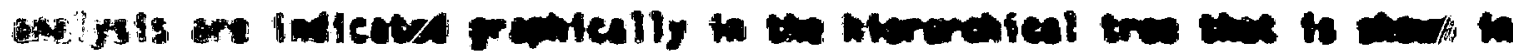

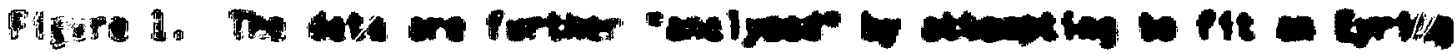

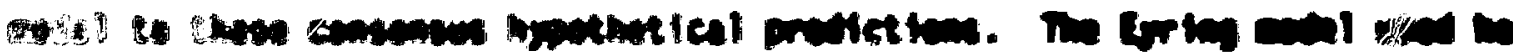

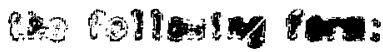

$$
\begin{aligned}
& \text { 2xmparin) } \\
& \text {-(a) mercent) } \\
& \text { (a) }
\end{aligned}
$$

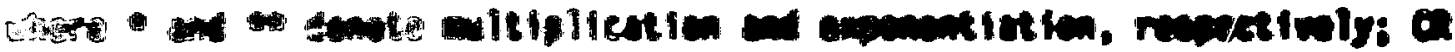

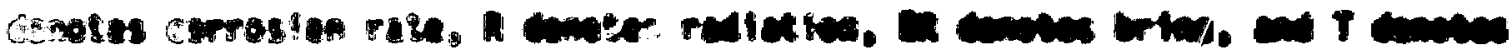

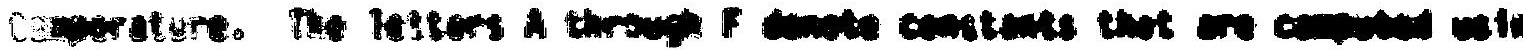

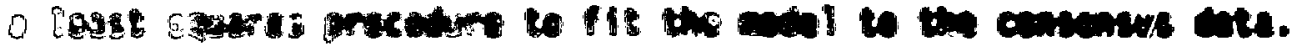

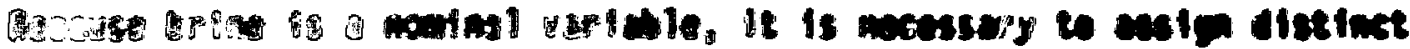

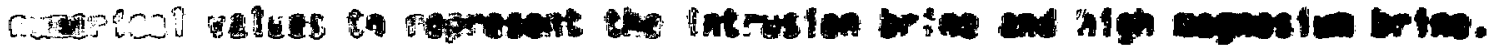

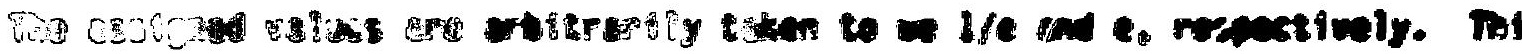

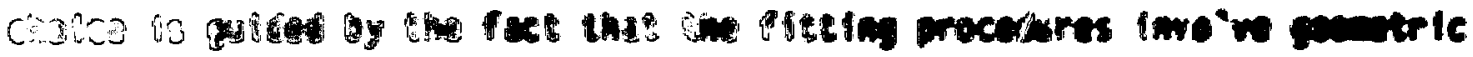

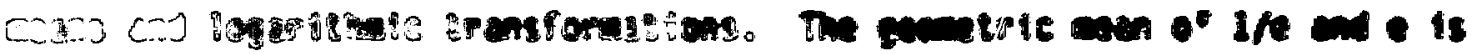
$000 \%$ c C 


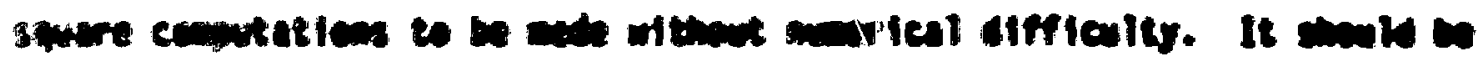

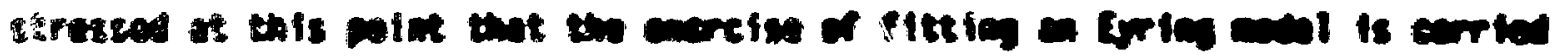

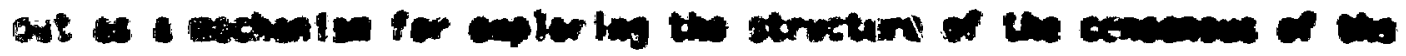

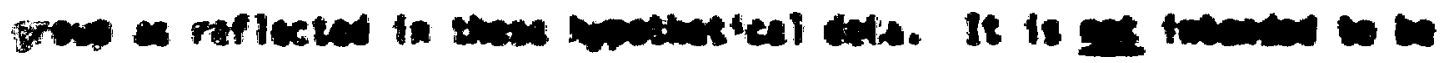

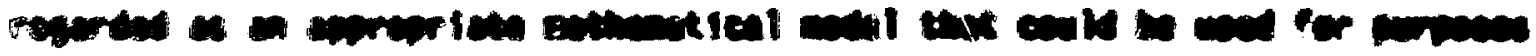

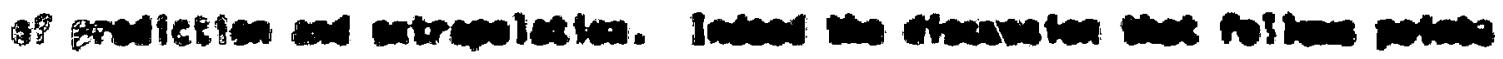

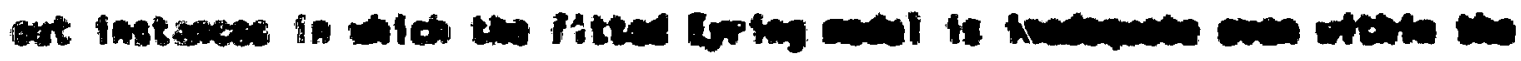

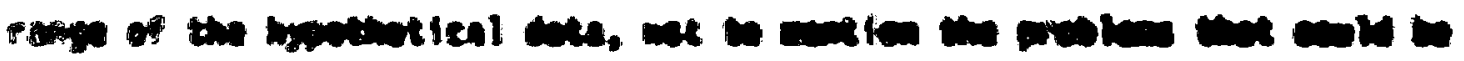

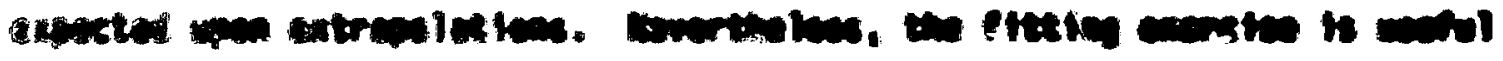

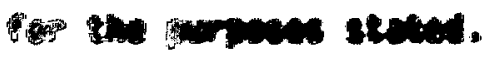

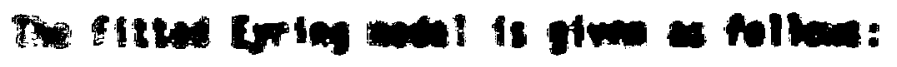

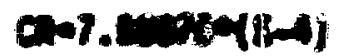

$$
\begin{aligned}
& \text { aneman! } \\
& \text { (a) } \\
& \text {-(c) lo(1.Pn-mbenam) }
\end{aligned}
$$

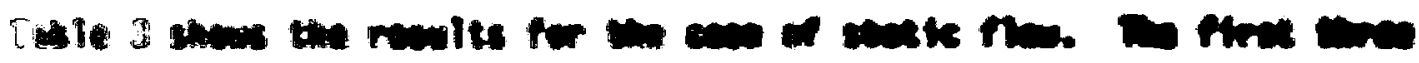

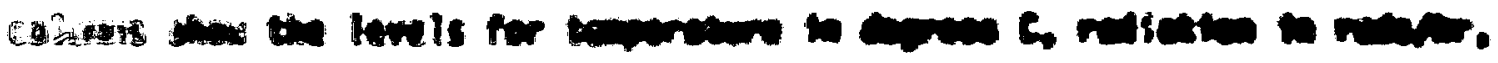

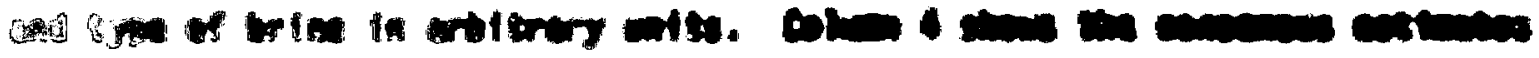

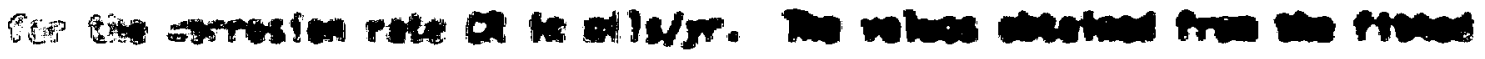

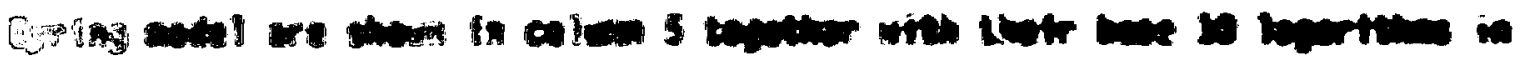
Cho last colve: 


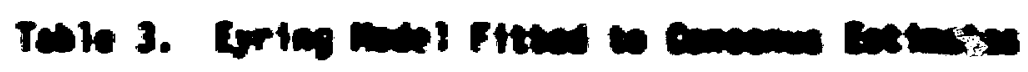

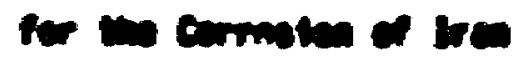

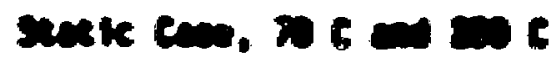

\begin{tabular}{|c|c|c|c|c|}
\hline 2 & $a$ & a & a & $\operatorname{ma}$ \\
\hline$\pi$ & קוגו & $\begin{array}{l}2 n \\
\dot{2 n} \\
\bullet\end{array}$ & $\begin{array}{l}20 \\
20 \\
10 \\
40\end{array}$ & $\begin{array}{l}2 \pi \\
20 \\
100\end{array}$ \\
\hline 200 & שו & $\underset{w}{w}$ & مص & הח \\
\hline
\end{tabular}

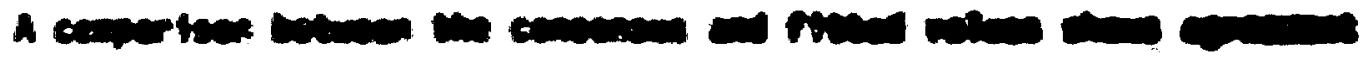

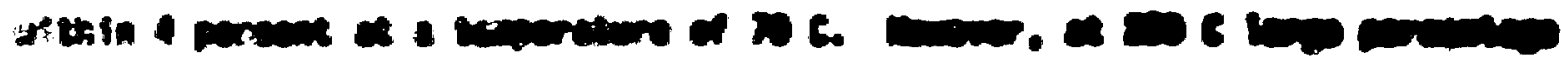

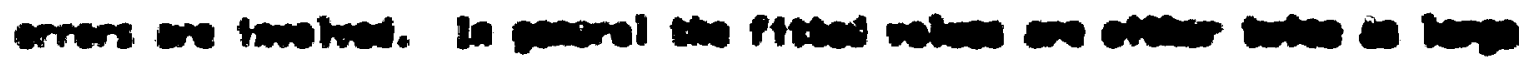

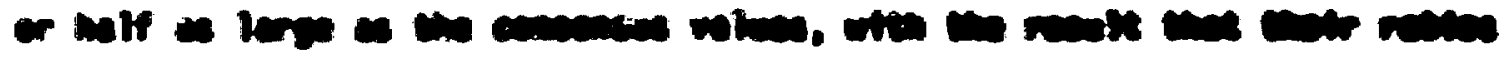

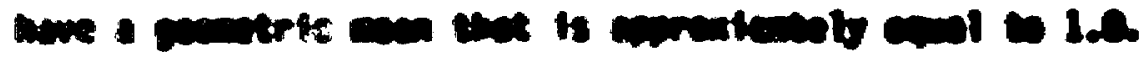

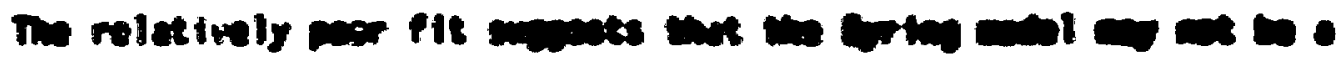

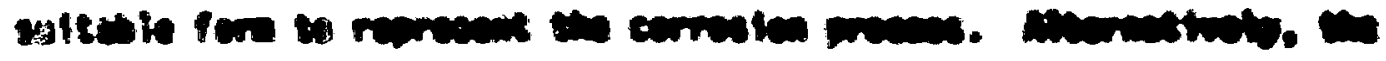

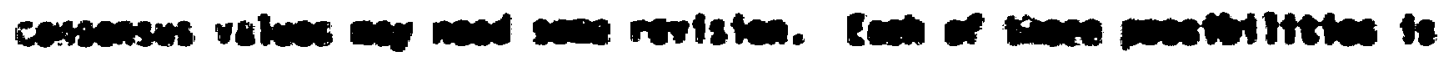
ortefly extentan mien. 


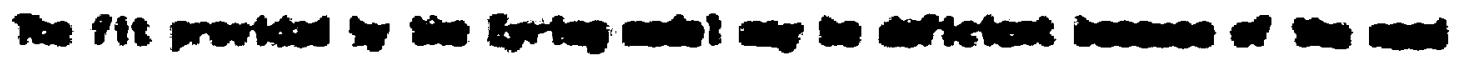
דמש

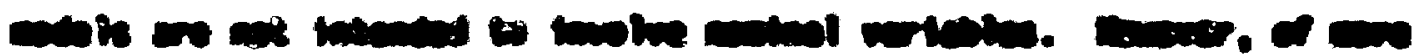

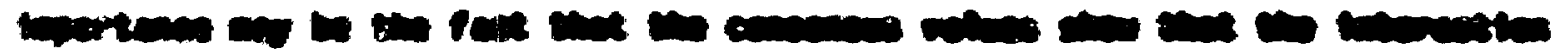

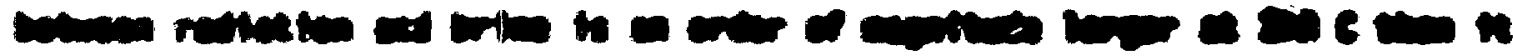
is a c.

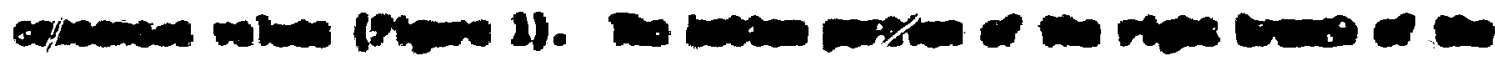
די

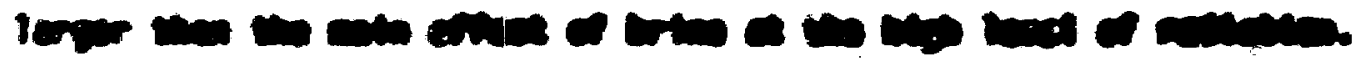

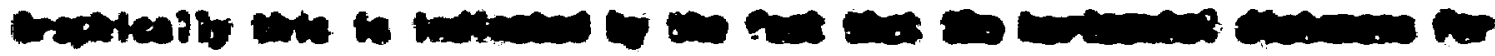

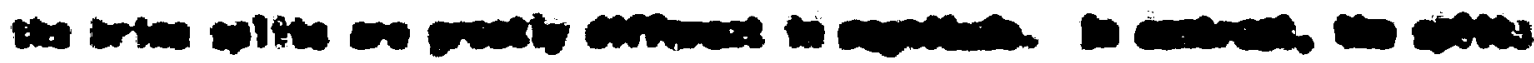

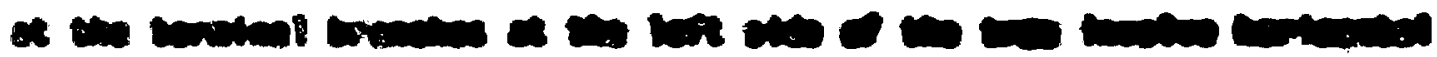

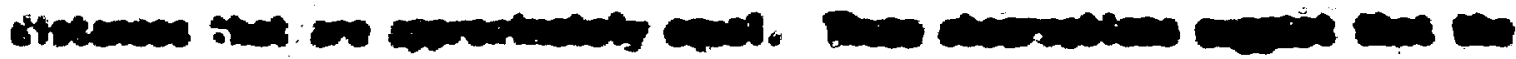

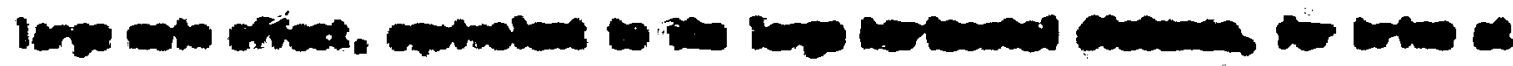

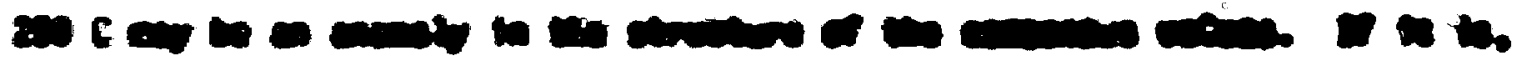

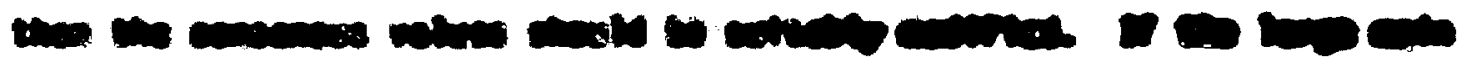

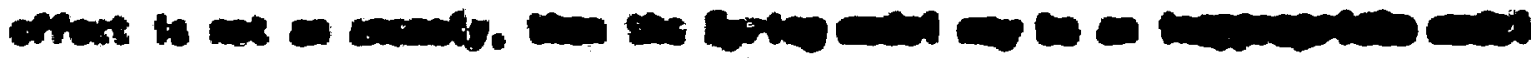

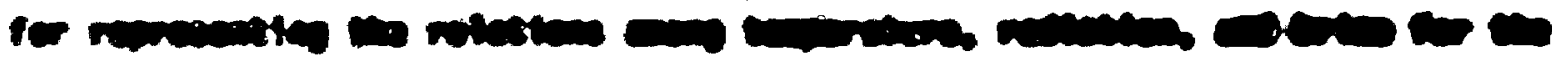

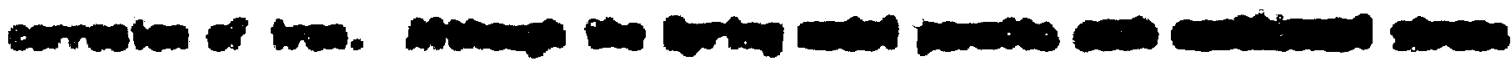

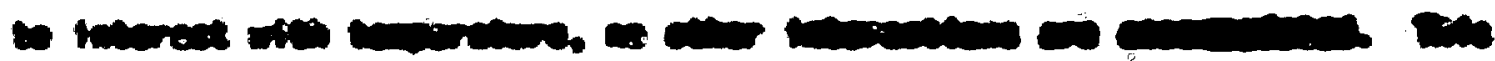

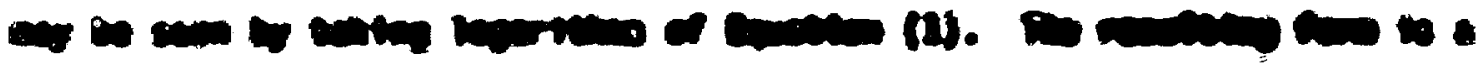
הם

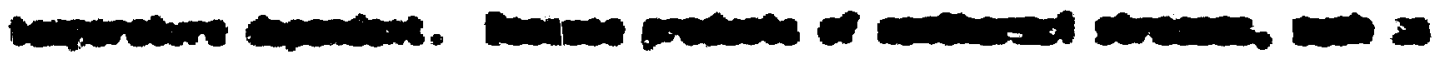

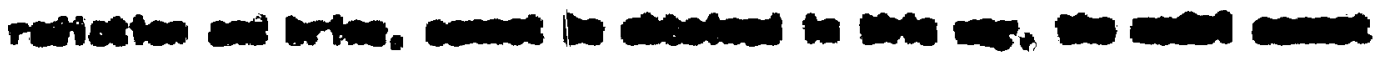
. 


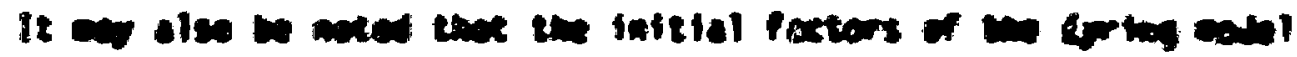

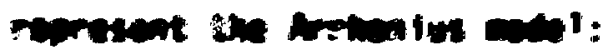

\section{omaipiert}

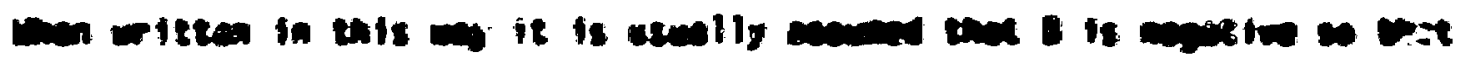

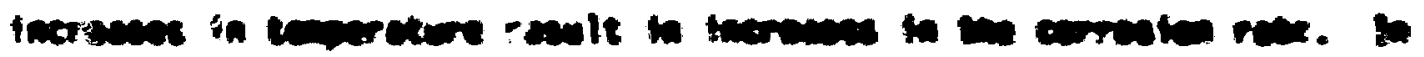

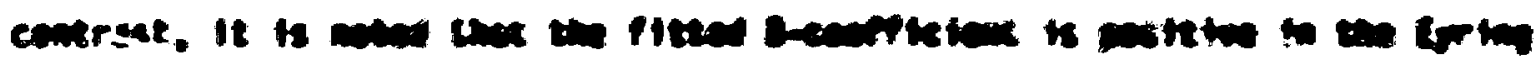

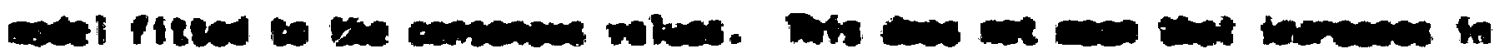

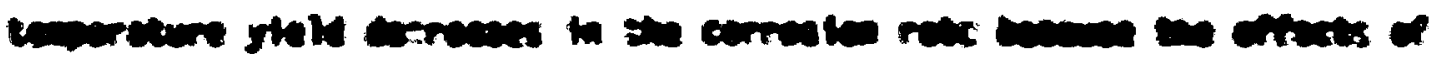

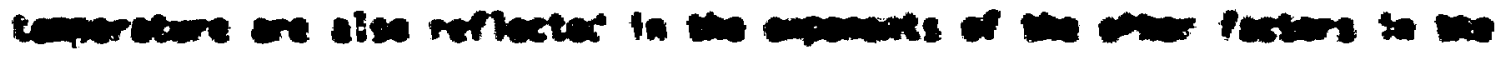
trim anis.

If a skile

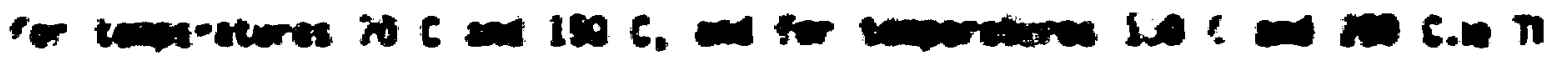

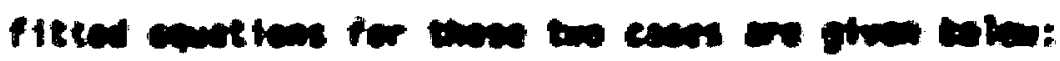

$$
\begin{aligned}
& \text { orel.emanc-3) } \\
& \text { arexinit) } \\
& \text {-(n) }-(1.2 \mathrm{~m}-2 \mathrm{n} . \mathrm{sen}) \\
& \text { (10) } \infty(0.130-20.50 \pi \text { ) }
\end{aligned}
$$

for the values of $70: 5$ and $150 \mathrm{C} ; 0$

$$
\begin{aligned}
& \text { ano3. } \sin 04(-4) \\
& \text { cis(2man) } \\
& (n)=(2.072-20.23 \pi /) \\
& \text { (m) }=(2.3347-390.007)
\end{aligned}
$$

or the values at $150 \mathrm{C}$ end 250 :. 
Tabits 4 and 5 show the results for thase tac cases. Gain the onorell

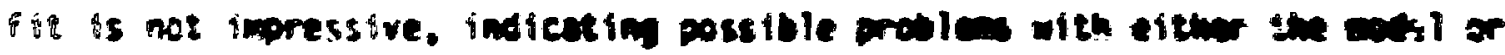

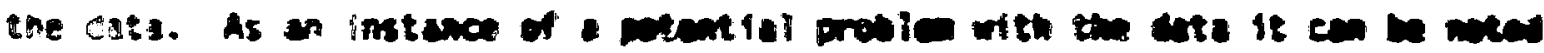

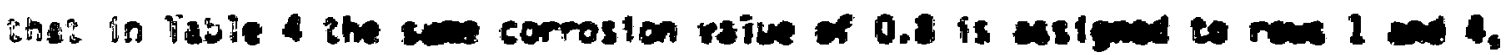

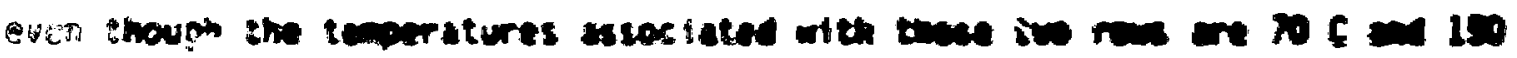

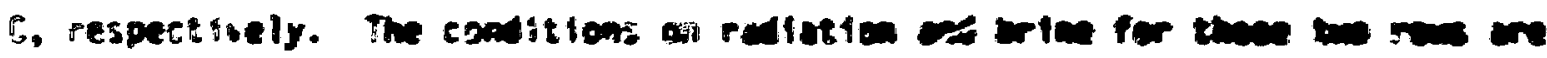

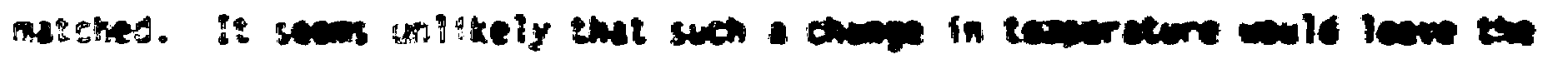
coprostion rate unctinest.

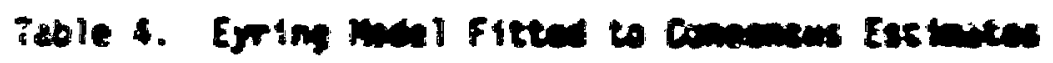

fer une corsticn of Inn

Stafts tare, $0 \mathrm{C}$ an $\mathrm{C}$

\begin{tabular}{|c|c|c|c|c|c|}
\hline I & ก & $m$ & $a$ & DST $a$ & $u(a)$ \\
\hline \multirow[t]{4}{*}{0} & 1000 & $1 / 2$ & 0.8 & 0.77 & -0.312 \\
\hline & 1000 & 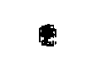 & 2.8 & 2.00 & $0.4 x$ \\
\hline & 00000 & 210 & 2.0 & 1.0 & 0.045 \\
\hline & 100000 & $e$ & 4.0 & $3 . \simeq$ & 0.50 \\
\hline \multirow[t]{4}{*}{285} & 1000 & Ife & 0.8 & 1.13 & 0.6) \\
\hline & 1000 & 2 & 5.0 & 3.57 & 0.2) \\
\hline & 100000 & die & 5.3 & 4.6 & 0.012 \\
\hline & 100000 & $e$ & 9.0 & 12.73 & 2.20 \\
\hline
\end{tabular}




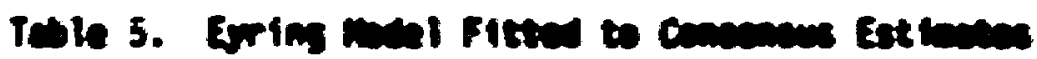

for the comberes of Ino

sent is cane, If 6 an 6

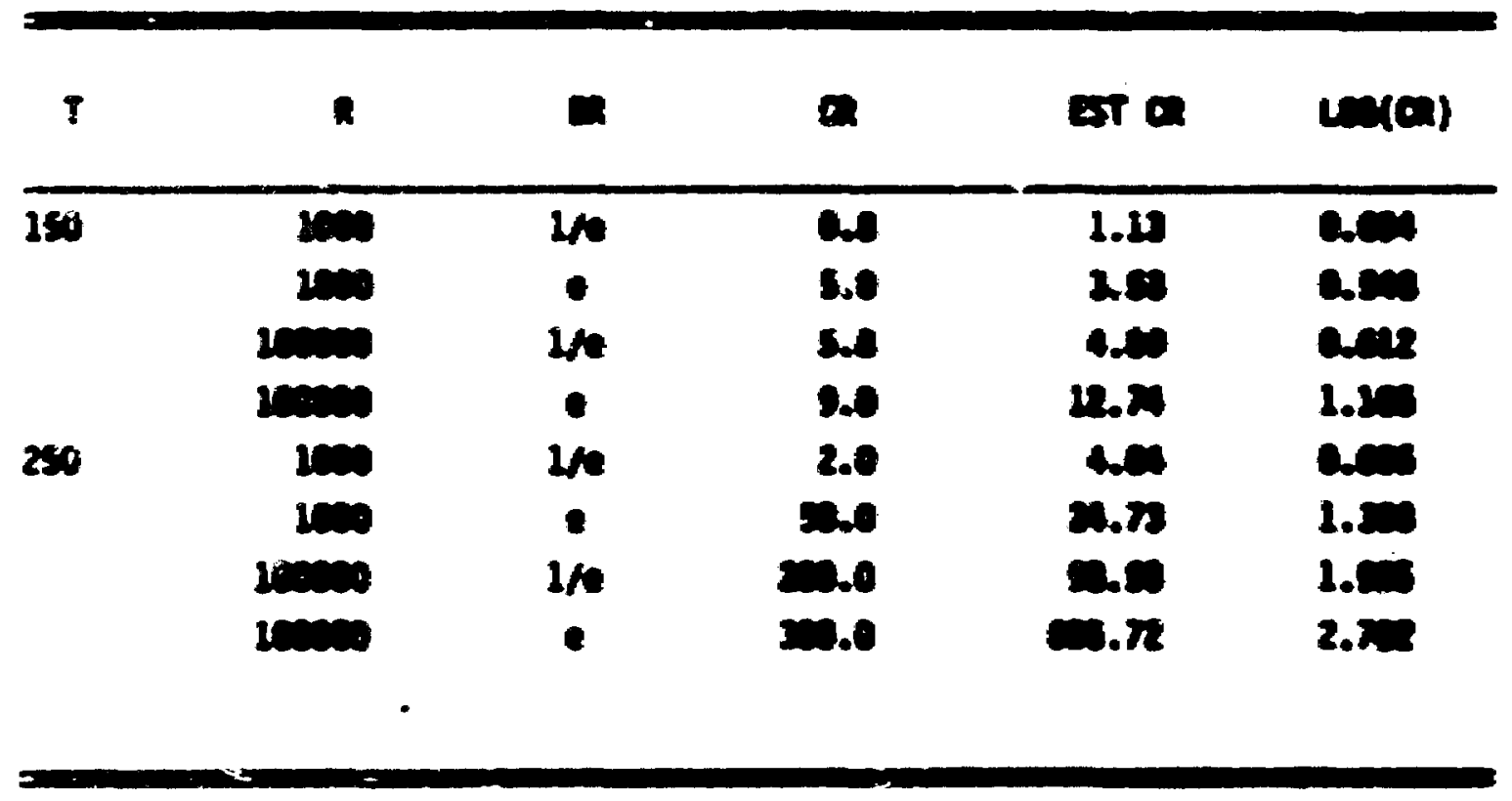

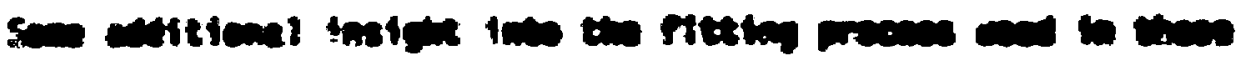

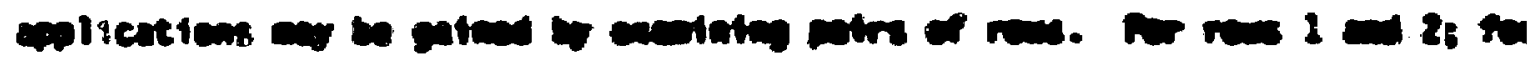

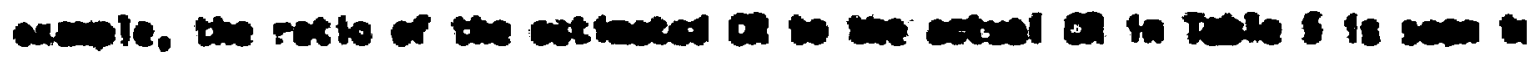

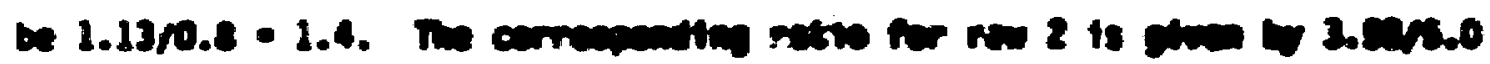

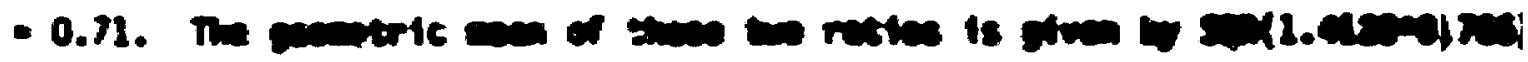

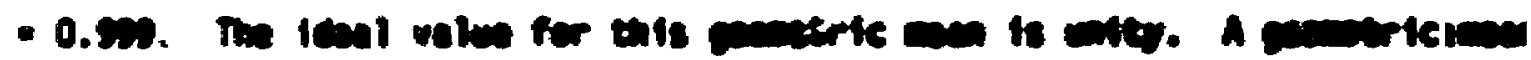

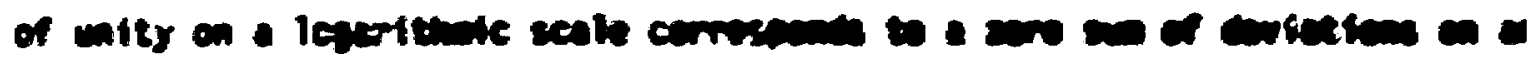

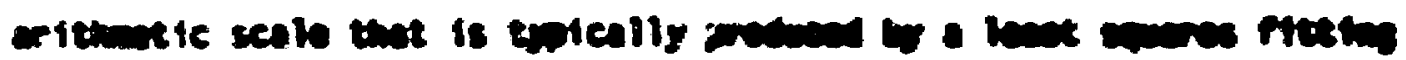

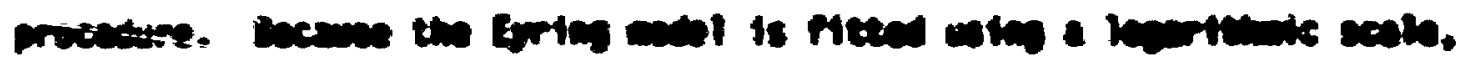

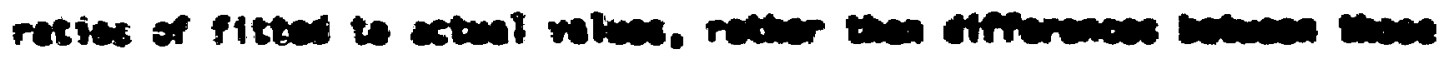

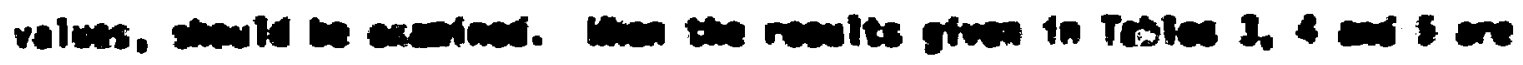

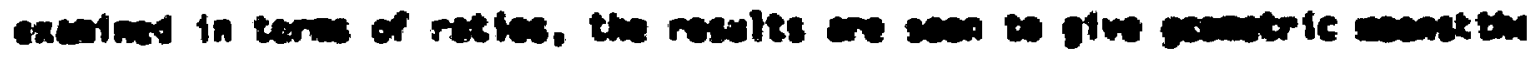

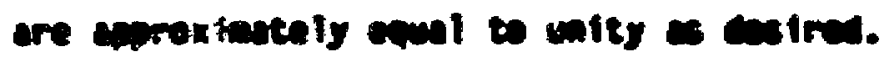




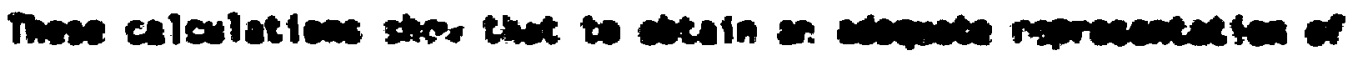

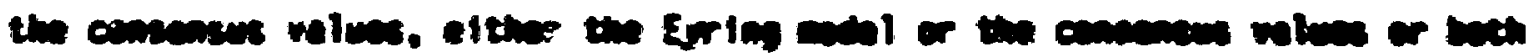

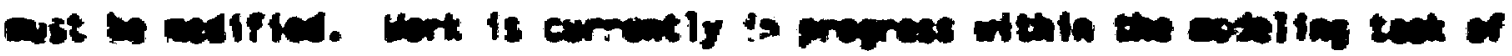

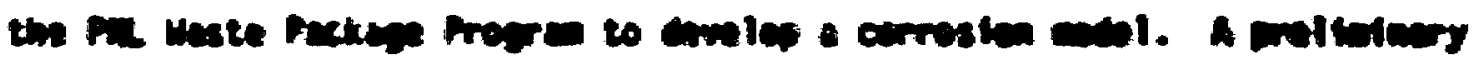

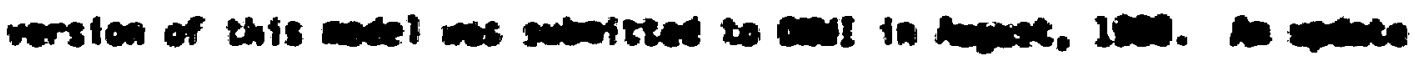

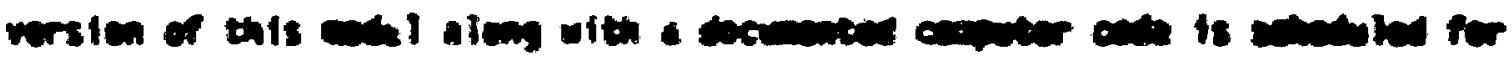

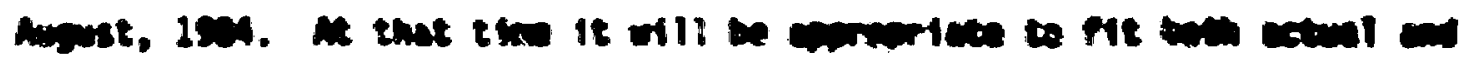

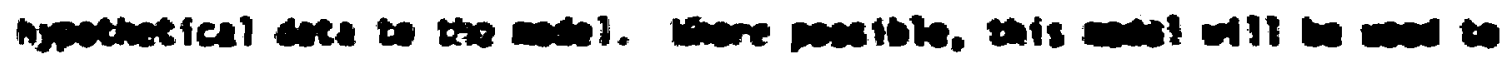

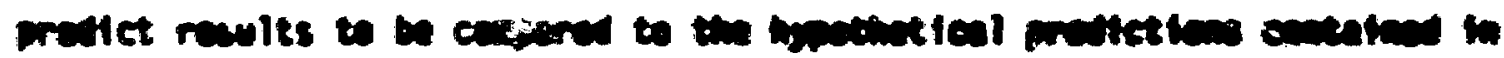

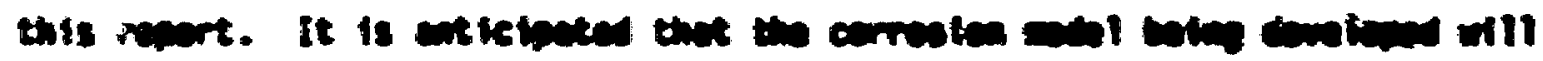

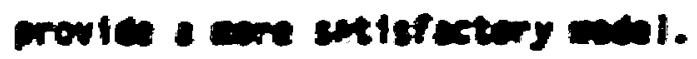

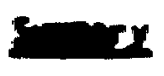

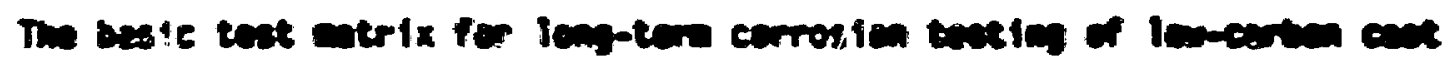
steel is the follewing:

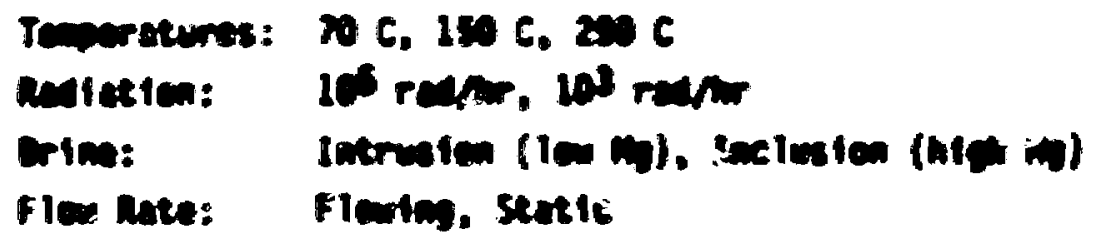

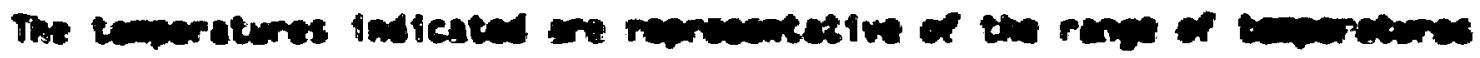

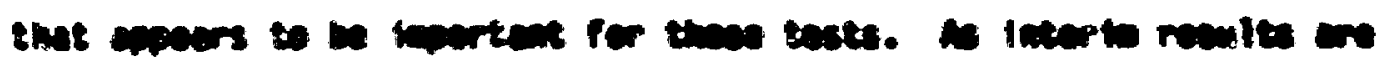

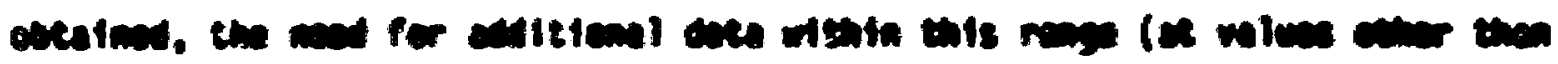

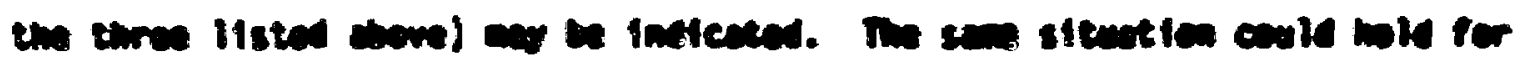

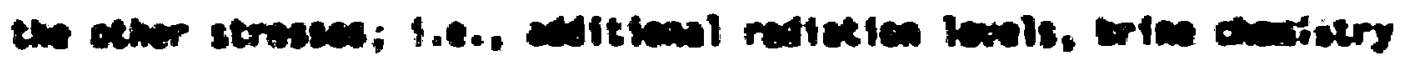

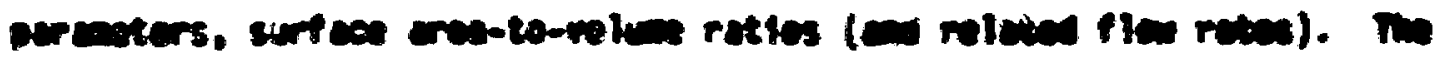

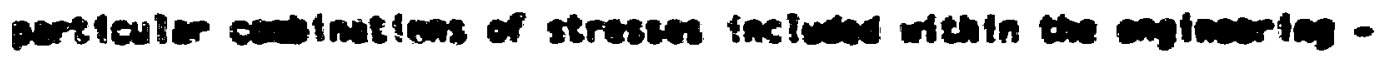

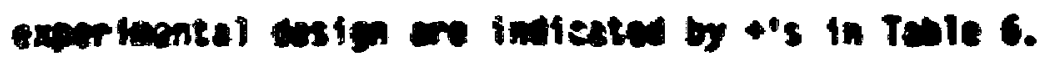




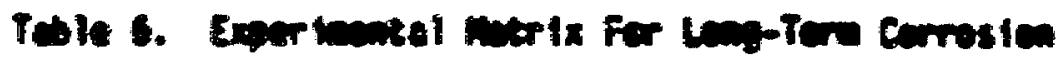
Jesting of Lon-corten cast stal

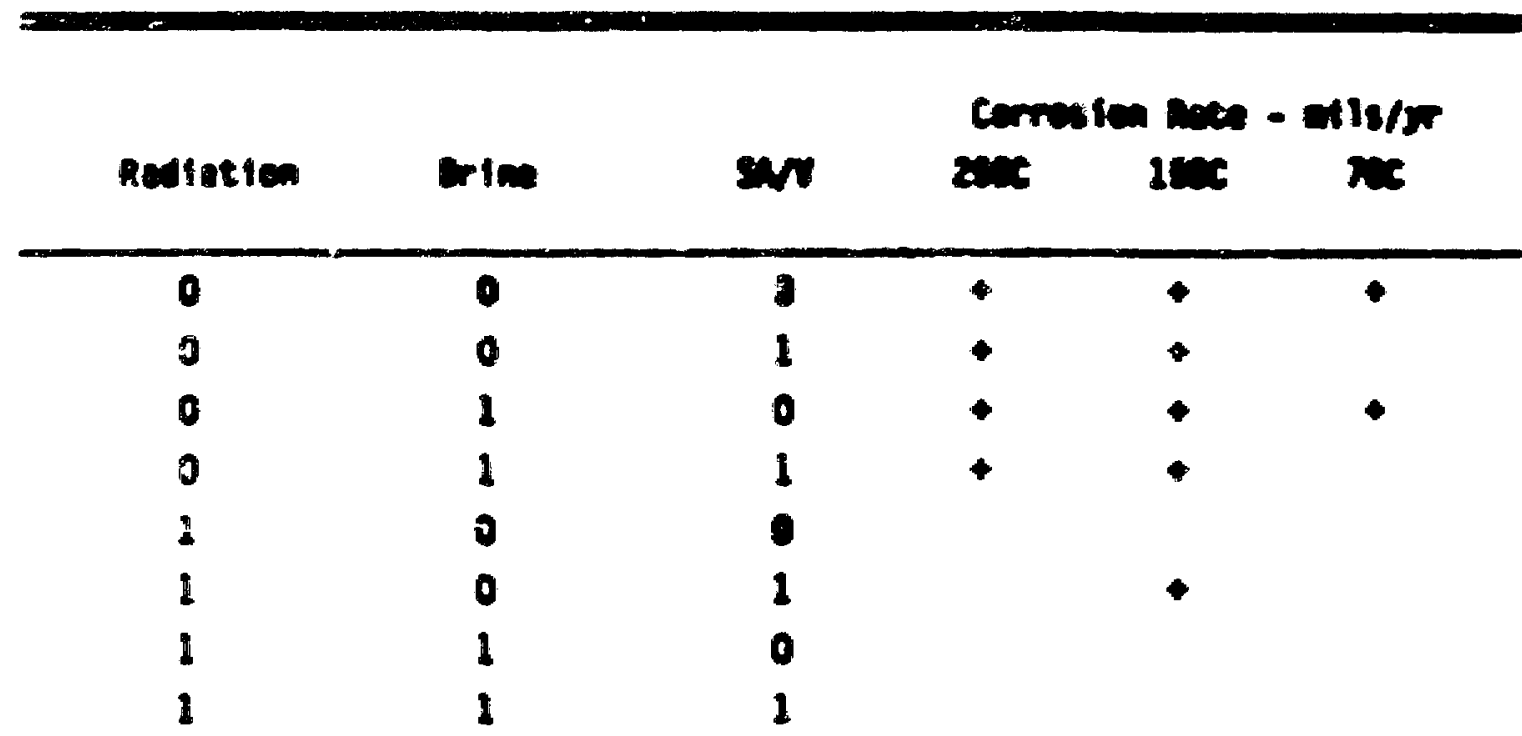

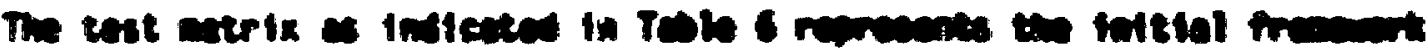

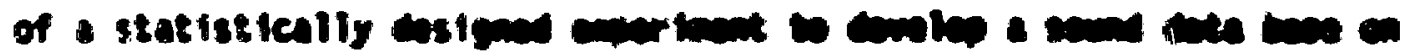

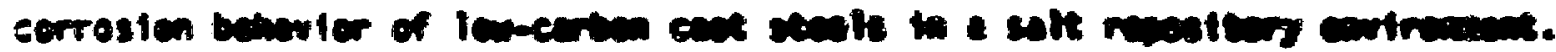

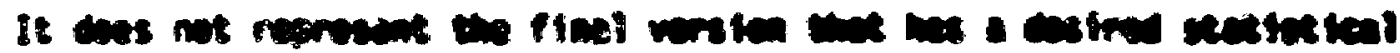

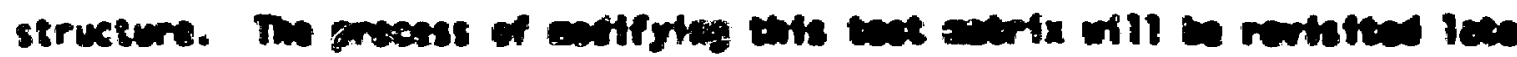

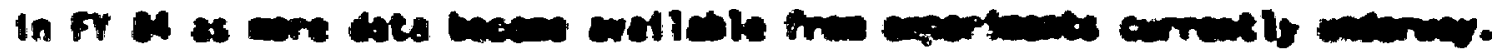

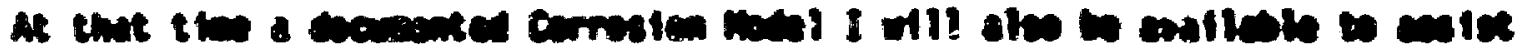
in cufiaim future che ropolnewes.

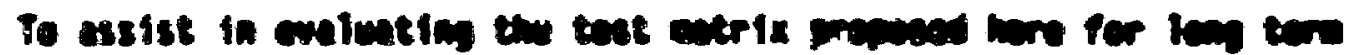

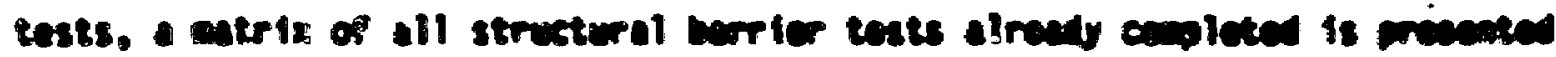
In remendix $A$. 
Manex A

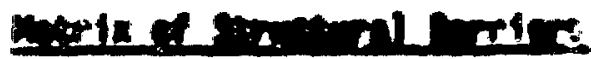

bus aty 


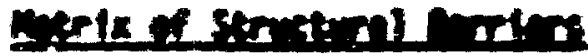 \\ Ints conlen:}

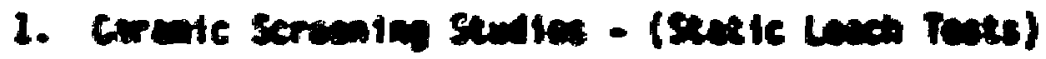

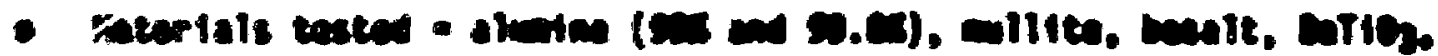

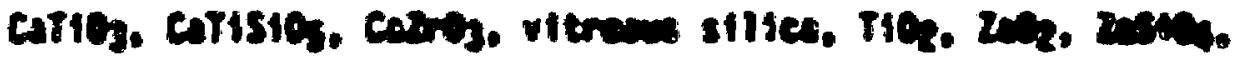

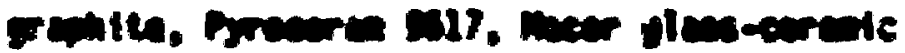

- Tenoretere - in c enc

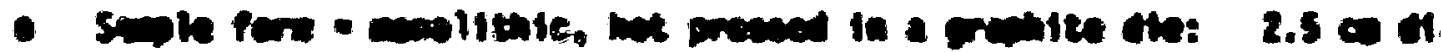

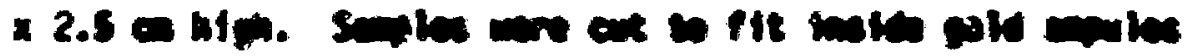

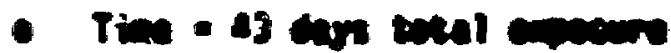

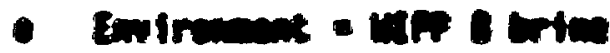

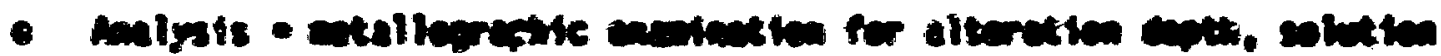
malests ier motix elonema

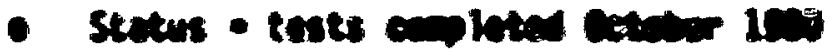

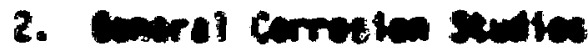

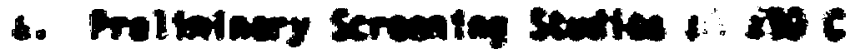

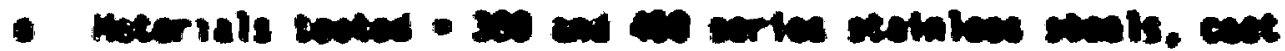

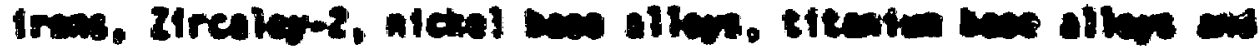

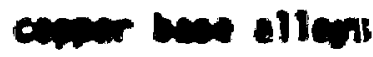

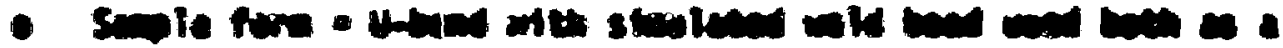

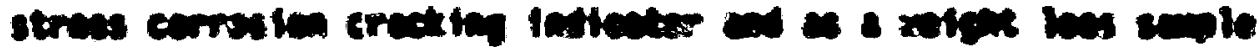

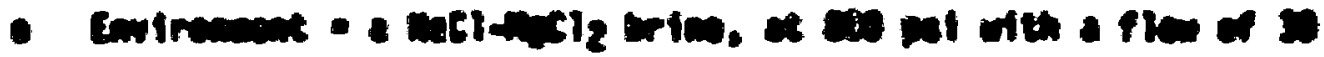

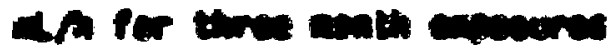

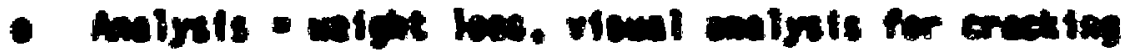

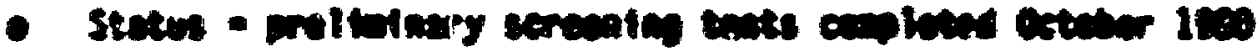

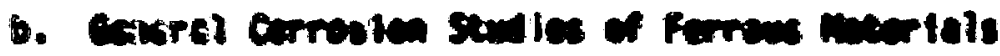

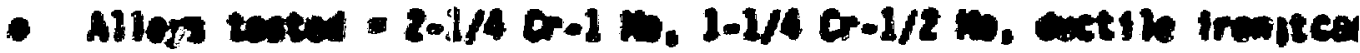

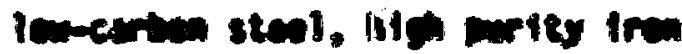

- Sopter - flat couprese and blaves

- Tenersture - 180 C 


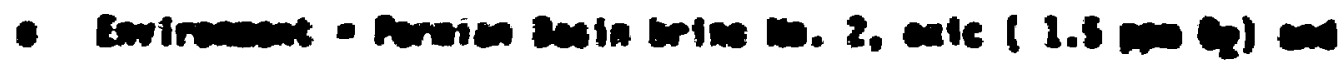
make ( 0.5 m 02 )

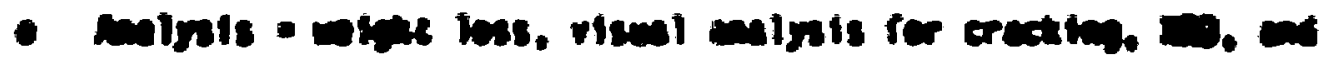

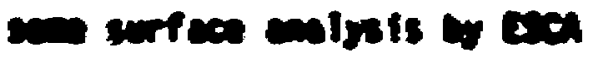

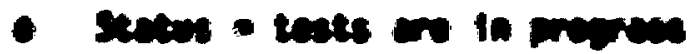

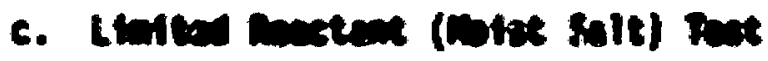

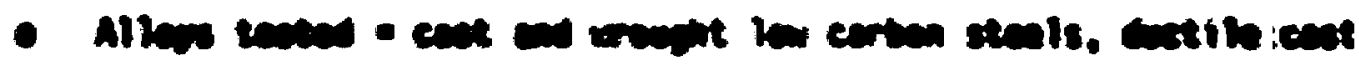

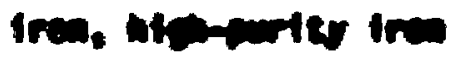

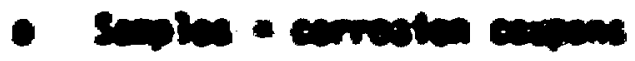

- Tonreve - inc 6

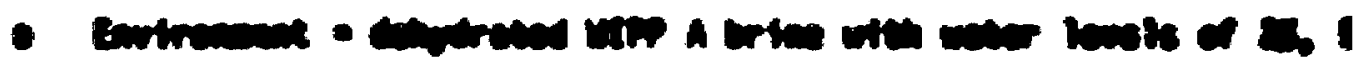

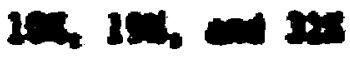

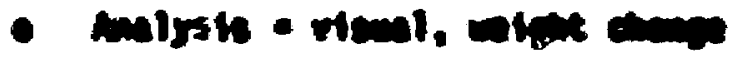

- Tre - 3 man

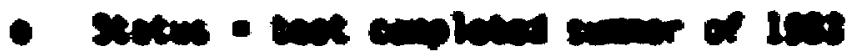

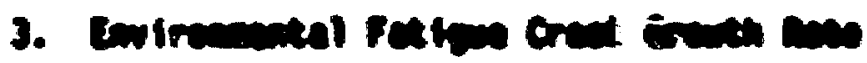

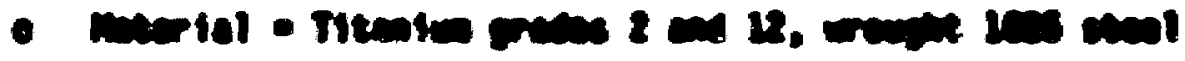

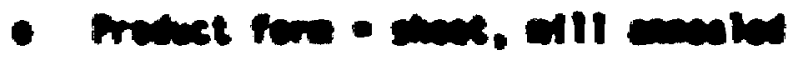

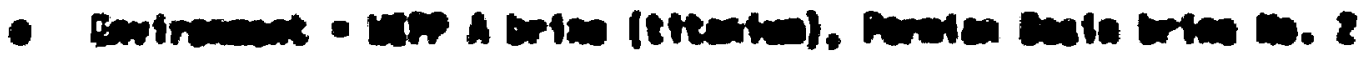
(stavi)

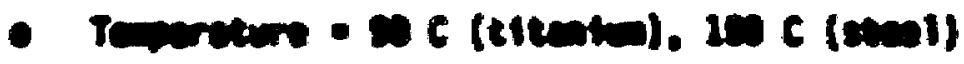

- Oriencution - R, tT

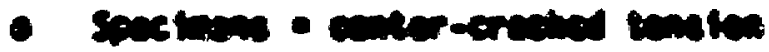

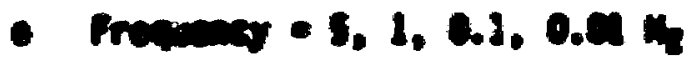

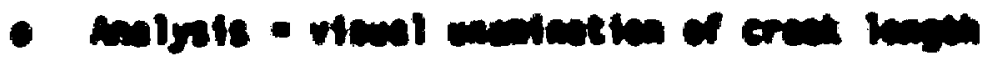

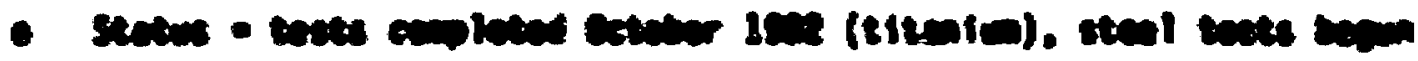

moner 180

4. Sicu Strain ane reation

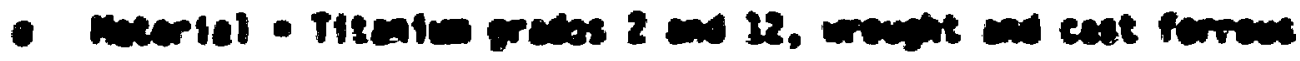
meterials 


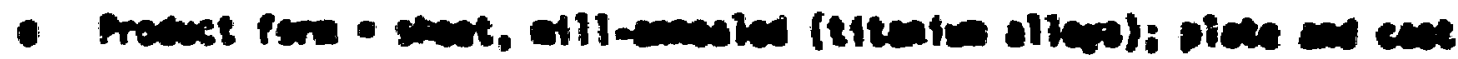

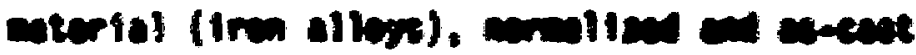

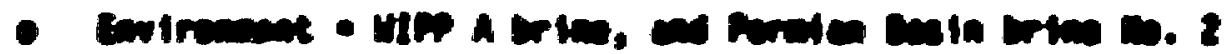

- Tenereters - 100 c an tes

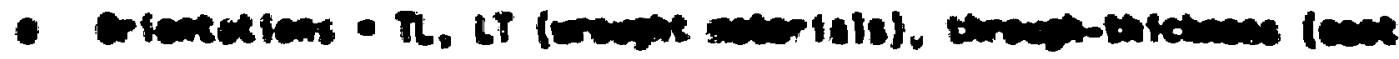
acteristis)

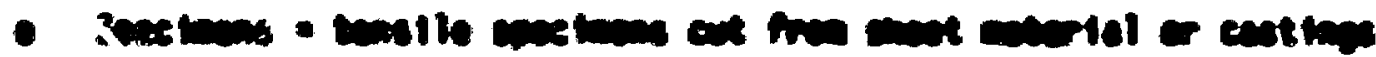

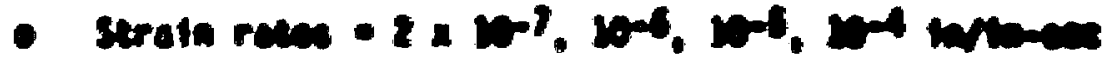

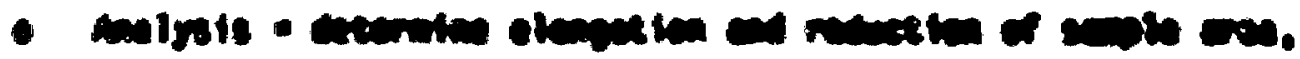

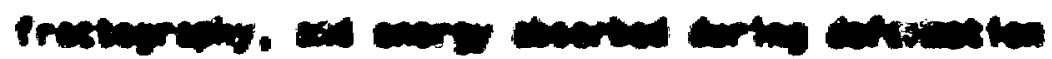

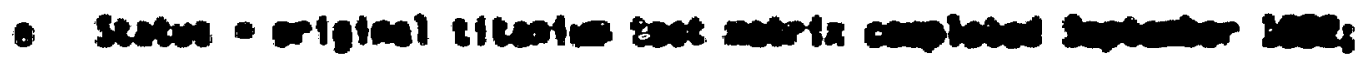

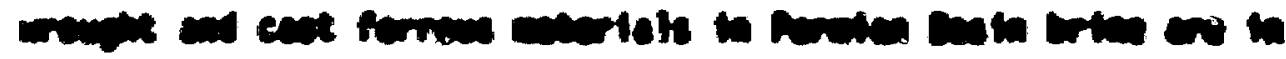

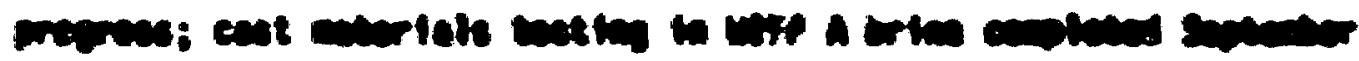

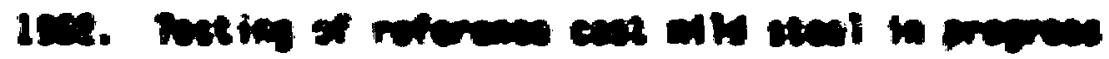

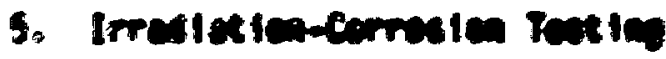

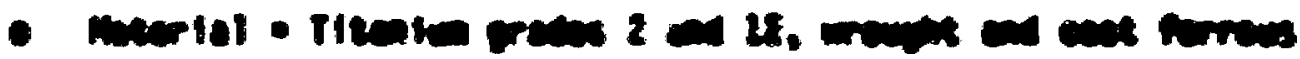
encertals

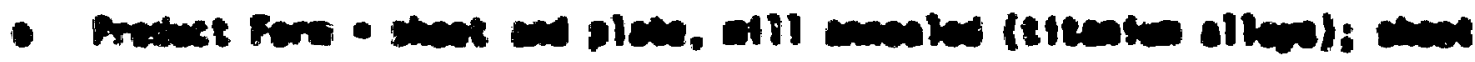

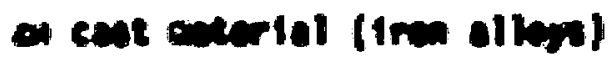

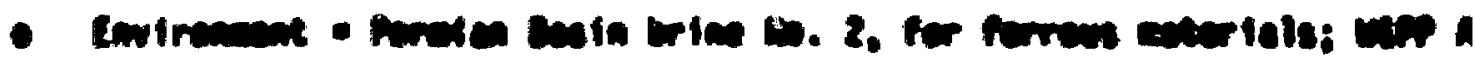
crics. to stemb alke

- Tomeranti - inc

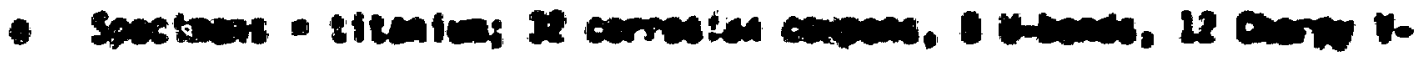

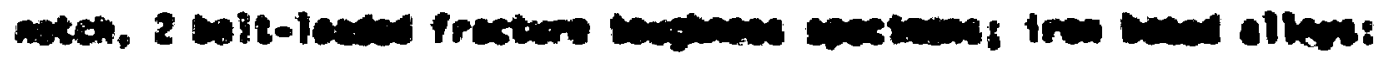

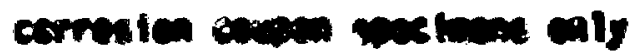

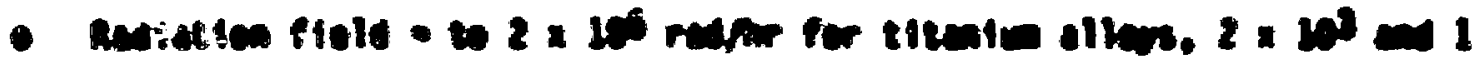

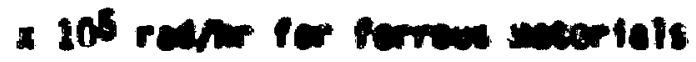

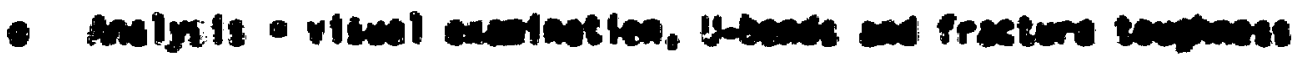

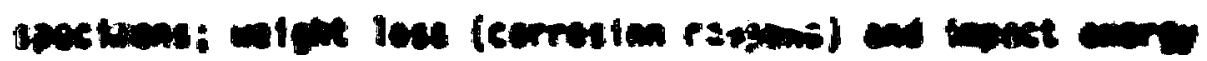

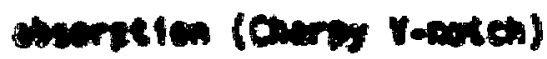


nomeno

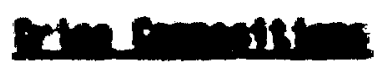



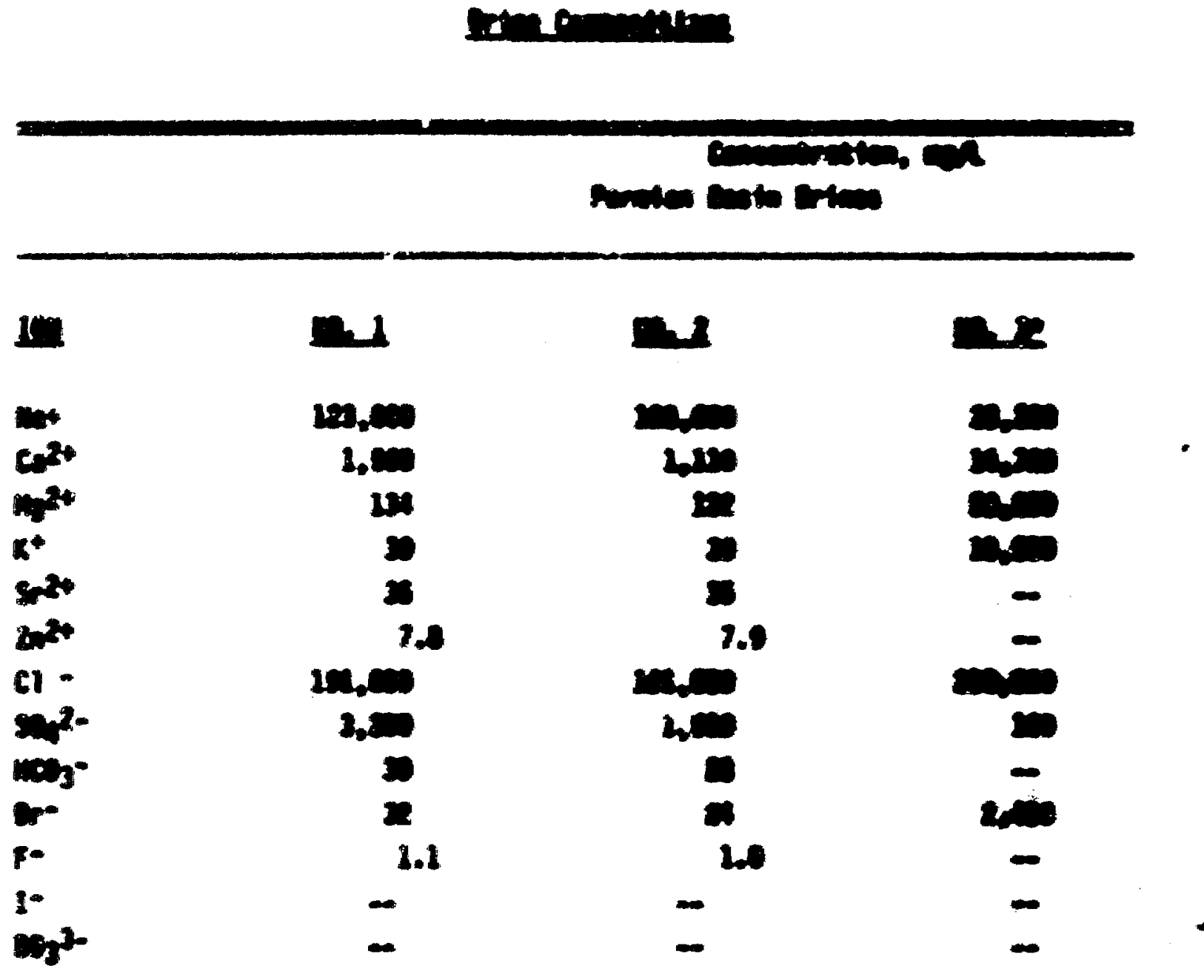

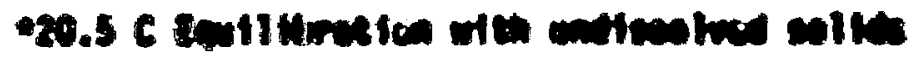

